\title{
Plasticity of Subventricular Zone Neuroprogenitors in MPTP (1-Methyl-4-Phenyl-1,2,3,6-Tetrahydropyridine) Mouse Model of Parkinson's Disease Involves Cross Talk between Inflammatory and Wnt/ $\beta$-Catenin Signaling Pathways: Functional Consequences for Neuroprotection and Repair
}

\author{
Francesca L'Episcopo, ${ }^{1}$ Cataldo Tirolo, ${ }^{1}$ Nunzio Testa, ${ }^{1}$ Salvatore Caniglia, ${ }^{1}$ Maria C. Morale, ${ }^{1}$ Michela Deleidi, ${ }^{2}$ \\ Maria F. Serapide, ${ }^{3}$ Stefano Pluchino, ${ }^{2,4}$ and Bianca Marchetti ${ }^{1,5}$ \\ ${ }^{1}$ OASI Institute for Research and Care on Mental Retardation and Brain Aging, Neuropharmacology Section, 94018 Troina, Italy, ${ }^{2} \mathrm{CNS}$ Repair Unit, Institute \\ of Experimental Neurology, Division of Neuroscience, San Raffaele Scientific Institute, 20132 Milan, Italy, ${ }^{3}$ Department of Physiological Sciences, University \\ of Catania, 95125 Catania, Italy, ${ }^{4}$ Department of Clinical Neurosciences, Cambridge Centre for Brain Repair and Stem Cell Initiative, University of \\ Cambridge, Cambridge CB2 OPY, United Kingdom, and 5 Department of Clinical and Molecular Biomedicine, Pharmacology Section, Medical School and \\ Faculty of Pharmacy, University of Catania, 95125 Catania, Italy
}

In Parkinson's disease (PD), neurogenesis is impaired in the subventricular zone (SVZ) of postmortem human PD brains, in primate nonhuman

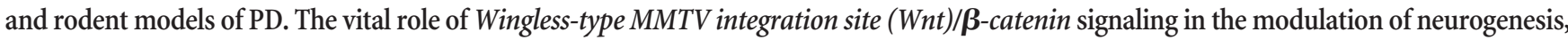

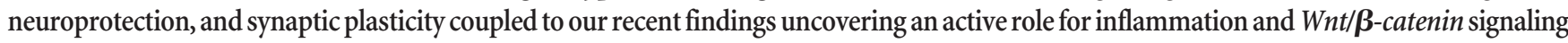
in MPTP-induced loss and repair of nigrostriatal dopaminergic (DAergic) neurons prompted us to study the impact of neuroinflammation and the Wnt/ק-catenin pathway in the response of SVZ neuroprogenitors (NPCs) in MPTP-treated mice. In vivo experiments, using bromodeoxyuridine and cell-specific markers, and ex vivo time course analyses documented an inverse correlation between the reduced proliferation of NPCs and the generation of new neuroblasts with the phase of maximal exacerbation of microglia reaction, whereas a shift in the microglia proinflammatory phenotype correlated with a progressive NPC recovery. Ex vivo and in vitro experiments using microglia-NPC coculture paradigms pointed to NADPH-oxidase (gpPHOX ${ }^{91}$ ), a major source of microglial ROS, and reactive nitrogen species as candidate inhibitors of NPC neurogenic potential via the activation of glycogen synthase $3\left(\mathrm{pGSK}-3 \beta^{\mathrm{Ty} 216}\right)$, leading to loss of $\beta$-catenin, a chief downstream transcriptional effector. Accordingly, MPTP/MPP ${ }^{+}$(1-methyl-4-phenyl-1,2,3,6-tetrahydropyridine) caused $\beta$-catenin downregulation and pGSK-3 $\beta^{\text {Tyr216 }}$


nism reversed MPTP-induced neurogenic impairment ex vivo/in vitro or in vivo. Reciprocally, pharmacological modulation of inflammation prevented $\beta$-catenin downregulation and restored neurogenesis, suggesting the possibility to modulate this endogenous system with potential consequences for DAergic neuroprotection and self-repair.

\section{Introduction}

The generation of new neurons in the subventricular zone (SVZ) of the brain continues throughout adult life and may contribute to

\footnotetext{
Received 0ct. 18, 2011; revised Dec. 12, 2011; accepted Dec. 13, 2011

Author contributions: S.P. and B.M. designed research; F.L., C.T., N.T., S.C., M.C.M., M.D., M.F.S., and S.P. performed research; F.L., C.T., N.T., S.C., M.C.M., M.D., S.P., and B.M. analyzed data; F.L., M.C.M., S.P., and B.M. wrote the paper.

The authors declare no competing financial interests.

This work was supported by the Italian Ministry of Health (contract 82; PS-CARDI0 ex 56 and PS-NEURO ex 56 to B.M.; Young Investigator Award GR08-7 to S.P.), the Italian Ministry of Research (Curr. Res. 2008-2011 to B.M.), the Italian Multiple Sclerosis Foundation (partial grant 2004/R/15 and 2010/R/31 to S.P.), the National Multiple Sclerosis Society (partial Grant RG-4001-A1 to S.P.), the Italian Ministry of Research and University (to B.M.), Wings for Life (Grant XBAG/163 to S.P.), Banca Agricola Popolare di Ragusa (unrestricted grant to S.P.), the OASI (IRCCS) Institution for Research and Care on Mental Retardation and Brain Aging, the European Research Council (ERC-2010-StG Grant 260511-SEM_SEM), and John and Lucille van Geest Trust (unrestricted grant to S.P.).

Correspondence should be addressed to Dr. Bianca Marchetti, Department of Clinical and Molecular Biomedicine, Pharmacology Section, Faculty of Pharmacy, University of Catania, Viale A. Doria, 95125 Catania, Italy. E-mail: biancamarchetti@libero.it.

DOI:10.1523/JNEUROSCI.5259-11.2012

Copyright $\odot 2012$ the authors $\quad 0270-6474 / 12 / 322062-24 \$ 15.00 / 0$
}

endogenous repair mechanisms after brain damage and/or disease (Curtis et al., 2007). In Parkinson's disease (PD), a neurodegenerative disorder characterized by the selective degeneration of dopaminergic (DAergic) neurons in the substantia nigra pars compacta, neurogenesis is impaired. The decreased proliferation of neural stem/progenitor cells (NPCs) in the SVZ of human PD brains, in primate nonhuman, rodent 1-methyl-4-phenyl1,2,3,6-tetrahydropyridine (MPTP), and 6-hydroxydopamine models, has been attributed to the loss of the neurotransmitter dopamine (Baker et al., 2004; Hoglinger et al., 2004; Freundlieb et al., 2006; O'Keeffe et al., 2009a; Lennington et al., 2011). Other studies have proposed dopamine-independent effects of MPTP, but the cellular contributors and signaling pathways through which MPTP may exert its direct action on SVZ cells are currently unknown (He et al., 2006; Shibui et al., 2009). Here, we focused on glia and dissected the influence of MPTP, astrocytes, and microglia on the SVZ response to PD. 
Indeed, NPCs are in intimate contact with surrounding glia, forming the so-called SVZ "stem cell niche" that can influence NPC proliferation and differentiation (Lim and Alvarez-Buylla, 1999; Alvarez-Buylla et al., 2001; Song et al., 2002; Kazanis, 2009). Importantly, in the striatum bordering the SVZ of PD experimental models, astrocytes and microglia exhibit remarkable morphological and functional changes, including expression of an array of proinflammatory and anti-inflammatory cytokines and chemokines, as well as the production of reactive oxygen species (ROS) and reactive nitrogen species (RNS) (Marchetti and Abbracchio, 2005; Gao and Hong, 2008; Hirsch and Hunot, 2009). Of special interest, MPTP-dependent inflammatory mechanisms are recognized to contribute to nigrostriatal DAergic degeneration and self-repair (L'Episcopo et al., 2010a). However, the potential signaling pathways involved in the neuroinflammatory regulation of neurogenesis (Ekdahl et al., 2003, 2009; Monje et al., 2003; Butovsky et al., 2006; Pluchino et al., 2008) in PD are ill defined.

One attractive pathway chiefly involved in the modulation of neurogenesis, neuroprotection, and synaptic plasticity is the Wingless-type MMTV integration site $(W n t) / \beta$-catenin signaling system (Kalani et al., 2008; Maiese et al., 2008; Toledo et al., 2008; Munji et al., 2011; Zhang et al., 2011). The Wnt/ $\beta$-catenin pathway plays a central role in the generation, survival, and protection of midbrain DAergic neurons (Prakash et al., 2006; Inestrosa and Arenas, 2010; L'Episcopo et al., 2011a,b). Interestingly, in response to nigrostriatal injury, reactive astrocytes express Wnt1 and protect DAergic neurons against different neurotoxic insults via the activation of $W n t / \beta$-catenin signaling (L'Episcopo et al., 2011a,b). In addition, reactive astrocytes and $W n t / \beta$ catenin signaling activation promote neurogenesis from adult NPCs (L'Episcopo et al., 2011a).

Here, using in vivo, ex vivo, and in vitro experiments; different glial-NPC coculture paradigms; along with pharmacological antagonism/RNA silencing experiments coupled to functional studies, we provide evidence supporting an active and concerted role of reactive astrocytes and microglia in the remodeling of the SVZ niche after MPTP/1-methyl-4-phenyl-1,2,3,6-tetrahydropyridine $\left(\mathrm{MPP}^{+}\right)$injury, at least in part regulated by cross talk between inflammation and $W n t / \beta$-catenin signaling cascades, with potential consequences for DAergic neuroprotection and self-repair.

\section{Materials and Methods}

\section{Mice and treatments}

Eight- to ten-week-old male C57BL/6 mice (body weight, 24-26 g; Charles River, Calco) received $n=4$ intraperitoneal injections of vehicle (saline, $10 \mathrm{ml} / \mathrm{kg}$ ) or MPTP-HCl (20 $\mathrm{mg} \mathrm{kg}^{-1}$ free base; Sigma-Aldrich) dissolved in saline, $2 \mathrm{~h}$ apart in $1 \mathrm{~d}$, according to the acute MPTP injection paradigm (Jackson-Lewis and Przedborski, 2007). Mice were killed at different (1-42 d) time points after MPTP administration (see Fig. 1A). Studies were conducted in accordance with the Guide for the Care and Use of Laboratory Animals (NIH) and approved by the Institutional Animal Care and Use Committee.

At the indicated days after MPTP treatment, mice were given bromodeoxyuridine (BrdU; $50 \mathrm{mg} \mathrm{kg}^{-1}$, injected four times, $2 \mathrm{~h}$ apart) according to Ahlenius et al. (2009) and killed $2 \mathrm{~h}$ after the last injection.

\section{Immunohistochemistry}

Mice were deeply anesthetized and transcardially perfused, and the brains were carefully removed, postfixed overnight, placed in $20 \%$ sucrose in $0.1 \mathrm{M}$ phosphate buffer for $24 \mathrm{~h}$, frozen $\left(-80^{\circ} \mathrm{C}\right)$, and stored until further analyses (Morale et al., 2004). Criostatic coronal sections (14 $\mu \mathrm{m}$ thick) containing the SVZ $(0.74,0.5,0.14$, and $0.02 \mathrm{~mm}$ anterior to bregma) were collected according to Paxinos and Watson (1997) and mounted on poly-L-lysine-coated slides. The following preabsorbed pri- mary antibodies were used: rat anti-BrdU (1:200; Sigma-Aldrich), goat anti-doublecortin (DCX;1:400; Santa Cruz Biotechnology), mouse antiproliferating cell nuclear antigen (PCNA) (1:500; Dako), mouse anti-glial fibrillary acidic protein (GFAP;1:500; Sigma-Aldrich), rabbit antiGFAP (Dako), sheep anti-epidermal growth factor receptor (EGF-R; 1:50; Millipore), goat anti-ionized calcium-binding adapter molecule 1 (IBA1; 1:200; Novus Biologicals), rabbit polyclonal, anti-inducible nitric oxide synthase (iNOS;1:200; Santa Cruz Biotechnology), rabbit anti-3nitrotyrosine (3-NT; 1:200; Millipore), rat anti-dopamine transporter (DAT; 1:500; Millipore), mouse anti-neuron-specific nuclear protein (NeuN; 1: 500; US Biologicals), and rabbit anti-cleaved Caspase3 (1:200; Cell Signaling Technology). Immunohistochemistry for PCNA required antigen retrieval performed by incubating the sections in antigen retrieval solution (10× Target Retrieval Solution; Dako) diluted to $1 \times$ in distilled water. The antigen retrieval solution was preheated in a water bath at $80^{\circ} \mathrm{C}$ before the sections were added for $30 \mathrm{~min}$. The sections were subsequently washed three times in PBS at room temperature before immunohistochemistry was performed. Visualization of incorporated BrdU requires DNA denaturation performed by incubating the sections in $\mathrm{HCl}$ for $30 \mathrm{~min}$ at $65^{\circ} \mathrm{C}$. After overnight incubation, sections were rinsed and incubated in darkness for $2 \mathrm{~h}$ with CY3-conjugated donkey anti-rat, donkey anti-rabbit, and donkey anti-goat antibodies (1:200; Jackson ImmunoResearch Laboratories), mounted on glass slides, and coverslipped with glycerol-based mounting medium. Nuclei were counterstained with 4',6-diamidino-2-phenylindole (DAPI) in mounting medium (Vector Laboratories) or propidium iodide (PI). In all of these protocols, blanks were processed as for experimental samples except that the primary antibodies were replaced with PBS.

\section{Microscopical analysis}

Counting was performed blind to treatment condition. Immunostaining was examined using a Leica LCS-SPE confocal microscope. Briefly, four coronal sections through the SVZ, located at $0.74,0.5,0.14$, and $0.02 \mathrm{~mm}$ anterior to bregma (Paxinos and Watson, 1997), were analyzed bilaterally. Stereological estimations of $\mathrm{BrdU}^{+}, \mathrm{PCNA}^{+}, \mathrm{DCX}^{+}, \mathrm{EGF}^{+}{ }^{+}$, $\mathrm{GFAP}^{+}$(cell numbers per cubed millimeter of SVZ; Nv), were performed using a semiautomatic stereology system (ExploraNova Mercator), using conventional stereological equations (Gundersen and Jensen, 1987), with the formula: $\mathrm{Nv}=\mathrm{NC} /(t+D)$, where $\mathrm{NC}$ is the number of cells $/ \mathrm{mm}^{2}, t$ is the thickness of the section, and $D$ is the cell diameter. Quantification of the percentage of each phenotype marker expressing $\mathrm{BrdU}$ (i.e., $\mathrm{DCX}^{+} / \mathrm{BrdU}^{+}, \mathrm{EGF}^{+} \mathrm{R}^{+} / \mathrm{BrdU}^{+}$, and $\mathrm{GFAP}^{+} / \mathrm{BrdU}^{+}$cells) was performed in 100 cells in high-magnification fields in the SVZ in four sections per brain, with LAS-SPE imaging software (Leica). 3D reconstruction from $z$-series was used to verify colocalization in the $x-y, y-z$, and $x-z$ planes (see Fig. $1 C$ ).

\section{Determination of dopaminergic end points in striatum}

Measurements of fluorescence intensity (FI) of DAT-immunoreactive (IR) fibers in striatum (Str) were performed by computer-assisted image analysis software (Leica), and changes in average FI (mean \pm SD) were expressed as percentage of saline-injected controls. Determination of high-affinity synaptosomial dopamine uptake were performed in Str of saline and MPTP mice, and dopamine uptake levels (total high affinity and mazindol noninhibitable) were expressed as percentage of control as described (Morale et al., 2004; L’Episcopo et al., 2010b, 2011a,b,c).

\section{SVZ dissection and cell isolation}

Animals were deeply anesthetized with halothane and killed by cervical dislocation. Brain coronal sections from vehicle- and MPTP-treated mice were taken from mice $2 \mathrm{~mm}$ from the anterior pole of the brain, excluding the optic tracts, and $3 \mathrm{~mm}$ posterior to the previous cut, at the indicated time intervals [1-35 d posttreatment (dpt); see Fig. 2]. The SVZs were then dissected out under a microscope. Dissected tissue was transferred to Earl's balanced salt solution (Invitrogen) containing 1 $\mathrm{mg} / \mathrm{ml}$ papain (27 U/mg; Sigma-Aldrich), $0.2 \mathrm{mg} / \mathrm{ml}$ cysteine (SigmaAldrich), and $0.2 \mathrm{mg} / \mathrm{ml}$ EDTA (Sigma-Aldrich) and incubated for 45 min at $37^{\circ} \mathrm{C}$ on a rocking platform. Tissues were then transferred to DMEM/F-12 medium (1:1 v/v; Invitrogen) containing $0.7 \mathrm{mg} / \mathrm{ml}$ ovomucoid (Sigma-Aldrich) and mechanically dissociated. After digestion, 
the number of viable cells was determined by trypan blue (SigmaAldrich) exclusion. The green fluorescent protein-positive $\left(\mathrm{GFP}^{+}\right)$cells were isolated from the SVZ and established as described in detail previously (Pluchino et al., 2003, 2005; L’Episcopo et al., 2011a).

\section{Primary neural stem/precursor cell cultures}

To analyze self-renewal, continuous in vitro propagation was performed in neurosphere growth medium (DMEM/F-12 containing $2 \mathrm{~mm}$ L-glutamine, $0.6 \%$ glucose, $0.1 \mathrm{mg} / \mathrm{ml}$ apo-transferrin, $0.025 \mathrm{mg} / \mathrm{ml}$ insulin, $9.6 \mu \mathrm{g} / \mathrm{ml}$ putrescin, $6.3 \mathrm{ng} / \mathrm{ml}$ progesterone, $5.2 \mathrm{ng} / \mathrm{ml} \mathrm{Na}$ selenite, $2 \mu \mathrm{g} / \mathrm{ml}$ heparin) supplemented with EGF $(20 \mathrm{ng} / \mathrm{ml})$ and FGF2 (10 $\mathrm{ng} / \mathrm{ml}$ ), and the estimated total number of cells was calculated by multiplying the amplification rate (total number of cells obtained at a given subculture passage per 250,000) for the total number of cells obtained at the previous passage, as described (Pluchino et al., 2008). Data from continuous in vitro propagation experiments were expressed as absolute number of viable cells \pm SEM from a total of $n \geq 3$ independent experiments.

\section{In vitro neurosphere formation assay}

Primary cells isolated from the SVZs of either vehicle- or MPTP-treated mice ( $n \geq 4$ per group) were plated in 24 -well uncoated plates ( 0.5 $\mathrm{ml} /$ well; Corning) at a density of 8000 cells $/ \mathrm{cm}^{2}$ in growth medium, as described (Gritti et al., 2002; Pluchino et al., 2008). Under these conditions, neurospheres are derived from single cells and serve as an index of the number of in vivo neural stem cells (Morshead and van der Kooy, 1992; Morshead et al., 1994). The number of primary neurospheres with a diameter $(\wp) \geq 100 \mu \mathrm{m}$ in each well was counted $7 \mathrm{~d}$ after plating. To determine the self-renewal capacity, we mechanically dissociated primary spheres into single-cell suspensions and recultured them under the same conditions as primary cultures. Again, we determined the number of secondary neurospheres after $7 \mathrm{~d}$. The diameter of the single primary and secondary neurospheres was measured under an inverted microscope (Axiovert S100TV). Data were expressed as either mean clonal efficiency (namely, percentage of colony-forming cells, over total plated cells) or mean diameter (in micrometers), both \pm SEM from a total of $n \geq 3$ independent experiments.

\section{In vitro differentiation conditions}

To analyze proliferation, individual spheres (e.g., primary, secondary, established from either saline or MPTP mice; GFP ${ }^{+}$-expressing cells) were mechanically dissociated, and single cells were plated at a final density of $1 \times 10^{5}$ cells/cm on poly-D-lysine-coated 24 -well plates in differentiation medium consisting of a mixture of a 1:1 of F-12 and MEM, containing HEPES and glutamine, with N2 supplements (Invitrogen), with $1 \%$ fetal calf serum (FCS). Proliferation was studied by addition of the nucleotide analog $\operatorname{BrdU}(5 \mu \mathrm{M})$ at $2 \mathrm{DIV}$, in cell cultures exposed to the different treatment/coculture paradigms, and the cells were fixed after $24 \mathrm{~h}$ (i.e., at 3 DIV). For neuronal differentiation studies, neurospheres plated in differentiation medium were allowed to differentiate for 5-10 DIV in the absence or presence of the different treatments/ coculture paradigms, as described. The direct effect of the neurotoxin $\mathrm{MPP}^{+}$was studied in NPCs grown with or without glia, and in the absence or presence of activator/inhibitors of $\mathrm{Wnt} / \beta$-catenin signaling (see Figs. 4, 6, 7), as described below.

\section{Isolation and culture of astrocyte and microglia}

Mixed glial cell cultures were obtained from mouse brain, at postnatal days 2-3, as described in detail (Gallo et al., 2000a; Gennuso et al., 2004). The cultures were allowed to grow and differentiate until they reached confluency (14-16 DIV), and the resulting mixed cultures (65 $\pm 6 \%$ $\mathrm{GFAP}^{+}$astrocytes, $24 \pm 4 \% \mathrm{IBA}^{-1}{ }^{+}$microglia, and $5 \pm 2 \%$ oligodendrocytes, by immunocytochemistry) were used for coculture experiment (NPC-glia). For purified microglia and purified astrocyte cell preparations, the mixed glial cultures established as described were allowed to grow and differentiate until confluence (14-16 DIV), when the loosely adherent microglial cells were separated by shaking for $5 \mathrm{~h}$ at $37^{\circ} \mathrm{C}$ and $150 \mathrm{rpm}$, counted, and cultured in microglia medium (RPMI-1640 supplemented with $10 \%$ FCS, 1 mM L-glutamine, 1 mm sodium pyruvate, 50 $\mathrm{mm} \beta$-mercaptoethanol, $100 \mathrm{U} / \mathrm{ml}$ penicillin, and $100 \mathrm{mg} / \mathrm{ml}$ streptomy- cin). The primary astrocytes, obtained after separation of microglia ( $>95 \%$ of the cells were GFAP-IR astrocytes), and the enriched microglial ( $>95 \%$ of the cells were IBA1-IR microglia) monolayers were rinsed with sterile PBS and replated at a final density of $0.4-0.6 \times 10^{5} \mathrm{cells} / \mathrm{cm}^{2}$ in poly-D-lysine (10 $\mu \mathrm{g} / \mathrm{ml})$-coated 6-, 12-, or 24-well plates, or in insert membranes $(0.4 \mu \mathrm{m}$ of polyethylene terephthalate) for indirect coculture (BD Biosciences).

\section{Glial-NPC cocultures and treatments}

The direct effect of $\mathrm{MPP}^{+}$was studied in the absence (monotypic cultures) or presence (coculture) of glia, using $\mathrm{GFP}^{+}$cells (L'Episcopo et al., 2011). GFP ${ }^{+}$cells at passages $8-12$ were used in all in vitro experiments. Astrocyte, microglial, or mixed astrocyte-microglial monolayers were freshly cocultured with $\mathrm{GFP}^{+}$cells for different time intervals, according to proliferation (3 DIV) and differentiation (5-10 DIV) studies (L'Episcopo et al., 2011a). Both NPC monotypic and glial-NPC cocultures received increasing doses $(5-25 \mu \mathrm{M})$ of $\mathrm{MPP}^{+}$(see Fig. 4). These doses were selected based on our previous studies on primary mesencephalic DAergic neurons in culture (L'Episcopo et al., 2011a;b). For proliferation studies, $\mathrm{MPP}^{+}$was applied at 2 DIV, the nucleotide analog $\operatorname{BrdU}(5 \mu \mathrm{M})$ was added, and the cells were fixed after $24 \mathrm{~h}$, i.e., at 3 DIV. For differentiation studies, $\mathrm{GFP}^{+}$cells grown alone, or layered on top of astrocyte (NPC-Astro), microglia (NPC-Micro), or mixed astrocyte-microglial (NPC-glia) preparations, shifted in differentiation medium, and cells were allowed to differentiate. MPP ${ }^{+}$was applied at 5 and 9 DIV, and the cells were fixed after $24 \mathrm{~h}$ (see Fig. 4). Additionally, we studied the effect of coculture of GFP ${ }^{+}$cells with microglia isolated "ex vivo" from naive or MPTP mice (see Fig. 5). Reciprocally, the effect of coculture of astrocytes with NPC isolated ex vivo from naive and MPTP mice, both in the absence or presence of $\mathrm{Wnt} / \beta$-catenin signaling activation/antagonism, was also studied as described (see Fig. 7).

For immunocytochemistry, cell cultures were fixed in 4\% paraformaldehyde in PBS or with paraformaldehyde/PBS followed by ice-cold acidic ethanol and $\mathrm{HCl}$ for BrdU staining (L'Episcopo et al., 2011a). The following markers were used: mouse anti-Tuj1 (Covance Research Products) and rabbit anti-microtubule-associated protein 2abc (Map2a; Abcam) as neuronal markers; rabbit anti-GFAP ( Millipore), rat antiBrdU (Abcam), mouse anti-BrdU (Dako), goat anti-IBA1 (Novus Biologicals), rabbit polyclonal, and anti-iNOS (Santa Cruz Biotechnology). Nuclei were counterstained with DAPI. Analyses were performed using a confocal laser microscope and computer-assisted image analysis (Leica). For quantification of the amount of cells expressing a given marker or marker combinations, the number of $\mathrm{Map}^{2}{ }^{+}$cells was determined relative to the total number of DAPI-labeled nuclei or relative to $\mathrm{GFP}^{+}$cells; the number of $\mathrm{BrdU}^{+}$cells was determined relative to the total number of $\mathrm{DAPI}^{+}$cells or $\mathrm{GFP}^{+}$cells, using the Leica Lite software and threedimensional overlay to avoid false-positive/negative overlay and double counting.

\section{Ex vivo isolation and culture of macrophage/microglia, \\ measurement of RNS, and intracellular ROS}

Isolation of brain macrophage/microglia from saline and MPTP mice was performed in $n=8$ mice per group as described in detail (Marchetti et al., 2002; Morale et al., 2004; L'Episcopo et al., 2011c), 3 d after saline or MPTP (i.e., at the peak of microglial activation; see Fig. $3 B$ ). Cells were immunoreacted for activated macrophage/microglial-specific [IBA1; macrophage antigen-1 (Mac-1)/CD11b] and nonspecific (GFAP for astrocyte, galactocerebroside for oligodendrocyte, or neurofilament for neuron) markers. The isolated cells $\left(>95 \% \mathrm{IBA}^{+}\right.$cells) were counted and plated at a final density of $0.4-0.6 \times 10^{5} \mathrm{cells} / \mathrm{cm}^{2}$ in poly-D-lysine $(10 \mu \mathrm{g} / \mathrm{ml})$-coated 6-, $12-$, or 24 -well plates, or in insert membranes $(0.4$ $\mu \mathrm{m}$ of polyethylene terephthalate) for indirect coculture (BD Biosciences). The cells were cultured in microglia medium (RPMI-1640 supplemented with $10 \%$ FCS, $1 \mathrm{~mm}$ L-glutamine, $1 \mathrm{~mm}$ sodium pyruvate, 50 mм $\beta$-mercaptoethanol, $100 \mathrm{U} / \mathrm{ml}$ penicillin, and $100 \mathrm{mg} / \mathrm{ml}$ streptomycin) and used as follows. Part of the cells were processed $24-48 \mathrm{~h}$ after plating for ROS measurement using the redox membrane-permeant probe $2^{\prime}, 7^{\prime}$-dichlorofluorescein diacetate (DCF-DA; $50 \mu \mathrm{M}$, added for $1 \mathrm{~h}$ at $37^{\circ} \mathrm{C}$ ), and cells were viewed under the confocal microscope 
(Gennuso et al., 2004). Measurement of iNOS-derived NO was performed in cell-free supernatant using Griess reagent (Marchetti et al., 2002; Morale et al., 2004; L'Episcopo et al., 2011c). To study the effect of inhibition of oxidative and nitrosative stress mediators, the freshly prepared IBA ${ }^{+}$cells were cultured in the absence or presence of the ROS antagonist apocynin (Apo; $0.5 \mathrm{~mm}$ ) (Gao et al., 2003) and the specific iNOS inhibitor L-Nil [L-N6-(1-iminoethyl)-lysine, $50 \mu \mathrm{M}$; SigmaAldrich] (Marchetti et al., 2002; Morale et al., 2004) applied after plating, and determinations were performed $24-48 \mathrm{~h}$ after treatment (see Fig. 5).

Coculture of microglia isolated ex vivo from saline and MPTP mice with GFP-expressing NPCs

To study the effect of microglia exposure in vivo to MPTP (MPTPmicroglia) on NPC neurogenic potential, the freshly isolated microglial preparations from saline and MPTP mice, as above, were cocultured with $\mathrm{GFP}^{+}$NPC. As a control (ct-insert), a nonmicroglial preparation (i.e., neuronal GT1-7 cells) was used (Gallo et al., 2000b). For proliferation studies, NPCs were layered on top of the microglial cell monolayers, and after $24 \mathrm{~h}$, the nucleotide analog bromodeoxyuridine $(5 \mu \mathrm{M})$ was added and the cells fixed after $24 \mathrm{~h}$ (i.e., $48 \mathrm{~h}$ after microglial exposure). For differentiation studies, NPCs were grown for 3-4 DIV in differentiation medium as above (N2 medium without growth factors and 1\% FCS), the freshly prepared microglial cells were added on top, and the cells were fixed at 5-6 DIV ( $48 \mathrm{~h}$ after the microglial exposure). The cultures were fixed and processed for fluorescent immunocytochemistry as described. Indirect coculture paradigms, i.e., NPCs exposed to saline-microglia, MPTP-microglia, or ct-inserts, were performed as above. The inserts containing the saline, MPTP-microglial monolayers, or ct-inserts were added on top of the NPCs (L'Episcopo et al., 2011a). NPC survival was estimated by counting the number of $\mathrm{GFP}^{+}$cells over the DAPI-positive nuclei and by determination of Caspase3 activity (see Fig. 5).

\section{Caspase3 activity}

To verify changes in cell survival, the cells were lysed in ice-cold lysis buffer containing 25 mм HEPES, 5 mм EDTA, 1 mм EGTA, 5 mм $\mathrm{MgCl}_{2}$, $5 \mathrm{~mm}$ dithiothreitol (DTT), $1 \mathrm{~mm}$ phenylmethylsulfonyl fluoride, and 10 $\mu \mathrm{g} / \mathrm{ml}$ each of pepstatin and leupeptin, $\mathrm{pH}$ 7.5. The cells were left for 20 min on ice and then sonicated. The lysate was centrifuged for $20 \mathrm{~min}$ at $10,000 \times g$, and the supernatant was quickly frozen in a methanol dry ice bath and stored at $-80^{\circ} \mathrm{C}$. Lysates $(30 \mu \mathrm{g}$ protein $)$ were incubated at $37^{\circ} \mathrm{C}$ in a buffer containing 25 mM HEPES, pH 7.5, 10\% sucrose, 0.13 -[(3cholamido propyl) dimethyl ammonio]-1-propanesulphonate, and 10 mM DTT with the fluorogenic substrate DEVD-AFC ( $15 \mu \mathrm{m}$ in dimethylsulfoxide; Calbiochem), and quantification of the DEVD-like fluorescent signal was assessed in a luminescence spectrophotometer (excitation, $400 \mathrm{~nm}$; emission, $505 \mathrm{~nm}$ ) (L'Episcopo et al., 2011b). Enzymatic activity is expressed as arbitrary fluorescent units.

\section{Western blot analysis}

Inflammatory mediators and Wnt- $\beta$-catenin signaling components were studied by Western blot analysis (L'Episcopo et al., 2010a, 2011a,b,c). Protein extracts were prepared from tissues (Str, SVZ) isolated from saline or MPTP mice ( $n=6$ per group per time point) and from cell cultures within the different experimental groups. Protein samples were diluted to equivalent volumes containing $20 \mu \mathrm{g}$ of protein and boiled in an equal volume of Laemmli SDS boiling buffer (Sigma-Aldrich) for 10 min. Samples were loaded into a $9-12 \%$ SDS-polyacrylamide gel and separated by electrophoresis for $3 \mathrm{~h}$ at $100 \mathrm{~V}$ (L'Episcopo et al., 2010b, $2011 \mathrm{a}, \mathrm{b}, \mathrm{c})$. Proteins were transferred to polyvinylidene difluoride membrane (GE Healthcare) for $1.5 \mathrm{~h}$ at $300 \mathrm{~mA}$. The following primary antibodies were used: rabbit anti-Macl (Abcam); rabbit anti-p47PHOX (Millipore); mouse anti-gp91PHOX, mouse anti- $\beta$-catenin, rabbit anti3 -NT, and mouse anti-glycogen synthase kinase-3 $\beta$ (GSK-3 $\beta$ ) (all from Transduction Laboratories); and mouse anti-GSK-3 $\beta$ phospho-Tyr216 (BD Biosciences). Membranes were reprobed for $\beta$-actin (Cell Signaling Technology) or GSK-3 $\beta$ immunolabeling as internal controls. The bands from the Western blots were densitometrically quantified on $\mathrm{x}$-ray films using ImageQuantity One. Data from experimental bands were normalized to $\beta$-actin. Values are expressed as percentage of saline-injected controls (see Figs. 3, 5, 9) or as signal intensity values (fold changes) compared with saline control (see Fig. 6, 7). Western blot measurements were repeated three times independently.

\section{RNA extraction, reverse transcription, and real-time PCR}

Dysregulation of the $W n t / \beta$-catenin signaling pathway in SVZ cells from MPTP mice was also studied measuring the expression level of Axin2, a direct Wnt target transcriptionally induced after the reception of a Wnt/ $\beta$-catenin signal (Jho et al., 2002). RNA extraction was performed in cell samples from MPTP- and saline-injected mice homogenized in $1 \mathrm{ml}$ of QIAzol Lysis reagent (79306; QIAGEN) using a rotor-stator homogenizer, as described in detail (L'Episcopo et al., 2011a,b). Total RNA was isolated from homogenized samples using the RNeasy Lipid Tissue kit (74804; QIAGEN) including Dnase digestion. At the end, RNA samples were redissolved in $30 \mu \mathrm{l}$ of RNase-free water, and their concentrations were determined spectrophotometrically by $\mathrm{A}_{260}$ (Nanodrop-ND 1000); the cDNA was synthesized from $2 \mu \mathrm{g}$ of total RNA using the Retroscript kit (Ambion). After purification using the QIAquick PCR Purification kit (QIAGEN), 250 ng of cDNA were used for real-time PCR using predeveloped Taqman Assay reagents (Applied Biosystems). Real-time quantitative PCR was performed with the Step One Detection System (Applied Biosystems) according to the manufacturer's protocol, using the TaqMan Universal PCR master mix (4304437). The assay identifications for Axin2 (Mm00443610_m1 and $\beta$-catenin (Mm00483039_m1) were from Applied Biosystems. For each sample, we designed a duplicate assay, and $\beta$-actin (4352341E; Applied Biosystems) was used as the housekeeping gene. Results are expressed as arbitrary units.

\section{Effect of manipulation of $\mathrm{Wnt} / \beta$-catenin signaling in vitro}

Pharmacological activation/antagonism. To study the effect of pharmacological activation of $W n t / \beta$-catenin signaling in NPCs alone, we used the specific GSK-3 $\beta$ inhibitor AR-AO14418 [ $N$-(4-methoxybenzyl)- $N^{\prime}-(5-$ nitro-1,3-thiazol-2-yl)urea] (AR; $5 \mu \mathrm{M}$; Osakada et al., 2007; L'Episcopo et al., 2011a,b) or the Wnt ligand Wnt1 (100 ng/ml). AR or Wnt1 was applied $1 \mathrm{~h}$ before $\mathrm{MPP}^{+} / \mathrm{PBS}$ exposure, and NPCs were fixed after $24 \mathrm{~h}$ (L'Episcopo et al., 2011a,b). For Wnt/ $\beta$-catenin antagonism studies in astrocyte-NPC cocultures, we used Dickkopf-1 (Dkk-1; $100 \mathrm{ng} / \mathrm{ml}$; R \& D Systems). Dkk-1 is a high-affinity ligand for LRP6 and inhibits Wnt signaling by preventing Frizzled (Fz)-lipoprotein receptor-related protein 6 (LRP6) complex formation induced by Wnt (Semënov et al., 2001). Dkk1 was applied to NPCs just before the start of the coculture with astrocytes, and the cell was fixed at the indicated time intervals for proliferation/differentiation studies.

Transient gene silencing with small interfering RNA. To test the effect of GSK-3 $\beta$ or $\beta$-catenin protein depletion, we used targeted mRNA degradation using small interference RNA (siRNA) performed essentially as described (Brazas and Hagstrom, 2005). GSK-3 $\beta$ siRNA (sc-3525), $\beta$-catenin siRNA (sc-29210) (He and Shen, 2009), and control siRNA (sc-37007) were purchased from Santa Cruz Biotechnology, and siRNA introduction was performed according to the protocol provided by Santa Cruz Biotechnology, as reported in detail in our previous study (L'Episcopo et al., 2011b). Briefly, to prepare lipid-siRNA complexes, 80 pmol of the indicated siRNA duplex in $100 \mu$ l of Transfection medium (sc-36868) and $6 \mu \mathrm{l}$ of siRNA Transfection reagent (sc-29528) in $100 \mu \mathrm{l}$ of Transfection medium were combined, incubated for $30 \mathrm{~min}$ at $25^{\circ} \mathrm{C}$, and diluted with $800 \mu$ l of prewarmed Transfection medium. NPCs from saline and MPTP mice, dissociated and plated on 24 plate cells in growth medium, were rinsed once with serum-free DMEM, and $1000 \mu$ l of lipidsiRNA mixture described above was applied per well. After incubation for $6 \mathrm{~h}$ at $37^{\circ} \mathrm{C}$ in a humidified $5 \% \mathrm{CO}_{2}$ cell culture chamber, an additional $1 \mathrm{ml}$ of $20 \%$ FBS in DMEM was added per well, and lipofection was allowed to continue overnight. The next morning, the lipofection medium was aspirated, and transfected cells were refed with fresh growth medium. The cells were collected $72 \mathrm{~h}$ after transfection for Western blot assays.

\section{Effect of manipulation of $\mathrm{Wnt} / \beta$-catenin signaling, in vivo} Systemic injections and intracerebroventricular infusions. To link the Wnt/ $\beta$-catenin signaling pathway to MPTP-induced neurogenic impairment in vivo, we addressed (1) the effect of pharmacological activation of Wnt/ $\beta$-catenin signaling using the specific GSK- $3 \beta$ inhibitor AR by systemic 
or SVZ administration (Adachi et al., 2007; L'Episcopo et al., 2011a,b) and (2) the effect of Wnt/ $\beta$-catenin signaling antagonism with Dkk1 intracerebroventricular infusion (Zhang et al., 2008) in the absence or presence of AR systemic administration. Pilot experiments were performed to verify doses and timing capable to decrease active GSK-3 $\beta$ in the SVZ of both intact and MPTP mice. To test the systemic effect, AR was injected in intraperitoneally at a dose regimen $(10 \mathrm{mg} / \mathrm{kg}$ twice per day) (L'Episcopo et al., 2011a,b), starting $3 \mathrm{~h}$ after MPTP. To kill the mice, we selected 3 d post-MPTP, corresponding to maximal neurogenic impairment and exacerbated microglial reaction (see Fig. 3).

For intracerebroventricular infusion, AR $(100 \mu \mathrm{M})$, or the vehicle alone, was infused into the left lateral ventricle of the brain with a miniosmotic pump (model 1007D; flow rate, $0.5 \mu \mathrm{l} / \mathrm{h}$; Alzet Osmotic pumps, Cupertino, CA). The cannula was implanted stereotaxically at the following coordinates: anterior, $0 \mathrm{~mm}$; lateral, $1.1 \mathrm{~mm}$; depth, $2.3 \mathrm{~mm}$ (relative to bregma and surface of the brain). For $W n t / \beta$-catenin antagonism, we used recombinant human Dkk1 protein (rh-Dkk1; R \& D Systems) intracerebroventricular infusion, essentially as reported by Zhang et al. (2009). Dkk1 was dissolved in sterile physiologic saline $(0.9 \% \mathrm{NaCl})$ at a final concentration of $1 \mu \mathrm{g} / \mu \mathrm{l}$. The infusions of $D k k 1$ or the vehicle were performed unilaterally as above using a $2 \mu \mathrm{l}$ Hamilton microsyringe. The volume of the solution was infused at a rate of $0.25 \mu \mathrm{l} / \mathrm{min}$. The needle was kept in place for $5 \mathrm{~min}$ after each infusion before retraction. To address the ability of $W n t / \beta$-catenin activation to reverse $D k k 1$ effect, unilateral infusion of $D k k 1$ or vehicle was preceded by saline or AR systemic injections as above, starting $48 \mathrm{~h}$ before intracerebroventricular administration. The mice were killed $48 \mathrm{~h}$ after $D k k 1 /$ vehicle infusion, and the brains were processed as described for protein expression and neurochemical and histhopathological determinations.

Effect of pharmacological modulation of inflammation. To study whether pharmacological modulation of inflammation affects NPC proliferation after MPTP injury via Wnt/ $\beta$-catenin signaling in SVZ in vivo, we addressed the effect of the cyclooxygenase inhibitor, NO-releasing drug (CINOD) 2-fluoro- $\alpha$-methyl(1,1' -biphenyl)-4-acetic-4-(nitrooxy)butyl ester (HCT1026; kindly provided by Nicox Research Institute, Bresso, Milan, Italy), which belongs to a novel class of nonsteroidal anti-inflammatory drugs endowed with strongly reduced side effects (Keeble and Moore, 2002; Fiorucci et al., 2007; L'Episcopo et al., 2010b, 2011c). HCT1026 was administrated in the diet at a dose regimen (HCT1026, $190 \mathrm{ppm}$ in the diet or $30 \mathrm{mg}$ $\mathrm{kg}^{-1}$ per day per animal) shown to mitigate glial neuroinflammatory reaction and afford DAergic neuroprotection, when compared with mice fed with a control diet [plain Teklas 2018 chow (ct diet)] (see L'Episcopo et al., 2010b, 2011c). The HCT1026 diet was started $7 \mathrm{~d}$ before MPTP, and mice were killed at $3 \mathrm{~d}$ (at the peak of neuroinflammatory microglial reaction) and $14 \mathrm{~d}$ after MPTP (corresponding to the phase of stabilization of DAergic degeneration) (Jackson-Lewis and Przedborski, 2007; L'Episcopo et al., 2010b, 2011a).

\section{Data analysis}

Statistical significance between means \pm SEM was analyzed by a two-way ANOVA and Student's $t$ test for paired or unpaired data. Experimental series performed on different days were compared by the Student-Newman-Keuls $t$ test. A value of $p<0.05$ was considered to be statistically significant.

\section{Results \\ Loss and recovery of SVZ NPC proliferation and neuroblast formation after MPTP treatment}

To assess the contribution of the inflammatory reaction in the SVZ response, we first verified, in vivo, spatiotemporal changes in proliferation and neuroblast formation at different time intervals (1-42 d) during loss and recovery of nigrostriatal DAergic neurons, according to the acute MPTP injection paradigm (L'Episcopo et al., 2011a), and correlated the temporal changes in the intrinsic NPC proliferation capacity, ex vivo (Fig. 1A). As reported in both rodent and primate models of PD (Baker et al., 2004; Borta and Hoglinger, 2007; O'Keeffe et al., 2009a), we found that MPTP induced a significant decrease of PCNA ${ }^{+}$and
$\mathrm{BrdU}^{+}$(Fig. $1 B, D$ ) starting by $1 \mathrm{~d}$ after MPTP injury through 14 $\mathrm{dpt}$ (from $16.5 \pm 2.0$ of saline mice to $6.0 \pm 0.5 \times 10^{3} \mathrm{PCNA}^{+}$ cells measured $14 \mathrm{dpt}$ ).

The reduced proliferation of MPTP mice was accompanied by a severe reduction of $\mathrm{DCX}^{+}$neuroblasts (Fig. $\left.1 \mathrm{~B}, \mathrm{G}\right) 1-14 \mathrm{dpt}$ (from $870 \pm 25$ of saline mice to $280 \pm 35 \times 10^{3} \mathrm{DCX}^{+}$cells measured $14 \mathrm{dpt}$ ). The temporal window of neurogenic impairment was associated with the DAergic degeneration phase, as measured by the almost 70-80\% depletion of DAT protein in Str, paralleled by a comparable decrease in high-affinity DA uptake by striatal synaptosomes (Table 1). At the midbrain level, the cumulative MPTP dose of $80 \mathrm{mg} \mathrm{kg}^{-1}$ resulted in a severe $(\geq 60 \%)$ loss of DAergic cell bodies measured 1-21 dpt (L'Episcopo et al., 2011a).

Importantly, between 14 and $28 \mathrm{dpt}$, a significant recovery of cell proliferation (Fig. $1 B, D$ ) was observed in SVZ, reaching preMPTP values by 35 and $42 \mathrm{dpt}\left(13.0 \pm 1.2\right.$ and $15.0 \pm 1.5 \times 10^{3}$ PCNA cells measured at 35 and $42 \mathrm{dpt}$, respectively). Likewise, $\mathrm{DCX}^{+}$cells (Fig. $1 B, G$ ) exhibited a significant recovery between 14 and $28 \mathrm{dpt}$, returning back to normal by 35 and $42 \mathrm{dpt}$ (798 35 and $875 \pm 48 \times 10^{3} \mathrm{DCX}^{+}$cells at 35 and $42 \mathrm{dpt}$, respectively) and coinciding with progressive striatal DAergic reinnervation (Table 1$)$. At the midbrain level, a reduced ( $\leq 38 \%)$ DAergic cell loss was observed by 35-42 dpt (L'Episcopo et al., 2011a).

As observed previously in nigrostriatal lesioned rodents (Mao et al., 2001; L. W. Chen et al., 2002, 2004; Morale et al., 2004, 2006; Mohapel et al., 2005; L'Episcopo et al., 2010a,b, 2011a,b) and primates (Tandé et al., 2006), astrocyte cell number was significantly increased in the Str of MPTP mice, a phenomenon thought to result from an early reaction of gliogenic precursor cells intrinsic to the striatum (Tandé et al., 2006; Borta and Hoglinger, 2007). Here, the specialized GFAP ${ }^{+}$astrocytes (Bcells) adjacent to the SVZ, ensheating $\mathrm{BrdU}^{+}$cells in salineinjected mice, were also markedly affected after MPTP injury (Fig. 1 B): $\mathrm{GFAP}^{+}$astrocytes were increased (from $120 \pm 12$ of saline mice to $205 \pm 16 \times 10^{3} \mathrm{GFAP}^{+}$cells measured $14 \mathrm{dpt}$ ) and displayed a highly reactive phenotype, as revealed by hypertrophic cell bodies and increased thickness and length of processes, resulting in an overall disruption of $\mathrm{GFAP}^{+}-\mathrm{BrdU}^{+}$cell interactions in SVZ (Fig. $1 B, E$ ). With time, however, $\mathrm{GFAP}^{+}$astrocytes shifted to a less reactive phenotype, and morphologic interactions with NPCs in SVZ were seemingly restored back to salineinjected controls (Fig. 1B). SVZ astrocytes are infrequently dividing stem cells, which generate frequently dividing, transit amplifying C-cells, which in turn produce restricted neuroblasts, A-cells (Doetsch et al., 1997, 1999). Previous studies have identified epidermal growth factor as a crucial regulator of SVZ expansion, and EGF-R ${ }^{+}$cells in the SVZ were shown to correspond mainly to the rapidly cycling transit amplifying C-cells (Doetsch et al., 2002). Given the indication that C-cell proliferation is decreased after MPTP (Hoglinger et al., 2004; O'Keeffe et al., 2009a; b), we next analyzed sections double stained for BrdU/PCNA and the neuroblast markers DCX, BrdU/PCNA, and GFAP, as well as BrdU/PCNA and EGF-R as C-cell markers (Doetsch et al., 2002; Hoglinger et al., 2004; O'Keeffe et al., 2009b) (Fig. 1C, F, H-J). In accordance with previous studies, the percentage of $\mathrm{DCX}^{+}$cells expressing BrdU (Fig. $1 \mathrm{H}$ ), or the percentage of $\mathrm{GFAP}^{+}$cells expressing BrdU (Fig. $1 F$ ), did not change significantly during the window of SVZ impairment, whereas an increase in $\mathrm{GFAP}^{+}$ cells expressing PCNA was observed in the Str of MPTP mice, within 24 h of MPTP injury (Fig. $1 B$ ). Although, not specifically addressed in the present study, we did not find clear evidence of a cell density gradient from the Str to the SVZ, or vice versa, 1-14 
A

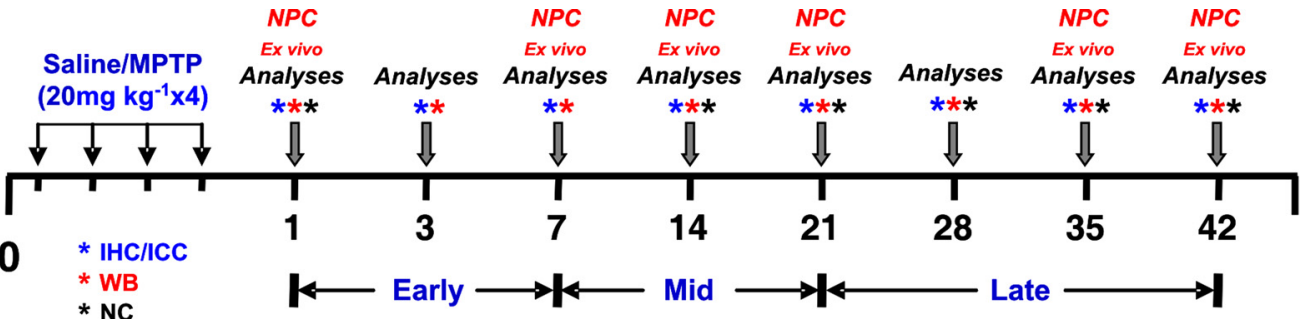

B
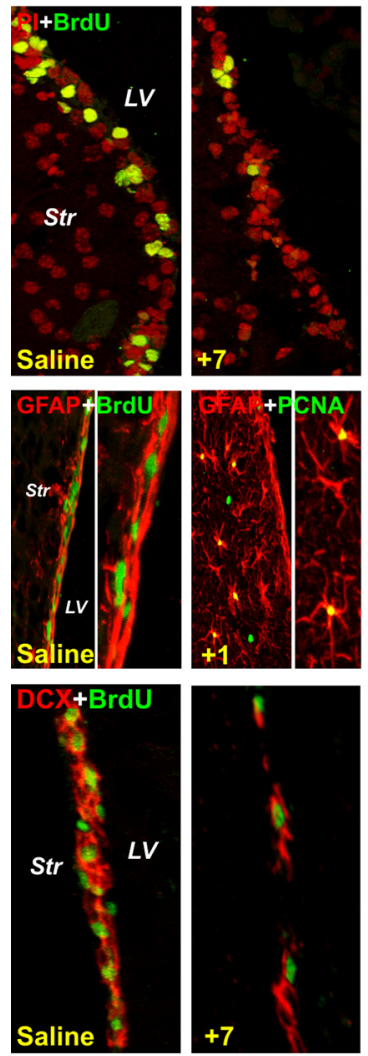
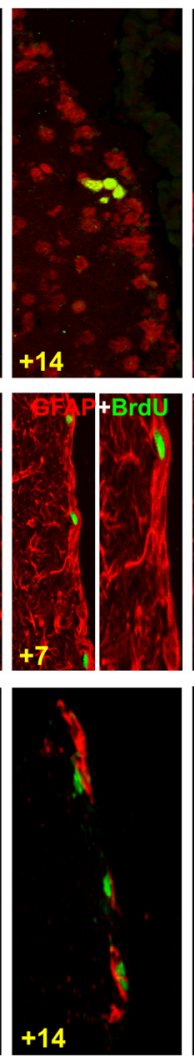


D
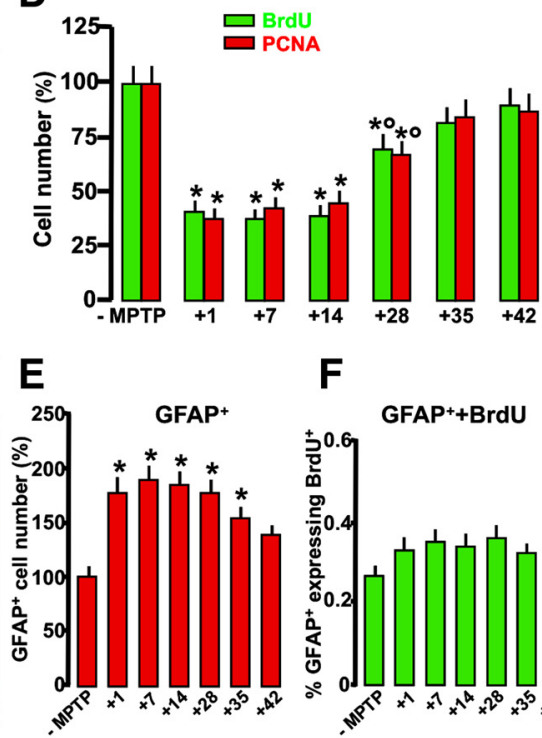

$F$



$\mathrm{H}$

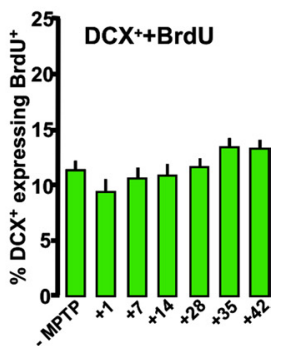

C
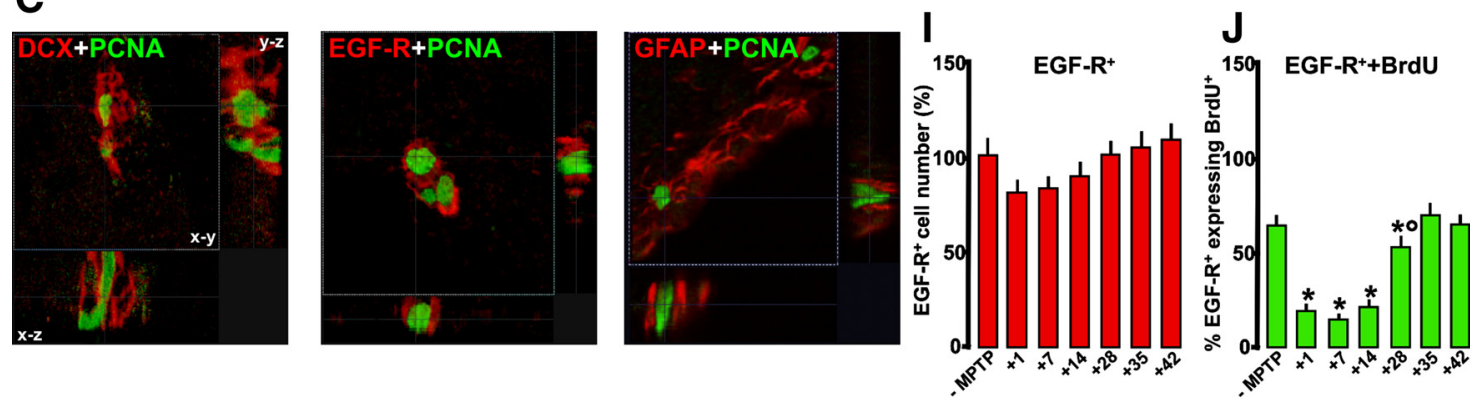

Figure 1. Loss and recovery of SVZ neuroprogenitor proliferation and neuroblast formation after MPTP treatment in vivo. A, Scheme of experimental design showing time points studied after saline and MPTP treatments (7-8 mice per time point). For ex vivo studies of neuroprogenitors, the SVZ region was microdissected and aseptically prepared for isolation and culture of NPCs. For immunohistochemistry (IHC), groups of mice were anesthetized and transcardially perfused (6 mice per time point). For neurochemical (NC) and Western blot (WB) analyses (5 mice per time point), the brains were rapidly dissected and stored at $-80^{\circ} \mathrm{C}$. ICC, Immunocytochemisty. B, Representative confocal images of BrdU ${ }^{+}$(green) counterstained with the nuclear marker PI (red), and dual staining with GFAP (red) and BrdU (green), with GFAP (red) and PCNA (green), and with DCX ${ }^{+}$(red) and BrdU (green). C, Orthogonal reconstructions of confocal microscopic images of dual staining with DCX and PCNA, EGF-R and PCNA, and GFAP and PCNA in the $x-y, x-z$, and $y-z$ planes. D-J, Quantification of proliferation as assessed by numbers of $\mathrm{BrdU}^{+}$and PCNA ${ }^{+}$cells $(\boldsymbol{D}) ; \mathrm{GFAP}^{+}$cell numbers $(\boldsymbol{E})$ and percentage of GFAP ${ }^{+}$expressing $\operatorname{BrdU}(\boldsymbol{F}) ; \boldsymbol{D C X}^{+}$cell number $(\boldsymbol{G})$ and percentage of $\mathrm{DCX}{ }^{+}$expressing BrdU $(\boldsymbol{H})$; and EGF- $\mathrm{R}^{+}$cell numbers $(\boldsymbol{I})$ and percentage of EGF- $\mathrm{R}^{+}$expressing BrdU $(\boldsymbol{J})$. Differences were analyzed by ANOVA, followed by the Newman-Keuls test, and were considered significant when $p<0.05 .{ }^{*} p<0.05$ versus saline; ${ }^{\circ} p<0.05$ versus $1-14$ or $1-7 \mathrm{dpt}$, within each respective group. 
Table 1. MPTP-induced loss and recovery of dopaminergic end points in striatum

\begin{tabular}{|c|c|c|c|c|c|c|c|}
\hline \multirow[b]{2}{*}{ Analyses } & \multicolumn{7}{|c|}{ MPTP time course } \\
\hline & MPTP & +1 & +14 & +21 & +28 & $+35 d$ & $+42 d$ \\
\hline DAT immunoreactivity (FI, \% of control) & $100 \pm 15$ & $22 \pm 8^{*}$ & $25 \pm 10^{*}$ & $38 \pm 9^{*}$ & $51 \pm 9^{*}$ & $65 \pm 10^{*}$ & $75 \pm 12$ \\
\hline$\left[{ }^{3} \mathrm{H}\right]$ DA uptake (\% of control) & $100 \pm 18$ & $31 \pm 10^{*}$ & $29 \pm 8^{*}$ & $35 \pm 10^{*}$ & $45 \pm 10^{*}$ & $58 \pm 12^{*}$ & $68 \pm 12$ \\
\hline
\end{tabular}

Male C57BL/6 mice received $n=4$ intraperitoneal injections of vehicle (saline, $10 \mathrm{ml} / \mathrm{kg}$ ) or MPTP-HCI ( $20 \mathrm{mg} \mathrm{kg}^{-1}$ free base; Sigma-Aldrich) dissolved in saline, $2 \mathrm{~h}$ apart in $1 \mathrm{~d}$. For each set of analyses, five mice were used for the indicated time points. The brains were processed as indicated for DAT immunohistochemistry. Fluorescence intensity values (means $\pm \mathrm{SEM}$ ) are expressed as percentage of saline. Synaptosomial high-affinity [ $\left.{ }^{3} \mathrm{H}\right] \mathrm{DA}$ uptake in striatum (total high-affinity and mazindol noninhibitable) was determined as described, and the values are represented by the changes in DA uptake (expressed as percentage of control). Differences were analyzed by ANOVA, followed by the Newman-Keuls test, and were considered significant when $p<0.05 .{ }^{*} p<0.05$ versus MPTP.

$\mathrm{dpt}$, albeit migration of $\mathrm{GFAP}^{+}$cells from the adjacent Str might explain the observed increased density of astrocytes bordering the SVZ of MPTP mice. On the other hand, the percentage of EGF- $\mathrm{R}^{+}$cells expressing BrdU was significantly decreased during the temporal window of neurogenic impairment (Fig. 1J), whereas by $28 \mathrm{dpt}$, the percentage of EGF-R ${ }^{+} / \mathrm{BrdU}^{+}$cells increased to recover back to normal pre-MPTP levels within 35-42 dpt (Fig. $1 J$ ), supporting that the MPTP-induced acute reduction of EGF- ${ }^{+}$proliferation might reduce the generation of $\mathrm{DCX}^{+}$ cells. In addition, the $S V Z$ recovery phase involved a normalization of $\mathrm{GFAP}^{+}-\mathrm{BrdU}^{+}$cell interactions and increased EGF- ${ }^{+}$ cell proliferation, possibly resulting in generation of new $\mathrm{DCX}^{+}$ neuroblasts (Fig. $1 B$ ).

We next set to identify possible differences in intrinsic properties between NPCs from saline- and MPTP-treated mice at the indicated time intervals, by studying the self-renewal of CNS stem/progenitor cells by using an ex vivo assay. It has been shown that neurosphere-forming cells consist mostly of type $C$ (and type B) cells in vitro (Morshead et al., 1994). Therefore, we used a well established in vitro neurosphere assay to further characterize the SVZ stem cell population of MPTP mice, with the numbers of clonal neurospheres in vitro as a measure of the absolute number(s) of putative stem cells in vivo (Morshead et al., 1994; Rietze and Reynolds, 2006; Pluchino et al., 2008). We observed a significant reduction of the clonal efficiency of SVZ-derived primary neurospheres at all time points after MPTP $(p<0.005$, compared with saline-treated control mice) (Fig. 2A). This difference did peak at 14 and $21 \mathrm{~d}$ after MPTP, with the clonal efficiency of neurospheres from MPTP-treated mice being threefold lower than that of control neurospheres (Fig. 2A). This decline in clonal efficiency was further confirmed in secondary neurospheres at the very same time points (Fig. $2 A ; p<0.005$, compared with saline-treated control mice), thus further corroborating our own in vivo observation that significant impairment of the SVZ NPC compartment occurs at certain time points after MPTP. Interestingly, neurospheres (both primary and secondary) from MPTPtreated mice did not show differences in size at any time point, compared with neurospheres from control mice (Fig. $2 B$ ), thus suggesting that SVZ stem cells from MPTP-treated mice do not show intrinsic differences in their mitogenic capacity from cells derived from controls. Finally, we sought to investigate the proliferation capacity of NPCs from MPTP mice under chemically defined serum-free culture conditions in vitro. In line with clonal analyses, neurospheres from MPTP-treated mice between $24 \mathrm{~h}$ and $14 \mathrm{~d}$ did show again significant early impairment in their growth rate that was, however, completely recovered after $12 \mathrm{~d}$ in vitro in the presence of FGF-II and EGF, thus further confirming that there is not a cell-autonomous process accounting for the impairment in proliferation observed in vivo (Fig. 2C).

From both the in vivo and ex vivo findings, the present time course study indicated that MPTP-induced impairment of neurogenic potential may be attributable to environmental factors rather than to the intrinsic properties studied on NPC progeny.
In addition, the characterized biphasic response of the SVZ after MPTP injury accompanying the early degeneration and the late recovery of nigrostrial DAergic neurons thus set the temporal window for the study of the influence of neuroinflammation in SVZ plasticity.

\section{MPTP-induced upregulation and downregulation of inflammatory signals in striatum and SVZ is inversely correlated to loss and recovery of NPC proliferation}

The well established strong and localized microglial reaction in Str of MPTP-treated mice (see L'Episcopo et al., 2011a) was next temporally correlated with NPC proliferation in SVZ. To this end, we classified the stages of microglia activation according to Kreutzberg (1999) and counted stage $4 \mathrm{IBA}^{+}{ }^{+}$microglia, exhibiting a round-shaped cell body without processes, as opposed to quiescent stage 1 microglia, with elongated soma and thin/ramified processes (L'Episcopo et al., 2011c). As observed in Figure 3, $A$ and $B$, an inverse correlation between stage $4 \mathrm{IBAl}^{+}$microglia and $\mathrm{PCNA}^{+}$cells in the SVZ started as early as after $1 \mathrm{dpt}$ (Fig. $3 B$ ), when a sharp increase of activated ameboid-shaped IBA-1 ${ }^{+}$ microglia in both Str and SVZ was detected (Fig. $3 A, B$ ), compared with saline-injected mice, where only quiescent stage 1 $\mathrm{IBA}^{+}$microglia with elongated cell body and ramified processes were seen (Fig. $3 A$ ). Here again, numerous $\mathrm{PCNA}^{+} / \mathrm{IBA}^{+}{ }^{+}$cells were found early (within $24 \mathrm{~h}$ ) in Str of MPTP mice (Fig. 3A), suggesting their possible migration toward the adjacent SVZ. Correlation of microglia activation with SVZ proliferation indicated that a maximal decrease of $\mathrm{PCNA}^{+}$cells in SVZ correlated with the peak of reactive IBA1 ${ }^{+}$cells, whereas rescue of PCNA ${ }^{+}$ cells coincided with reactive $\mathrm{IBA} 1^{+}$cell abatement (Fig. $3 B$ ). By this time, IBA- $1^{+}$microglia with thinner and longer processes were observed in both SVZ and Str for the rest of the experimental period (Fig. $3 A$ ). Overactivation of microglia temporally related to NPC impairment was also indicated by the early and sharp increase of Mac-1 (Fig. 3C) and phagocyte oxidase (PHOX) (Fig. 3D) and by increased IBA1 ${ }^{+}$cells expressing iNOS in Str and SVZ (Fig. $3 E, F$ ). The severe striatal pro-oxidant/proinflammatory status herein observed is in line with our previous findings revealing upregulation of major oxidative/inflammatory mRNA species (including PHOX, NOs2, NOs3, Hmox1, and UCP2) peaking 3-24 h after MPTP (L'Episcopo et al., 2010b, 2011a). Conversely, PCNA ${ }^{+}$cell return to pre-MPTP levels (Fig. $3 B$ ) was preceded by downregulation of oxidative and proinflammatory mediators in Str (Fig. 3C, D, F). When PHOX- and iNOSderived $\mathrm{NO}$ are active at the same time, then microglia might produce peroxynitrite $\left(\mathrm{ONOO}^{-}\right)$, a potent toxin that may promote nitration of various proteins, and produce hydroxyl radicals that may impair mitochondrial functions (Gao et al., 2003, 2008; Mander and Brown, 2005; Gao and Hong, 2008; Hu et al., 2008). Given the vital role of astrocytes in brain homeostasis, particularly as ROS, peroxynitrite, and glutamate scavengers (Magistretti, 2006; Moncada and Bolanos, 2006; Chen et al., 2009; Sandhu et al., 2009), we then performed dual staining with 



Figure 2. Analyses of intrinsic properties of SVZ neuroprogenitor isolated ex vivo from vehicle and MPTP mice. At the indicated time intervals, brain coronal sections were taken from vehicle- and MPTP-treated mice, and the SVZs were rapidly dissected out and processed as described. A, Quantitative analysis of the clonal efficiency of neurospheres from naive and MPTP-treated mice. Data are represented as mean percentage of colonies per size over total plated cells ( $\pm S E M$ ) and have been obtained from a total of $n \geq 3$ independent experiments. $\boldsymbol{B}$, Size of neurospheres from naive and MPTP-treated mice. Data are represented as mean numbers (micrometers) ( \pm SEM) and have been obtained from a total of $n \geq 3$ independent experiments. Red in $\boldsymbol{A}$ and $\boldsymbol{B}$ represents neurospheres from naive mice, whereas green represents neurospheres from MPTP-treated mice. Filled bars in $\boldsymbol{A}$ and $\boldsymbol{B}$ represent primary neurospheres, whereas wide upward diagonal bars represent secondary neurospheres. $\mathbf{C}$, Growth rate analysis of NPC lines established from the SVZ of either naive or MPTP-treated mice. * $p \leq 0.005$ and ${ }^{* *} p \leq 0.0001$, compared with time point-matched controls. p.n., Primary neurosphere; s.n., secondary neurosphere.
GFAP and 3-NT, as a fingerprint of iNOSderived $\mathrm{NO}$ and peroxynitrite generation. Hence, a sharp increase in the 3-NTimmunofluorescent (IF) signal in striatal astrocytes and SVZ was observed shortly after MPTP, but not saline, injection (Fig. $3 E$ ). This increase in 3-NT immunofluorescence, supported by Western blot analysis (Fig. $3 G$ ), reached a peak $3 \mathrm{dpt}$ and subsided by $21 \mathrm{dpt}$, indicating astrocyte nitrosylation during the early window of NPC neurogenic impairment. Because previous studies showed MPTP-induced apoptosis in the SVZ (He et al., 2006; Shibui et al., 2009), and given the cytotoxic role of increased peroxynitrite generation, we next localized the death marker cleaved Caspase3. Double localization of the neuronal cell marker NeuN (green) with Caspase3 (red) in the striatal SVZ clearly documented the increased Caspase3-IF signal specifically localized in the SVZ but not in Str of MPTP mice (Fig. $3 E$ ) during the peak of microglia activation, while disappearing by $7 \mathrm{dpt}$ (data not shown), thereby indicating that a certain proportion of SVZ cells might be acutely damaged by MPTP challenge.

All together, these data indicated that MPTP-induced NPC impairment, in vivo and ex vivo, was preceded and accompanied by increased microglial inflammatory mediators and astrocyte nitration both in Str and SVZ, whereas a downregulation of striatal oxidative and inflammatory status preceded the recovery from neurogenic impairment, thus raising the question of the distinct roles played by the neurotoxin MPTP, activated astrocytes, and microglia.

$\mathrm{MPP}^{+}$directly impairs NPC survival, proliferation, and/or differentiation in a dose-dependent fashion

Previous studies proposed a possible dopamine-independent effect of MPTPinduced neuroblast apoptosis in the SVZ, but the cellular contributors and the signaling pathways involved in this process are currently unknown. It is generally accepted that the neurotoxin MPTP, converted into its active metabolite, $\mathrm{MPP}^{+}$, in astrocytes, is selectively transported into striatal DAergic terminals via the DAergic transporter DAT, where it induces oxidative stress, the opening of mitochondrial permeability transition pore, the release of cytochrome $c$, and the activation of caspases (Jackson-Lewis and Przedborski, 2007). In synergy with these early events accounting for $\sim 10 \%$ of DAergic neuronal death (Wu et al., 2002), glial inflammatory mechanisms are 
A
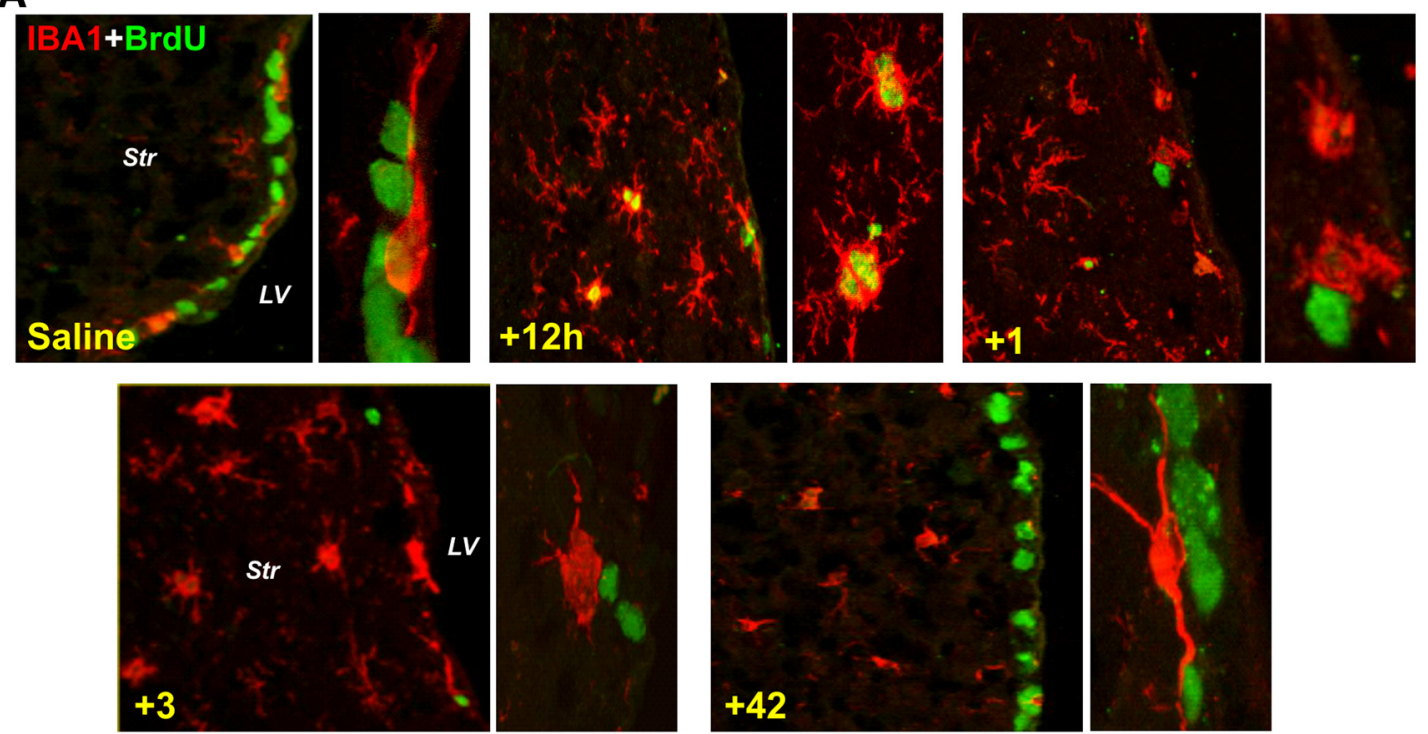

B



E
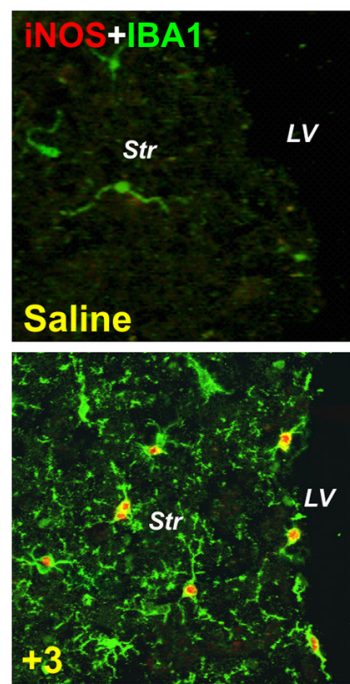

C

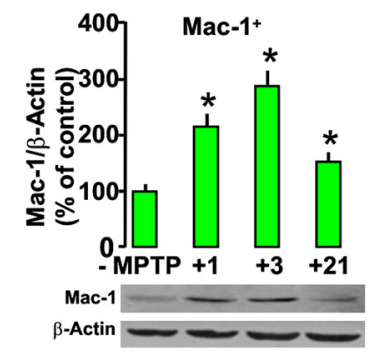

D

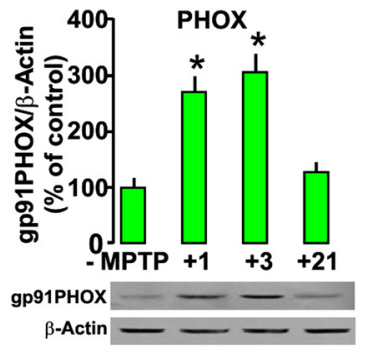

$\mathbf{F}$

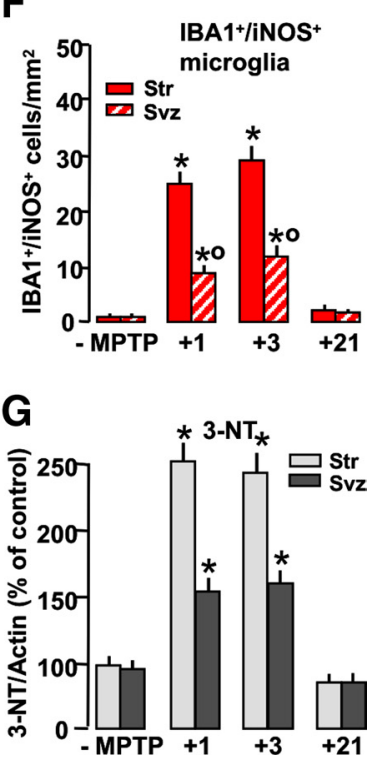

Figure 3. Inverse correlation between MPTP-dependent microglial activation and cell proliferation in SVZ. Mice treated with saline or MPTP were killed, and the brain was processed for immunohistochemical or Western blot analyses. A, Representative confocal images showing dual staining with IBA1 (red) and BrdU (green) in saline 1,3, and 42 d after MPTP. Note the juxtaposition of stage $1 \mathrm{IBA} 1^{+}$cell soma and process with BrdU ${ }^{+}$cells in the SVZ of saline mice. Within $12 \mathrm{~h}$ from MPTP-activated IBA ${ }^{+}{ }^{+}$, microglia expressing PCNA are observed in the Str. By $24 \mathrm{~h}$ and $3 \mathrm{dpt}$, stage $4 \mathrm{IBA} 1^{+}$microglia are seen both in Str and SVZ. By $42 \mathrm{dpt}$, BrdU ${ }^{+}$in the SVZ and IBA ${ }^{+}$microglia recovered back to saline-treated controls. $B$, Inverse correlation between NPC proliferation in the SVZ measured with PCNA (numbers of PCNA ${ }^{+}$cells $/ 10^{3}$ ) and stage $4 \mathrm{IBA} 1^{+}$microglia (cell number per cubed millimeter). Differences were analyzed by ANOVA, followed by the Newman-Keuls test, and were considered significant when $p<0.05 .{ }^{*} p<0.05 \mathrm{IBA} 1^{+}$cells versus saline and ${ }^{\circ} p<0.05 \mathrm{PCNA}^{+}$cells versus saline, within each experimental group. $\boldsymbol{C}, \boldsymbol{D}$, Western blotting of Mac- $1(\boldsymbol{C})$ and PHOX (D) in Str after saline or MPTP injection. Data from experimental bands were normalized to $\beta$-actin, before statistical ANOVA, and values were expressed as percentage of saline-injected controls. Differences were analyzed as above. ${ }^{0, *} p<0.05$, compared with saline. $\boldsymbol{E}$, Dual immunostaining with iNOS (red) and IBA1 (green), 3-NT (red) and GFAP (green), and cleaved Caspase3 (red) and NeuN (green) in Str and SVZ in saline and 3 dpt. Note the increased iNOS expression in IBA1 ${ }^{+}$microglia, increased 3-NT colocalization (orange to yellow) in Str astrocytes and SVZ, and increased Caspase3 localization in SVZ, 3 dafter MPTP. F, IBA1 ${ }^{+}$/iNOS cell counts 1, 3, and 21dpt. G, Immunoblotting shows increased 3-NT in Str and SVZ protein extracts peaking 3 dpt and subsiding by $21 \mathrm{dpt}$. 

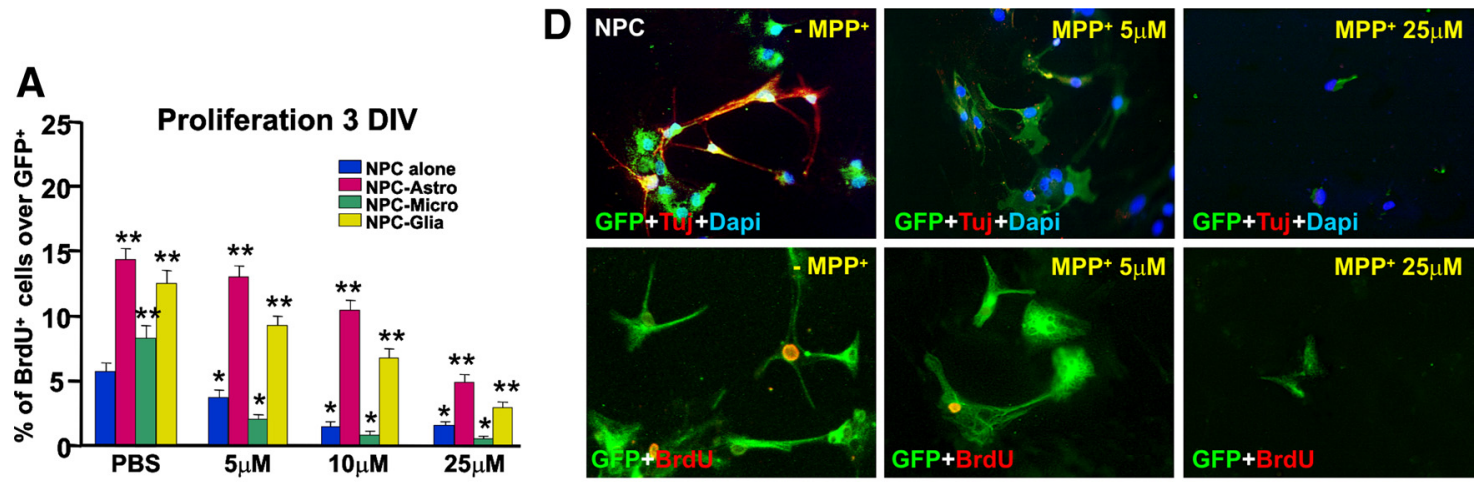

\section{B}

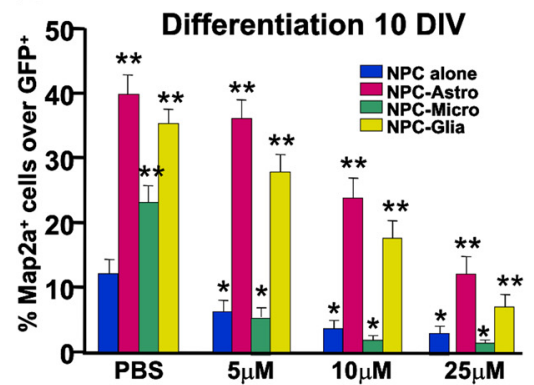

E
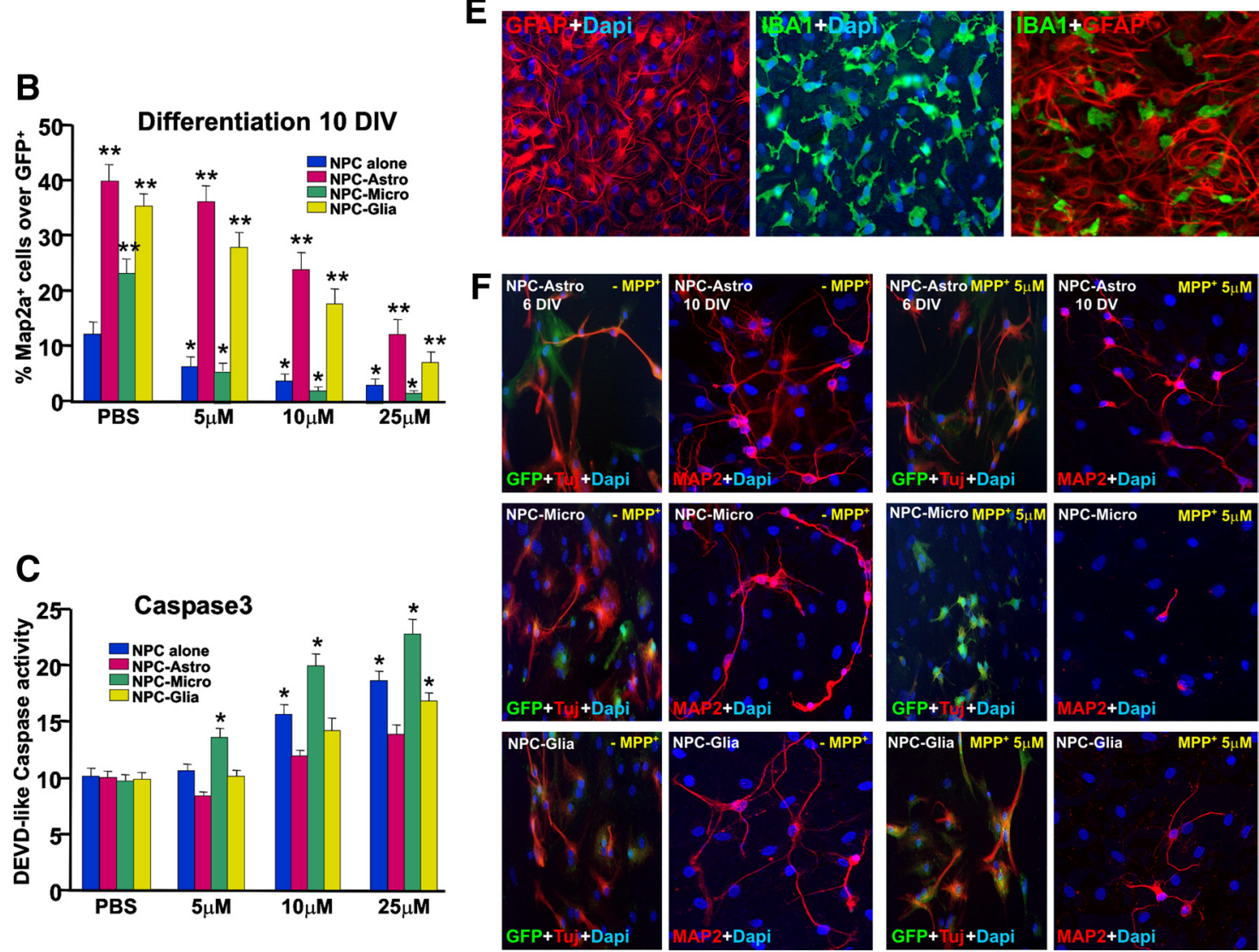

Figure 4. Effect of $\mathrm{MPP}^{+}$with or without glial cocultures on NPC survival, proliferation, and differentiation in vitro. The effect of increasing doses of $\mathrm{MPP}^{+}(5-50 \mu \mathrm{M})$ in the proliferation $(\boldsymbol{A})$, differentiation $(\boldsymbol{B})$, and Caspase3 activation ( $\boldsymbol{C}$ ) of adult GFP-expressing NPCs derived from the adult SVZ cultured alone $(\boldsymbol{D})$ or cocultured with purified astrocytes, purified microglia, or mixed astrocyte-microglia preparations $(\boldsymbol{E}, \boldsymbol{F}) \cdot \boldsymbol{A}, \mathrm{NPC}$ proliferation was assessed with BrdU as a marker for cell proliferation. $\boldsymbol{B}, \boldsymbol{F}$, Differentiation was measured at 6 DIV using Tuj ${ }^{+}(\boldsymbol{B})$ and at $10 \mathrm{DIV}$ using Map2a $(\boldsymbol{F})$ as neuronal differentiation markers. $\boldsymbol{C}$, Caspase3 activity, a marker of cell death, was determined using the fluorogenic substrate DEVD-AFC. Differences were analyzed as described and considered significant when $p<0.05$. In NPCs alone, the percentage of GFP ${ }^{+}$(green) cells expressing BrdU (red) and the percentage of Tuj ${ }^{+}$(red) neurons over the GFP ${ }^{+}$cells $(\boldsymbol{A}, \boldsymbol{B}, \boldsymbol{D})$ were dose-dependently reduced by MPP ${ }^{+}$exposure, compared with PBS-treated controls. DEVD-like fluorescent signal ( $C$ ) was dose-dependently increased $8 \mathrm{~h}$ after application of 10 and $25 \mu \mathrm{M}$ MPP ${ }^{+}$, but not $5 \mu \mathrm{M}$. Direct coculture of NPCs with purified microglia or purified astrocytes significantly increased the proportion of BrdU ${ }^{+}(\boldsymbol{A})$, Tuj ${ }^{+}$(red) cells out of the GFP ${ }^{+}$(green) cells $(\boldsymbol{F})$, and $\mathrm{Map2a}^{+}$cells $(\boldsymbol{B}, \boldsymbol{F})$, compared with NPCs cultured alone $(\boldsymbol{B}, \boldsymbol{D})$. Exposure of NPC-Astro cocultures to MPP ${ }^{+}$efficiently prevented MPP ${ }^{+}$-induced decreased Tuj ${ }^{+}(\boldsymbol{F})$, BrdU $\left.^{(\boldsymbol{A})}\right)$, and Map2a expression $(\boldsymbol{B}, \boldsymbol{F})$, whereas in NPC-Micro cocultures, MPP ${ }^{+}$inhibitory effects were not reversed $(\boldsymbol{A}, \boldsymbol{B}, \boldsymbol{F})$. Caspase3 activity was measured using the indirect coculture paradigm $(\boldsymbol{C})$. ${ }^{* *} p<0.05$ versus NPC alone; ${ }^{*} p<0.05$ versus PBS. Astrocyte inserts efficiently reversed MPP ${ }^{+}$-induced increase of DEVD-like fluorescent signal at 10 and $20 \mu \mathrm{M}$, whereas microglial inserts did not afford NPC protection ( $(\boldsymbol{C}$. In mixed astrocyte-microglial cultures (NPC-glia, $\boldsymbol{F}$ ), increasing astrocyte-to-microglia ratio resulted in astrocyte-dependent reversal of microglia inhibitory effects on NPC proliferation, differentiation, and survival as determined by Caspase3 activity (Fig. $\boldsymbol{A}-\boldsymbol{C}, \boldsymbol{F})$.

thought to contribute to nigrostriatal DAergic degeneration (Hirsch and Hunot, 2009). We thus thought to study a possible direct toxic effect of $\mathrm{MPP}^{+}$on NPC and addressed the contribution of glial-mediated mechanisms, by modeling glia-NPC cross talk in vitro. To this end, we used GFP-expressing NPCs derived from the adult SVZ (Pluchino et al., 2008; L'Episcopo et al., 2011a) exposed to increasing doses (5-25 $\mu \mathrm{M})$ of $\mathrm{MPP}^{+}$both in the absence or presence of glial cells in different coculture paradigms, as described, and assessed NPC proliferation (Fig. 4A) and differentiation (Fig. 4B). The doses of $\mathrm{MPP}^{+}$were selected according to our in vitro studies on primary mesencephalic DAergic neurons in culture (L'Episcopo et al., 2011a,b). In addition, we determined Caspase3 activity, a marker of MPTP/ $\mathrm{MPP}^{+}$-induced cell death, using the fluorogenic substrate 
DEVD-AFC (Fig. 4C). Both NPC monotypic and glial-NPC cocultures received increasing doses $(5-25 \mu \mathrm{M})$ of $\mathrm{MPP}^{+}$ (L'Episcopo et al., 2001b). For proliferation studies, $\mathrm{MPP}^{+}$was applied at $2 \mathrm{DIV}$, the nucleotide analog $\operatorname{BrdU}(5 \mu \mathrm{M})$ was next added, and the cells were fixed after 24 h, i.e., at 3 DIV. For differentiation studies, NPCs grown alone, or layered on top of astrocytes, microglia, or mixed astrocyte-microglial preparations, shifted in differentiation medium ( $\mathrm{N} 2$ medium and 1\% FCS), and cells were allowed to differentiate for 5-10 DIV. $\mathrm{MPP}^{+}$ was then applied and cells were fixed after $24 \mathrm{~h}$, with Tuj1 and MAP2a being used as specific neuronal markers. For cell-survival experiments, Caspase 3 activity was determined $8 \mathrm{~h}$ after $\mathrm{MPP}^{+}$.

As observed, $\mathrm{GFP}^{+} \mathrm{NPCs}$ grown in poly-D-lysine alone in N2 medium and in the presence of $1 \%$ of serum express TUJ-1, and some of the $\mathrm{GFP}^{+}$NPCs coexpress BrdU after 3 DIV (Fig. $4 A, D$ ). The effect of $\mathrm{MPP}^{+}$was dose dependent: the lowest $(\leq 5 \mu \mathrm{M})$ dose did not significantly modify the number of $\mathrm{GFP}^{+}$NPCs over the DAPI-stained nuclei, whereas an almost $30-60 \%$ decrease in $\mathrm{GFP}^{+} \mathrm{NPC}$ number was observed at 10 and $25 \mu \mathrm{M}$ doses of $\mathrm{MPP}^{+}$, compared with PBS-treated controls. The proliferative potential revealed by the percentage of $\mathrm{GFP}^{+}$NPCs expressing BrdU (Fig. $4 A, D$ ) and neuronal differentiation, as determined by the percentage of Tuj $1^{+}$at 6 DIV (Fig. $4 D$ ) and $\mathrm{MAP}^{+}{ }^{+}$neurons at 10 DIV (Fig. $4 B$ ) over the $\mathrm{GFP}^{+}$NPCs were dose-dependently reduced by $\mathrm{MPP}^{+}$, compared with PBS-treated controls. Finally, the DEVD-like fluorescent signal (Fig. 4C) was dose-dependently increased $8 \mathrm{~h}$ after application of 10 and $25 \mu \mathrm{M} \mathrm{MPP}{ }^{+}$, but not 5 $\mu \mathrm{M}$, implicating Caspase 3 activation at high $\mathrm{MPP}^{+}$doses. Although different factors play a role in MPTP/MPP ${ }^{+}$-induced neurogenic impairment in vivo, including complex cellular contributions and different time courses, the present results demonstrated the ability of the PD neurotoxin to directly impair adult SVZ neuroprogenitor survival, proliferation, and differentiation in vitro, in a dose-dependent fashion.

\section{Astrocytes and microglia differentially modulate $\mathrm{MPP}^{+}$-induced impairment of NPCs, in vitro}

Because astrocytes and microglia are recognized to importantly influence MPTP/MPP ${ }^{+}$toxicity after DAergic neurons, both in vivo and in vitro (Gao et al., 2003; Hu et al., 2008; Chen et al., 2009; Sandhu et al., 2009; L'Episcopo et al., 2011a,b), we next investigated a possible modulatory effect of glial cells after $\mathrm{MPP}^{+}$-induced NPC toxicity. To this end, we studied the effect of astrocyte ( $>95 \% \mathrm{GFAP}^{+}$astrocytes), microglia ( $>95 \%$ IBA1 ${ }^{+}$microglia), or mixed glial ( $\geq 65$ GFAP-IR astrocytes; $\leq 24 \%$ IBA1-IR microglia) (Fig. $4 E$ ) cell preparations cocultured with NPCs in the absence or presence of $\mathrm{MPP}^{+}$(Fig. $4 F$ ), as above. In basal conditions, direct coculture of NPCs with purified astrocytes had a robust effect on both proliferation (Fig. 4A) and neuroblast formation at either 6 or 10 DIV (Fig. $4 F$ ), as indicated by the almost threefold increase in the proportion of $\mathrm{BrdU}^{+}$(Fig. $4 A$ ), Tuj $1^{+}$(Fig. $4 F$ ), and MAP2 ${ }^{+}$(Fig. $4 B, F$ ) out of the GFP ${ }^{+}$ cells, compared with NPCs cultured alone. Coculture with purified microglia increased by almost twofold the proportion of $\mathrm{MAP}^{+}$(Fig. $4 B, F$ ) out of the GFP ${ }^{+}$cells and increased the proportion of $\mathrm{BrdU}^{+}$(Fig. 4A) cells out of the $\mathrm{GFP}^{+}$cells by almost 50\%, compared with NPC cultured alone. These findings are in agreement with previous studies, showing the ability of astrocyte and microglial monolayers (Lim and Alvarez-Buylla, 1999; Barkho et al., 2006; Butovsky et al., 2006; L'Episcopo et al., 2011a) to promote neurogenesis from adult NPCs. Interestingly, exposure of NPC-Astro cocultures to $\mathrm{MPP}^{+}$efficiently prevented $\mathrm{MPP}^{+}$-induced decreased Tuj $1^{+}$(Fig. $4 F$ ) and MAP2a ${ }^{+}$
(Fig. 4B,F) neuron production and BrdU expression (Fig. 4A), mimicking astrocyte-induced mesencephalic DAergic neuron protection (L'Episcopo et al., 2011a,b), albeit the effect of astrocytes decreased as a function of the concentration of $\mathrm{MPP}^{+}$. In sharp contrast, in NPC-Micro cocultures, $\mathrm{MPP}^{+}$inhibitory effects were not reversed (Fig. $4 A, B, F$ ). Hence, the decrease in the percentage of Tuj ${ }^{+}$and MAP2a ${ }^{+}$cells observed at both 6 and 10 DIV (Fig. $4 B, F$ ), as well as the percentage of $\mathrm{GFP}^{+}$cells labeled with BrdU (Fig. $4 A$ ) after $\mathrm{MPP}^{+}$, were comparable both in the absence or presence of microglia. These findings suggested that in the presence of $\mathrm{MPP}^{+}$, the microglia neurogenesis-promoting effects were inhibited. To verify whether the coculture influenced NPC survival, we measured Caspase 3 activity using the indirect coculture paradigm. In this model, the inserts containing the astrocyte or microglia monolayers were added on top of the NPCs. Hence, whereas astrocyte inserts efficiently reversed $\mathrm{MPP}^{+}$-induced increase of the DEVD-like fluorescent signal at 10 and $25 \mu \mathrm{M}$, microglial inserts did not afford NPC protection. On the contrary, a greater increase in DEVD-like IF signal (Fig. $4 C$ ) was observed in NPC-microglia cocultures at all $\mathrm{MPP}^{+}$ doses. The positive effect of reactive astrocytes versus microglia after $\mathrm{MPP}^{+}$exposure was also observed in mixed astrocyte-microglial cultures (NPC-glia), where the increasing astrocyte-to-microglia ratio resulted in a significant reversal of MPP ${ }^{+}$-induced reduced NPC survival (Fig. $4 C$ ), proliferation (Fig. $4 A$ ), and differentiation (Fig. $4 B, F)$.

These findings indicated that although astrocytes are endowed with protective and neurogenic capabilities both in the absence or presence of $\mathrm{MPP}^{+}$, microglia can increase NPC neurogenic potential in basal conditions, whereas in the presence of $\mathrm{MPP}^{+}$they further impair NPC survival, raising the question of the specific factors and the signaling pathways involved in microglial and astrocyte observed effects.

MPTP-induced increased microglial oxidative and nitrosative status impairs NPC proliferation and differentiation in vitro

To address the contribution of microglia in MPTP-induced SVZ impairment in vivo, and to investigate the nature of the microglial-derived factors involved, we sought to use macrophage/microglia acutely isolated ex vivo, from saline or MPTP. We selected $3 \mathrm{dpt}$ since it corresponds to the peak of microglial reaction, in vivo (Fig. 3), and used these cell preparations for the determination of PHOX, ROS, and iNOS-derived RNS and for coculture experiments with $\mathrm{GFP}^{+}$cells, as described.

In macrophage/microglia isolated from MPTP mice, PHOX expression was increased by $\sim 3.5$-fold compared with microglia isolated from saline-treated mice (Fig. 5A). Likewise, in line with previous studies (Morale et al., 2004; Hu et al., 2008; L'Episcopo et al., 2010a;b), the production of ROS and iNOS-derived RNS was significantly increased in macrophage/microglia isolated from MPTP mice, whereas in saline-treated mice very low to undetectable levels of ROS and RNS could be detected (Fig. $5 B-$ $D$ ), supporting the in vivo data (Fig. 3). The direct implication of these mediators was next studied by exposing NPCs to either microglia (Fig. 5E) or migroglial inserts (Fig. $5 F$ ) from saline or MPTP mice. A nonmicroglial insert (ct-insert) cultured in comparable conditions was used as a control. After $24 \mathrm{~h}$, we found an almost threefold decrease in $\mathrm{GFP}^{+}$cell incorporation of BrdU in MPTP-microglia-NPC, as opposed to microglia from salineinjected controls (Fig. 5E,F). Likewise, the number of MAP2a ${ }^{+}$ cells was sharply decreased compared with the number of neurons counted in NPCs exposed directly or indirectly to saline-microglia (Fig. $5 E-H$ ) or to ct-inserts (data not shown), supporting the 

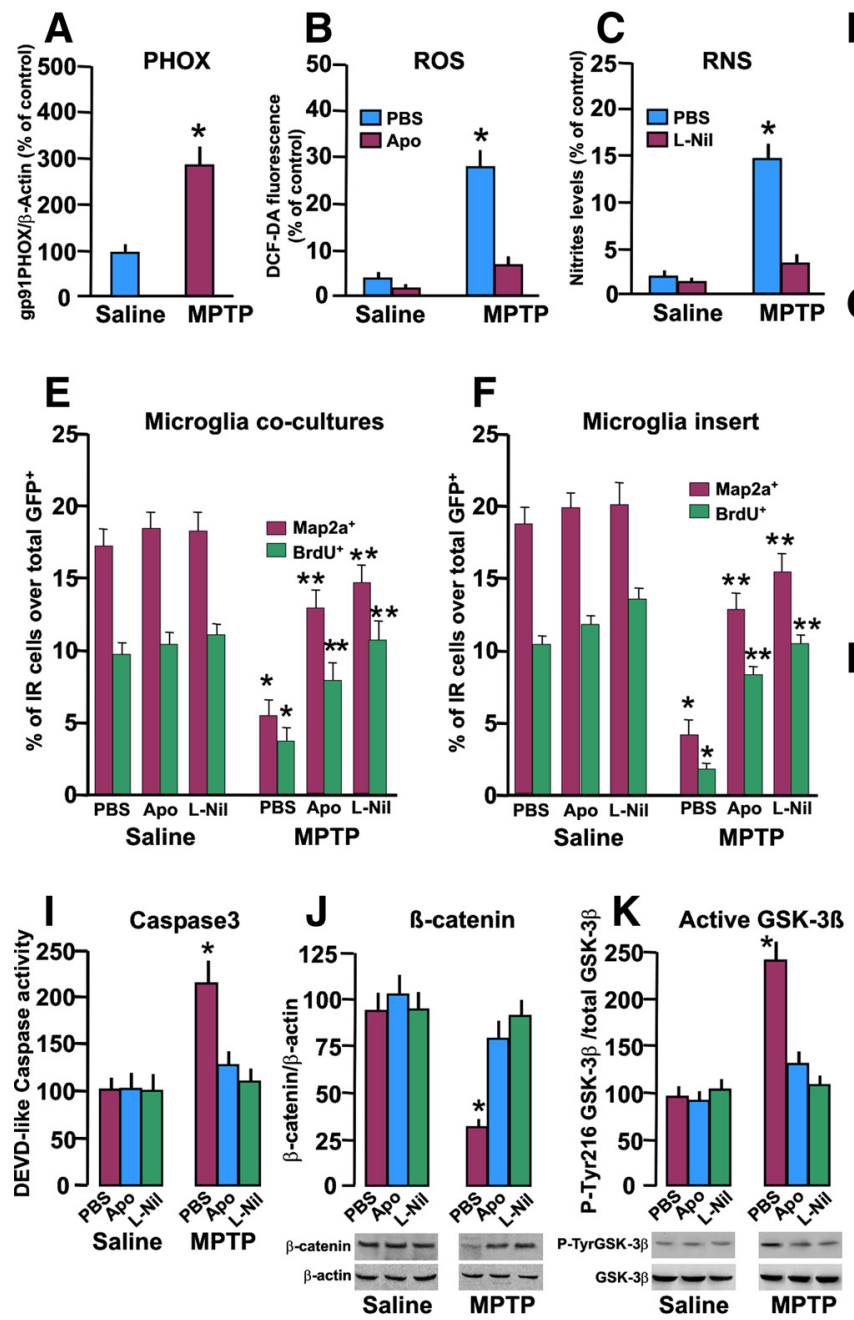

D

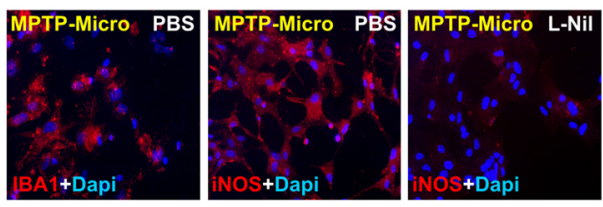

G

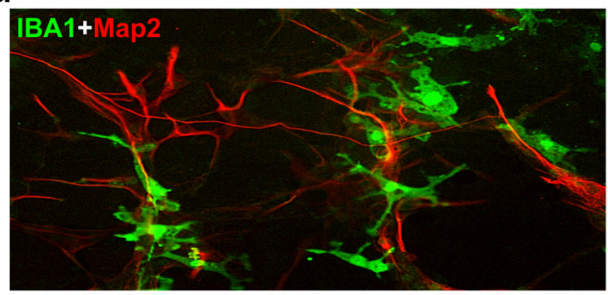

H


Figure 5. Effect of microglia isolated ex vivo from MPTP mice on NPC survival and proliferation/differentiation. Macrophage/microglia acutely isolated ex vivo, from saline or MPTP mice at 3 dpt, were processed as described for determination of $\mathrm{PHOX}, \mathrm{ROS}$, and RNS and for coculture with GFP ${ }^{+} \mathrm{NPC}$ for determination of proliferation and differentiation potential. Differences analyzed were considered significant when $p<0.05$. $\boldsymbol{A}-\boldsymbol{C}$, Increased expression of PHOX by Western blotting $(\boldsymbol{A})$, increased production of ROS revealed by the fluorogenic probe dichlorofluorescein diacetate (DCF-DA; $\boldsymbol{B})$, and exacerbated iNOS-derived RNS $(\boldsymbol{C})$ generation at the peak of microglial reaction ( $3 \mathrm{dpt}$ ), compared to macrophage/microglia from naive mice in the absence or presence of Apo (5 $\mathrm{mm}$ ) or with L-Nil $(50 \mu \mathrm{m})$ treatment. ${ }^{*} p<0.05$ versus saline. $\boldsymbol{D}$, Representative images showing IBA ${ }^{+}$microglial cells (red) counterstained with DAPI (blue) or iNOS (red) in basal conditions and after L-Nil $(\boldsymbol{F}) . \boldsymbol{E}, \boldsymbol{F}, \mathrm{GFP}^{+}$cells were exposed to either microglia $(\boldsymbol{E})$ or migroglial inserts $(\boldsymbol{F})$ from saline or MPTP mice, in coculture experiments for $24 \mathrm{~h}$, and GFP ${ }^{+}$cell incorporation of BrdU and changes in the number of Map2a ${ }^{+}$cells were determined. ${ }^{*} p<0.05$ versus saline; ${ }^{* *} p<0.05$ versus PBS. $\boldsymbol{G}$, Representative confocal image showing a coculture between microglial cells from saline mice stained with IBA1 (green) and NPCs from saline mice stained with Map2a (red) at 7 DIV. $\boldsymbol{H}$, Representative images showing NPC stained with Map2a (red) and counterstained with DAPI (blue) in coculture with either saline-microglia or MPTP-microglia, with or without L-Nil treatment. Staining with Map2a shows the neurogenic-promoting effect of saline-microglia as opposed to the marked inhibition of neuron formation in coculture with MPTP-microglia, an effect reversed by L-Nil. Note the increased Map2a process extension in L-Nil-treated microglial-NPC coculture. $\boldsymbol{I}$, DEVD-like fluorescent signal measured in NPCs cocultured with MPTP-microglia indicates activation of Caspase3-induced cell death. $\boldsymbol{J}, \boldsymbol{K}$, Western blot analysis of $\beta$-catenin ( $\boldsymbol{J}$ ) and active GSK-3 $\beta$ ( $K$; i.e., phosphorylated at tyrosine 216 residue, pTyr216 GSK-3 $\beta$ ). Data from the experimental bands were normalized to $\beta$-actin or GSK-3 $\beta$, as indicated, and values are expressed as percentage of PBS-treated cultures exposed to saline-microglia. ${ }^{*} p<0.05$ versus saline; ${ }^{* *} p<0.05$ versus PBS within experimental groups.

specificity of microglial-derived mediators in the observed inhibitory effects.

Further evidence for an inhibitory effect of MPTP-microglia was revealed by the sharp increase in the DEVD-like fluorescent signal measured in NPCs cocultured with MPTP- -microglia (Fig. 5I), but not a ct-insert (data not shown), indicating activation of Caspase3-induced cell death. Thus, in the presence of MPTP-induced microglia overactivation in vivo, the harmful oxidative and inflammatory microenvironment likely increased NPC vulnerability, impairing NPC survival and, consequently, neurogenic potential. Indeed, free radicals such as superoxide and NO released by reactive microglia are the major players responsible for enhanced toxicity of MPTP after DAergic neurons both in vivo and in vitro (Gao et al., 2003, 2008; Mander and Brown, 2005; Hu et al., 2008; L'Episcopo et al., 2010a,b,c).
A $P H O X-R N S-G S K-3 \beta / \beta$-catenin-regulated signaling cascade is involved in microglial-induced inhibition of NPC neurogenic potential

Given the inhibitory role of NO in adult SVZ neurogenesis (Packer et al., 2003; Matarredona et al., 2004, 2005; MorenoLópez et al., 2004; Torroglosa et al., 2007), we thus studied the effects of pharmacologically manipulating microglial oxidative and nitrosative status, by using the PHOX inhibitor apocynin and the specific inhibitor of iNOS-derived NO L-Nil, both in direct and indirect $\mathrm{GFP}^{+}$cocultures established with microglia isolated ex vivo from either saline- or MPTP-treated mice, or with ctinserts, as described. As observed, exposure of MPTP-microglia to Apo or L-Nil, significantly reduced PHOX-derived ROS and iNOS-derived RNS production, respectively (Fig. 5B-D). Accordingly, when compared with cocultures exposed to PBS, 
MPTP-microglial-NPC cocultures exposed to Apo or L-Nil significantly mitigated MPTP-microglia-induced decreased proliferation and differentiation of $\mathrm{GFP}^{+}$cells to levels measured in saline-microglial-NPC cocultures (Fig. $5 E, F, H$ ). On the other hand, the treated ct-inserts did not produce changes in either BrdU or Map2a expression in NPCs (data not shown). Interestingly, L-Nil treatment of microglial-NPC cocultures was characterized by increased MAP2a ${ }^{+}$process length (Fig. $5 H$ ). In addition, we observed a significant counteraction of MPTPmicroglia-induced Caspase3 activity (Fig. 5I) after Apo or L-Nil, whereas no effects followed coculture with treated ct-inserts, thereby supporting PHOX-derived ROS and iNOS-derived RNS as critical microglial harmful mediators of NPC neurogenic impairment.

We next addressed the mechanistic link between microglial harmful phenotype and signaling cascades impinging in NPC biochemical machinery. Recent studies on adult neural stem cell proliferation, migration of precursor cells, and neuronal differentiation have suggested a role for the $W n t / \beta$-catenin signaling system (Lie et al., 2005; Adachi et al., 2007; Zhang et al., 2011). Three different Wnt pathways have been described downstream of Frizzled receptor: the Wnt/ $\beta$-catenin pathway (known as the canonical pathway) and the noncanonical pathways, $\mathrm{Wnt} / \mathrm{Ca}^{+2}$ and Wnt/planar cell polarity (Logan and Nusse, 2004; Gordon and Nusse, 2006). The hallmark of the Wnt/ $\beta$-catenin pathway is the stabilization of cytosolic $\beta$-catenin. GSK- $3 \beta$ is part of a destruction complex that targets $\beta$-catenin for ubiquitination and degradation by the proteasome, whereas Wnt signaling inhibits GSK-3 $\beta$ activity, thus increasing the amount of $\beta$-catenin, which enters the nucleus, and associates with T-cell factor/lymphoid enhancer binding factor (TCF/LEF) transcription factors, leading to the transcription of Wnt target genes involved in cell survival, proliferation, and differentiation (Logan and Nusse, 2004). We thus investigated the impact of microglial-derived mediators on the expression of $\beta$-catenin and GSK-3 $\beta$. Western blot analyses indicated a significant downregulation of $\beta$-catenin protein in NPCs exposed to MPTP-microglia compared with saline-microglia or ct-insert (Fig. 5J). Conversely, upregulation of phosphoTyr216 GSK-3 $\beta$ (i.e., the active pGSK-3 $\beta$ ) was observed $4 \mathrm{~h}$ after addition of the inserts containing MPTP-microglia (Fig. 5K). Time course experiments indicated an inverse correlation between upregulation of active pTyr216 GSK- $3 \beta$ and the temporal loss of $\beta$-catenin protein in NPCs (data not shown), implicating activation of GSK-3 $\beta$ and subsequent degradation of $\beta$-catenin in MPTP-microglial induced inhibition of NPC proliferation and neuronal differentiation. The implication of microglialderived ROS and RNS in pTyr216 GSK- $3 \beta$ upregulation and inhibition of neurogenesis were next investigated. In both Apo- and L-Nil-treated cultures, a significant counteraction of active GSK- $3 \beta$ was observed (Fig. $5 \mathrm{~K}$ ). Accordingly, treatment with the ROS or iNOS inhibitors efficiently reversed the profound downregulation of $\beta$-catenin (Fig. $5 J$ ). Together, these results suggested that exacerbated oxidative and inflammatory microglial status may antagonize $\beta$-catenin signaling in NPCs and proposed a $R O S-R N S / G S K-3 \beta / \beta$-catenin signaling cascade contributing to microglial-induced inhibition of NPC neurogenic potential.

\section{MPTP-induced dysregulation of $W n t / \beta$-catenin signaling $e x$ vivo and in vitro}

Wht genes encode secreted glycoproteins and transduce signals via autocrine or paracrine mechanisms that regulate diverse developmental and postnatal processes, including neural stem proliferation and differentiation (Kalani et al., 2008; Kuwabara et al.,
2009; Munji et al., 2011). In the adult rodent, Wnt ligands (Wnt1, Wnt5a, Wnt7a) and Frizzled receptors are expressed in the SVZ (Shimogori et al., 2004). Of specific interest, using the Axin2d2EGFP reporter (Jho et al., 2002), considered an accurate reporter mouse for canonical Wnt activity in vivo, Adachi et al. (2007) demonstrated that $W n t / \beta$-catenin signaling is activated in type B and C cells of the adult SVZ. Moreover, by injecting retroviral vectors to activate or inhibit $\beta$-catenin signaling specifically in dividing cells of the adult mouse SVZ, these authors also documented that activation of Wnt/ $\beta$-catenin signaling is sufficient to increase the percentage of dividing $\mathrm{C}$-cells that give rise to new neurons in the SVZ. Importantly, $\beta$-catenin increases in the SVZ after intrastriatal TGF- $\alpha$ infusion in the 6-OHDA-lesioned rat $P D$ model, suggesting a role for Wnt signals in the proliferative regulation of the SVZ (Cooper and Isacson, 2004). Coupled to our previously documented MPTP modulation of Wnt $/ \beta$-catenin signaling components in Str and midbrain (L'Episcopo et al., 2010a), these data prompted us to verify the hypothesis of a dysfunctional Wnt/ $\beta$-catenin signaling as a contributor of MPTPdependent SVZ impairment. We first addressed changes in proliferative and differentiation potential associated with $\beta$-catenin and active GSK- $3 \beta$ expression in NPCs acutely isolated ex vivo from MPTP-treated mice. NPCs isolated from naive and MPTP mice at $7 \mathrm{dpt}$ were expanded, and proliferation/differentiation was measured as described. At 3 DIV, the capacity of NPCs isolated from MPTP mice to incorporate BrdU was reduced by threefold compared with NPCs from saline mice (Fig. 6A,B). To evaluate the neuronal differentiation potential of NPCs from saline and MPTP mice, cells were allowed to mature for 7 DIV in differentiation medium and then were stained with Map2a. Hence, NPCs from MPTP mice, ex vivo, produced Map2a ${ }^{+}$neurons (Fig. $6 A, B$ ), albeit with a significantly lower efficiency, as revealed by the almost $50-60 \%$ decrease compared with Map2 $\mathrm{a}^{+}$NPCs from saline mice. In addition, Map2 $\mathrm{a}^{+}$process length was sharply reduced in MPTP compared with saline NPCs (Fig. 6A).

We next looked at Wnt signaling components using Western blot analysis and found a decreased $\beta$-catenin signal in NPCs from MPTP mice, compared with the $\beta$-catenin signal in NPCs from saline mice, whereas active the GSK-3 $\beta$ signal was sharply increased (Fig. 6C). In keeping with these findings, using specific primers and quantitative real-time PCR, we found that expression levels of Axin2, a direct Wnt target induced by Wnt $/ \beta$ catenin activation (Jho et al., 2002), were downregulated in NPCs from MPTP mice compared with Axin2 expression levels measured in NPCs from saline-injected controls $(2.68 \pm 0.31$ arbitrary units in controls vs $1.15 \pm 0.20$ in MPTP; $p<0.05$ ), thus corroborating MPTP-induced inhibition of Wnt/ $\beta$-catenin signaling activity in SVZ cells. These results appeared of interest in light of the recent report showing disruption of $\beta$-catenin signaling in glial progenitor cells from Alzheimer's disease (AD) and AD transgenic mice brain (He and Shen, 2009). We thus took advantage of the siRNA strategy (He and Shen, 2009; L'Episcopo et al., 2011b) to further examine the relationship between the $\beta$-catenin signaling pathway in MPTP-induced neurogenic impairment and tested the role of $\beta$-catenin and GSK- $\beta$. To this end, NPCs from MPTP mice were transiently transfected with GSK- $\beta$ siRNA (Fig. 6D); alternatively, NPCs from saline mice were transiently transfected with $\beta$-catenin siRNA (Fig. $6 E$ ), as reported (He and Shen, 2009; L'Episcopo et al., 2011b). After 48-72 h of transfection, Western blot analysis indicated that treatment with GSK- $\beta$ siRNA decreased GSK- $\beta$ levels and increased the $\beta$-catenin levels in NPCs from MPTP mice (Fig. $6 D$ ), whereas 
A
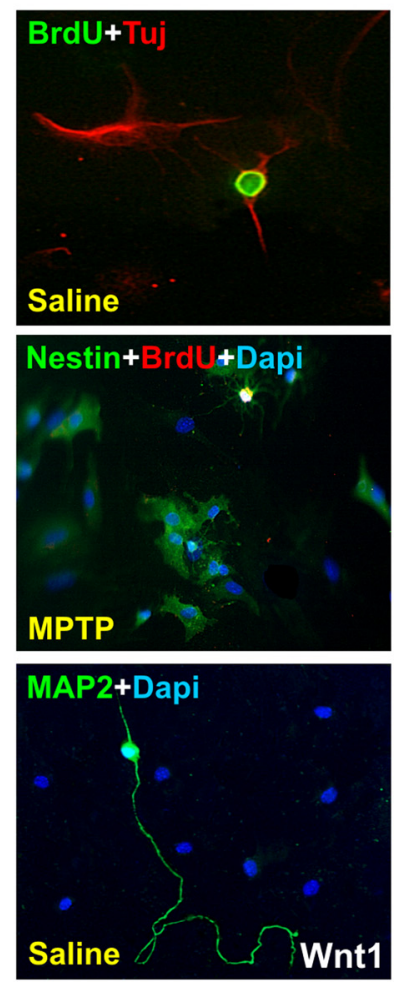

NPC alone
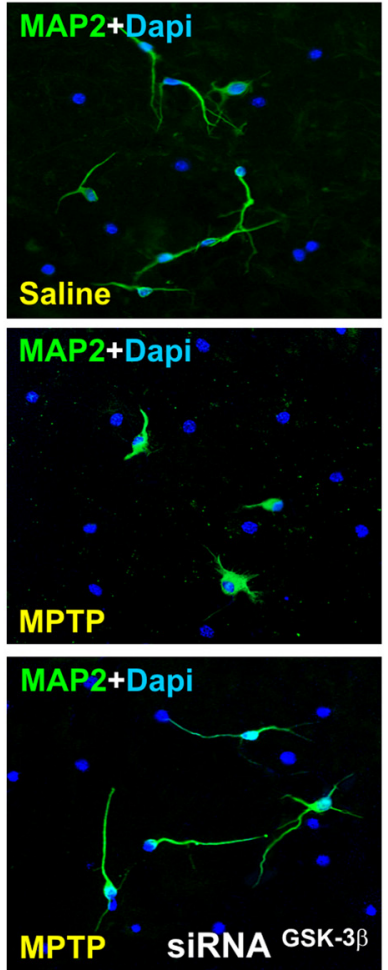

B

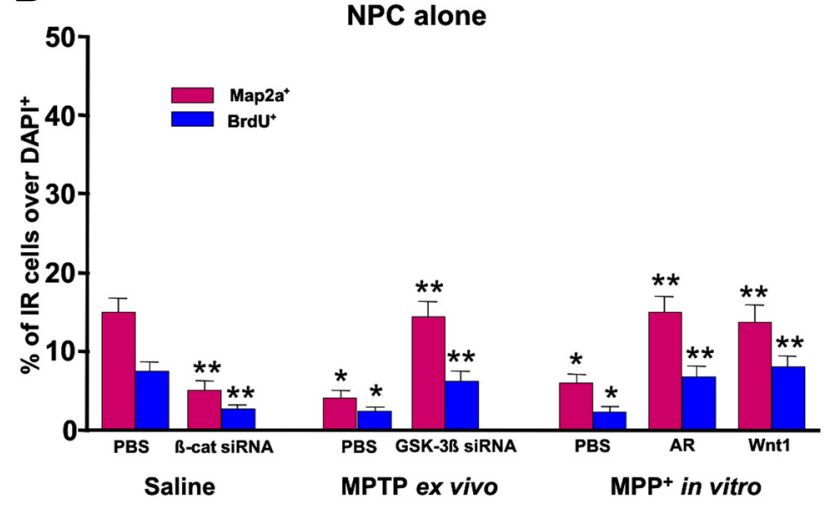

C



F
D

MPTP-NPC



GSK-3ß SIRNA

E



Saline-NPC
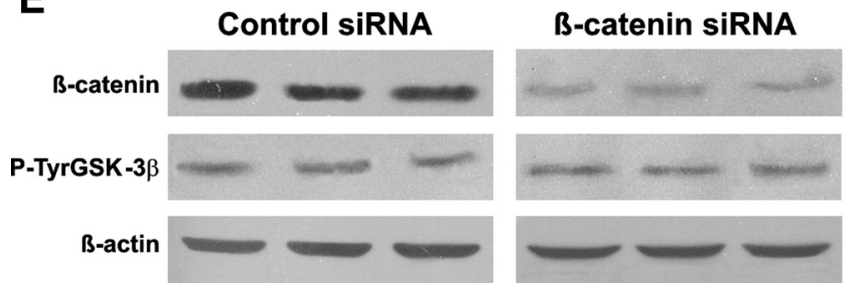


Figure 6. MPTP-induced impaired neurogenesis ex vivo and in vitro is associated to Wnt/ $\beta$-catenin signaling dysregulation. NPCs were acutely isolated ex vivo $7 \mathrm{~d}$ after MPTP or saline injection and expanded as described, and proliferation/differentiation was measured using BrdU, Tuj1, and Map2a. A, Representative immunocytochemical images of NPCs cultured alone and isolated from saline or MPTP, in the absence or presence of different treatments, as described. In NPCs from MPTP mice, a sharp loss of Map2a (green) and BrdU (red) was observed. $\boldsymbol{B}$, Proliferation measured at 3 DIV and differentiation at 7 DIV in NPCs isolated ex vivo from saline and MPTP mice, and effect of MPP ${ }^{+}$in vitro. NPCs of the indicated groups were exposed to different treatments, as described, and the percentage of BrdU ${ }^{+}$or Map2a ${ }^{+}$cells over the DAPI-stained nuclei was measured. C, Changes in $\beta$-catenin and P-TyrGSK-3 $\beta$ studied in NPCs by Western blotting using the indirect coculture paradigm. Protein levels were studied in NPCs from saline and MPTP mice (ex vivo) and in NPCs from saline mice directly exposed to MPP ${ }^{+}$(in vitro). Probing with an antibody to $\beta$-actin was used as an internal control. The values represent $\beta$-catenin and P-TyrGSK-3 $\beta$ signal intensities compared with control. The effects of the Wnt agonist Wnt (100 ng/ml) or the GSK-3 $\beta$ antagonist (AR, $5 \mathrm{~nm}$ ) are also illustrated. $\beta$-Catenin signal intensity is decreased in NPCs isolated ex vivo from MPTP mice, whereas active P-TyrGSK-3 $\beta$ signal is increased. Wnt1 and AR treatments increase $\beta$-catenin signal, whereas active GSK-3 $\beta$ signal is decreased. Likewise, direct NPC exposure to MPP ${ }^{+}$in vitro reduced $\beta$-catenin signal in the face of increased active GSK-3 $\beta$, whereas both Wnt1 and AR treatments increased $\beta$-catenin signal intensity while reducing active GSK-3 $\beta$ signal (C). Note the marked increase in Map2a ${ }^{+}$(green) process length $(A)$ and Map2a ${ }^{+}$cell number $(\boldsymbol{B})$ in NPCs exposed to the Wnt agonist Wnt1 $(100 \mathrm{ng} / \mathrm{ml})$. D, E, NPCs isolated ex vivo from MPTP mice were transiently transfected with GSK- $\beta$ siRNA (D), whereas NPCs from saline mice were transiently transfected with $\beta$-catenin siRNA ( $\boldsymbol{E}$ ) or control siRNA (see text for details). Western blotting documented that the transfection of NPCs from MPTP mice with GSK- $\beta$ siRNA reduced GSK- $\beta$ expression and promoted the expression of $\beta$-catenin (D), whereas $\beta$-catenin siRNA introduction in NPCs from saline mice decreased the expression of $\beta$-catenin without changing the expression of GSK- $\beta$ signal ( $\boldsymbol{E}$ ). Note the increased Map2a (green) cell production $(\boldsymbol{A})$ after introduction of GSK-3 $\beta$ siRNA in NPCs from MPTP mice $(\boldsymbol{A})$. $\boldsymbol{F}$, GFP-expressing NPCs grown in differentiation medium were treated with PBS or Wnt $1(100 \mathrm{ng} / \mathrm{ml})$ for $72 \mathrm{~h}$. Dual staining with $\beta$-catenin (red) and GFP (green) shows the distribution of the $\beta$-catenin-IF signal at the cell membrane of PBS-treated GFP, whereas Wnt1 application sharply increased the $\beta$-catenin IF signal at the membrane, cytoplasm, and growing GFP ${ }^{+}$processes. 
treatment with $\beta$-catenin siRNA decreased $\beta$-catenin protein levels without modifying GSK-3 $\beta$ in NPCs from saline mice (Fig. $6 E$ ). When BrdU was added after siRNA introduction in NPCs from MPTP mice and cells were fixed after $24 \mathrm{~h}$, we found that depleting GSK- $\beta$ resulted in a significant increase in the percentage of cells expressing BrdU, in comparison with cells treated with siRNA control (Fig. 6B). Likewise, in NPCs from MPTP mice grown in differentiation medium and transfected with GSK- $\beta$ siRNA, an increased percentage of MAP2 $\mathrm{a}^{+}$cells (Fig. $6 A, B)$ compared with levels measured in NPCs pretreated with a control siRNA (data not shown) were observed. Reciprocally, $\beta$-catenin siRNA introduction in NPCs from saline mice significantly reduced the percentage of $\mathrm{BrdU}^{+}$and MAP2a ${ }^{+}$cells (Fig. $6 B$ ), compared with NPCs treated with a control siRNA (data not shown). These results showed that reduced $\beta$-catenin in the face of upregulated GSK-3 $\beta$ may contribute to MPTP-induced SVZ impairment ex vivo; conversely, silencing GSK- $3 \beta$ via upregulation of $\beta$-catenin can reverse the decreased neurogenesis of MPTP mice.

These results raised the possibility that MPTP/MPP ${ }^{+}$might use this same signaling pathway to exert its direct action on SVZ cells. Based on the emerging evidence implicating active GSK- $3 \beta$ upregulation in oxidative stress-induced neuronal cell death mechanisms (Bhat et al., 2000; Grimes and Jope, 2001; King et al., 2001; Kaytor and Orr, 2002), particularly DAergic neuronal cell death (G. Chen et al., 2004; Nair and Olanow, 2008; Duka et al., 2009; Petit-Paitel et al., 2009; L'Episcopo et al., 2011a,b), we next verified the effect of a direct exposure of NPCs to $\mathrm{MPP}^{+}$in vitro and found decreased $\beta$-catenin signal associated with increased active GSK- $3 \beta$ signal, compared with control (Fig. $6 C$ ). We next tested the ability of exogenous activation of Wnt/ $\beta$-catenin signaling using a selective GSK-3 $\beta$ antagonist, AR-AO14418 (AR, 5 nM; Osakada et al., 2007; L'Episcopo et al., 2011a,b), or the Wnt ligand, Wnt1 $(100 \mathrm{ng} / \mathrm{ml})$, in both NPCs from MPTP ex vivo and $\mathrm{MPP}^{+}$in vitro (Fig. $6 \mathrm{~B}, C$ ). In the in vitro experimental paradigm, AR or Wnt 1 was applied $1 \mathrm{~h}$ before $\mathrm{MPP}^{+}$exposure, and cells were fixed $24 \mathrm{~h}$ after $\mathrm{MPP}^{+}$. As observed, both AR and Wnt1 efficiently reduced active GSK- $3 \beta$ signal and reversed the decreased $\beta$-catenin signal in NPCs from MPTP mice and NPCs acutely exposed to $\mathrm{MPP}^{+}$(Fig. 6C). These effects were associated with a significant reversal of a MPP ${ }^{+}$-induced decreased percentage of $\mathrm{BrdU}^{+}$- and Map2a ${ }^{+}$-expressing cells (Fig. 6B). In NPCs from saline mice and NPCs treated with PBS, Wnt1 sharply increased the Map2 $\mathrm{a}^{+}$process length (Fig. 6 A). Time course studies of Wnt1 effect on $\mathrm{GFP}^{+}$NPCs revealed an early increase in $\beta$-catenin immunofluorescence in the cytoplasm and nuclei of $\mathrm{GFP}^{+}$cells within $6 \mathrm{~h}$ from Wnt1 application, and by $24-48 \mathrm{~h}$, Wnt1-induced $\beta$-catenin immunofluorescence was sharply upregulated and distributed in $\mathrm{GFP}^{+}$cell membrane, cytoplasm, and particularly in the growing $\mathrm{GFP}^{+}$processes (Fig. $6 \mathrm{~F}$ ), compared with the less differentiated PBS-treated $\mathrm{GFP}^{+}$cells where $\beta$-catenin immunofluorescence appeared localized at the membrane (Fig. $6 F$ ).

Together, these ex vivo and in vitro results clearly established $\mathrm{MPTP} / \mathrm{MPP}^{+}$-induced inhibition of $\mathrm{Wnt} / \beta$-catenin signaling activity in SVZ NPCs.

\section{Astrocyte-derived factors and $W n t / \beta$-catenin signaling activation counteract MPTP-induced NPC impairment}

The majority of currently identified neurogenic factors, including Wnts, are associated with a specific population of local astrocytes in neurogenic niches, implicating their specific role in instructing neurogenesis of NPCs in the niche (Alvarez-Buylla et al., 2001; Castelo-Branco et al., 2004, 2006; Lie et al., 2005; Cahoy et al., 2008; Kazanis, 2009; Kuwabara et al., 2009; Munji et al., 2011). Given that astrocytes (1) protect NPCs from $\mathrm{MPP}^{+}$exposure and efficiently reversed the decreased proliferation and neuronal differentiation (Fig. $4 A-C$ ) and (2) express $W n t / \beta$ catenin signaling components and promote neurogenesis in vivo and in vitro (Lie et al., 2005; Castelo-Branco et al., 2006; Cahoy et al., 2008; L'Episcopo et al., 2011a,b), we thus set to determine whether striatal astrocyte coculture might overcome the impaired NPC neurogenic capabilities of MPTP mice via $\beta$-cateninmediated Wnt signaling activation. Hence, when astrocytes were layered on top of NPCs from MPTP mice (day 0), BrdU was next added (i.e., at 2 DIV), and cells were fixed after $24 \mathrm{~h}$ (i.e., at 3 DIV), a significant increase in cells expressing BrdU were observed (Fig. $7 A, B$ ). When the cells were allowed to mature for 7 DIV in differentiation medium, as above, the percentage of Map2a ${ }^{+}$neurons was significantly increased compared with NPCs cultured alone (compare Fig. $6 A, B$ with Fig. $7 A, B$ ), albeit the addition of the astrocyte monolayer to NPCs from saline mice more efficiently increased Map2 $\mathrm{a}^{+}$neuronal differentiation (Fig. $7 A, B)$. These results supported our previous findings documenting the ability of midbrain astrocyte coculture to promote neurogenesis from neuroprogenitors isolated from adult midbrain and SVZ (L'Episcopo et al., 2011a). In addition, they further corroborated our present data showing that NPCs isolated from MPTP mice ex vivo are not intrinsically impaired. The ability of astrocytes to promote neurogenesis in MPTP-impaired NPCs could be the result of the effect of various growth/neurogenic factors recognized to promote neurogenesis. Although these unknown molecules might act either directly or indirectly and/or via paracrine/autocrine mechanisms, we used different approaches to address the involvement of $\beta$-catenin signaling modulation (L'Episcopo et al., 2011a,b). The first step in the activation of the Wnt/ $\beta$-catenin signaling pathway is the interaction between $W n t$ proteins and the receptor protein $\mathrm{Fz}$ and the coreceptor low-density LRP5/6. We thus tested the effect of Wnt/ $\beta$-catenin antagonism using the soluble inhibitor Dkk1, which prevents $\mathrm{Fz} / \mathrm{Wnt} / \mathrm{LRP} 5 / 6$ complex formation in response to Wnts (Semënov et al., 2001). This treatment was previously shown to counteract the neurogenesis-promoting effect of activated midbrain astrocytes (L'Episcopo et al., 2011a). We then found that Dkk-1 at a dose of $100 \mathrm{ng} / \mathrm{ml}$ significantly decreased astrocyte-induced increased Map2 $\mathrm{a}^{+}$neurons, as well as the percentage of $\mathrm{BrdU}^{+}$cells (Fig. $7 \mathrm{~A}, B$ ) in NPCs from both saline and MPTP mice, suggesting that astrocyte activation of Wnt ligands by paracrine and/or autocrine mechanisms may contribute to the observed neurogenic effects. The implication of Wnt signaling was also indicated by Western blot analysis showing that $\beta$-catenin protein levels were not significantly decreased in NPCAstro cocultures, whereas preventive application of the specific Wnt/ $\beta$-catenin antagonist Dkk1 efficiently reversed astrocyteinduced increased $\beta$-catenin protein (Fig. $7 C$ ), thus indicating Wnts as candidate activators. In support of this finding, the active GSK- $3 \beta$ signal was upregulated in response to Dkk1 treatments of NPC-Astro, both in saline and MPTP groups (Fig. $7 C$ ). The potential role of $\beta$-catenin-mediated Wnt signaling in astrocyteNPC cocultures was also supported by depleting $\beta$-catenin via the introduction of $\beta$-catenin siRNA in NPC cultures, as described, which resulted in sharp depletion of $\beta$-catenin in the face of increased active GSK- $3 \beta$ expression (Fig. $6 E$ ). In $\beta$-catenindepleted NPCs, the astrocyte insert failed to increase NPC proliferation and neuronal differentiation (Fig. $7 A, B$ ), supporting that 
A


Co-cultures
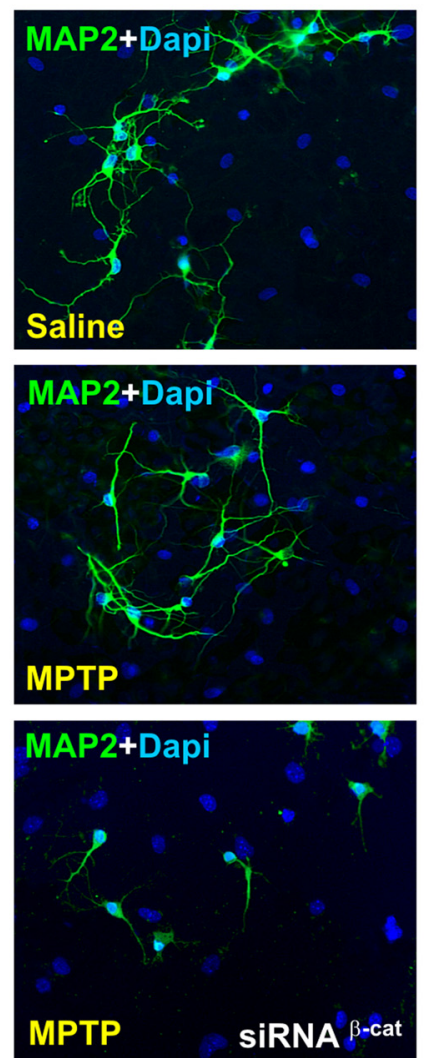

B

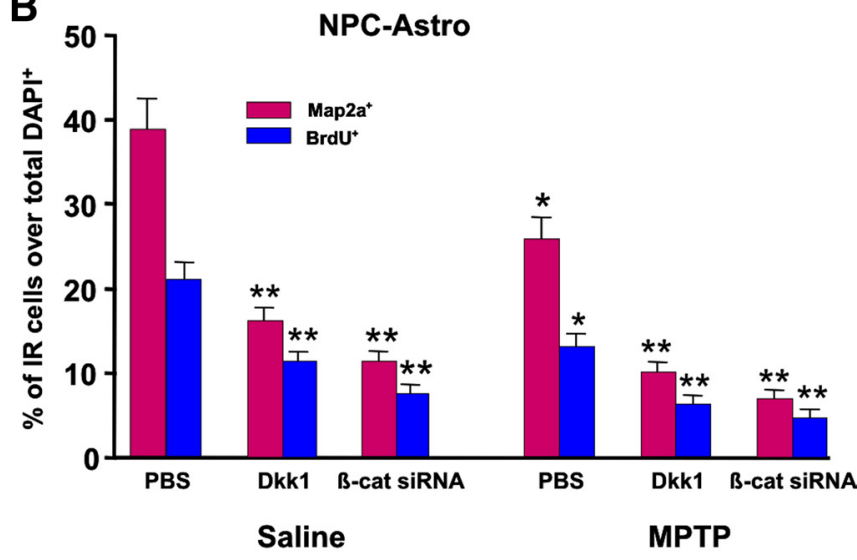

C
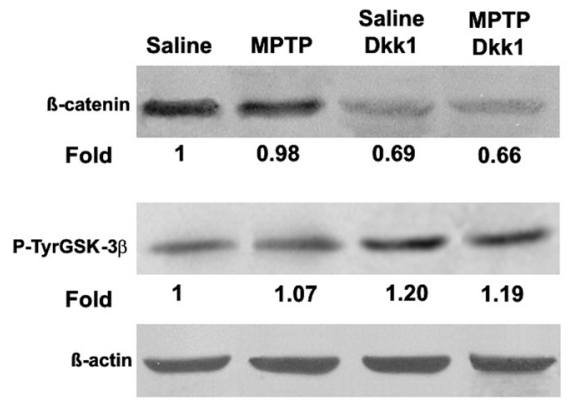

Figure 7. Astrocyte coculture and Wnt/ $\beta$-catenin signaling activation counteract MPTP-induced impaired neurogenesis ex vivo. NPCs were acutely isolated ex vivo $7 \mathrm{~d}$ after MPTP or saline injection, expanded as described, and cocultured with striatal astrocytes for proliferation and differentiation studies using BrdU, Tuj1, and Map2a. $A$, Representative images of NPCs isolated from saline or MPTP mice and cocultured with astrocytes stained with BrdU (green) and Tuj1 (red) at 3 DIV, or stained with Map2a (green) and DAPI (blue) at 7 DIV. Note the marked increase in Map2a ${ }^{+}$ (green) neuron production and process length by coculture with astrocytes both in saline and MPTP-NPCs. Wnt/ $\beta$-catenin antagonism with Dkk1 or $\beta$-catenin silencing markedly decreases Map2a ${ }^{+}$(green) neuron production and process extension. B, Proliferation measured at 3 DIV and differentiation at 7 DIV in NPCs isolated ex vivo from saline and MPTP mice. NPCs of the indicated groups were exposed to different treatments, and the percentage of BrdU ${ }^{+}$or Map2a ${ }^{+}$cells over the DAPI-stained nuclei were measured. Astrocyte coculture significantly decreases the MPTP-induced impaired proliferation and differentiation (compare with Fig. 6, $A$ and $B$ ). Note that Wnt/ $\beta$-catenin antagonism with Dkk1 (100 ng/ml) significantly reduced astrocyte-induced reversal of NPC impairment of MPTP mice $(\boldsymbol{A}, \boldsymbol{B})$. In NPCs from saline mice, transient transfection with $\beta$-catenin siRNA (see legend for Fig. 6 ) and coculture with astrocytes sharply decreased BrdU and Map2a ${ }^{+}$cells, compared with NPCs transfected with control siRNA (see text for details). In NPCs from MPTP mice, both Dkk1 and transient transfection with $\beta$-catenin siRNA significantly reduced the neurogenic promoting effect of astrocyte coculture $(\boldsymbol{A}, \boldsymbol{B})$. $^{*} p<0.05$ versus PBS within saline and MPTP groups, respectively; ${ }^{* *} p<0.05$ versus saline in NPC alone and NPC-Astro, respectively. $C$, Western blotting was performed in NPCs of saline and MPTP mice and cultured with astrocytes with the indirect coculture paradigm, as described. Probing with an antibody to $\beta$-actin was used as an internal control. The values represent $\beta$-catenin and P-TyrGSK-3 $\beta$ signal intensities compared with control. Comparable $\beta$-catenin signal is observed in saline- and MPTP-NPCs cocultured with astrocytes, whereas Dkk1 treatment decreased $\beta$-catenin signal in both saline- and MPTP-NPC, while increasing the intensity of the active GSK- $\beta$ signal.

besides others, $\beta$-catenin-mediated Wnt signaling may contribute to astrocyte neurogenic effects.

All together, the present findings indicated $\beta$-catenin-activated signaling as a point of convergence of $\mathrm{MPP}^{+}-$, microglial-, and astrocyte-derived factors and prompted us to begin elucidating the contribution of $W n t / \beta$-catenin signaling in vivo.

Pharmacological activation of $W n t / \beta$-catenin signaling in vivo reverses MPTP- or Dkk1-induced impaired proliferation We first used immunohistochemistry to localize $\beta$-catenin in the SVZ of saline- and MPTP-treated mice. In accordance with the study by Adachi et al. (2007), in the SVZ of control mice, the $\beta$-catenin-IF signal was detected at membrane, cytoplasm, or perinuclear regions of the DAPI-counterstained cell nuclei (Fig. $8 A$ ). Dual localization of $\beta$-catenin and BrdU revealed that a proportion of $\beta$-catenin ${ }^{+}$cells coexpressed BrdU (Fig. $8 A$ ). In contrast, MPTP treatment sharply downregulated the $\beta$-catenin-IF signal and the proportion of $\beta$-catenin ${ }^{+}$cells coexpressing BrdU (Fig. $8 A$ ). Because $\beta$-catenin is expressed in type $\mathrm{C}$ cells and since MPTP reduced the proliferation of C-cells, if the
$W n t / \beta$-catenin pathway is relevant for MPTP-induced neurogenic impairment of SVZ, then activation of $\beta$-catenin signaling should counteract MPTP-induced NPC impairment. We thus used pharmacological inhibition of GSK-3 $\beta$, resulting in the activation of $\beta$-catenin signaling to verify the functional importance of this pathway in cells of the SVZ. To test this hypothesis, we selected the GSK-3 $\beta$ antagonist AR, used in vitro, and performed systemic injections or local SVZ administration by intracerebroventricular infusion, as reported (Adachi et al., 2007). Pilot experiments were performed to verify doses and timing capable to decrease active GSK-3 $\beta$ in the SVZ of both intact and MPTP mice. To test the systemic effect, AR was injected intraperitoneally at a dose regimen (10 $\mathrm{mg} / \mathrm{kg}$ twice per day) (L'Episcopo et al., 2011a,b), starting $3 \mathrm{~h}$ after MPTP and continuing for $3 \mathrm{~d}$. For intracerebroventricular infusion, AR or the vehicle alone was infused into the left lateral ventricle of the brain. Groups of saline-injected mice received AR via intraperitoneal injections or intracerebroventricularly and served as controls. In agreement with previous findings (Adachi et al., 2007), direct GSK-3 $\beta$ antagonism by AR intracerebroventricular infusion re- 

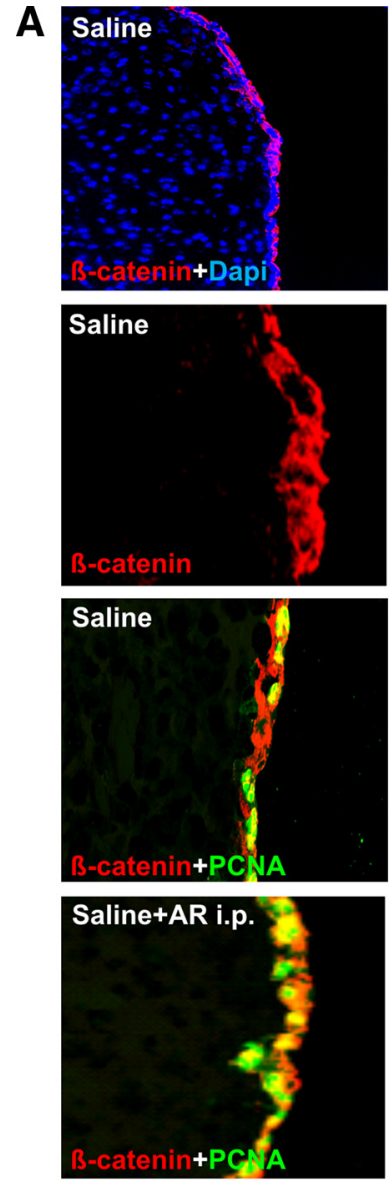

C

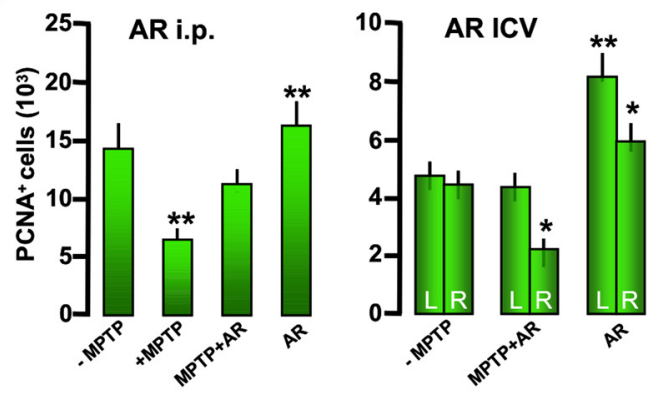

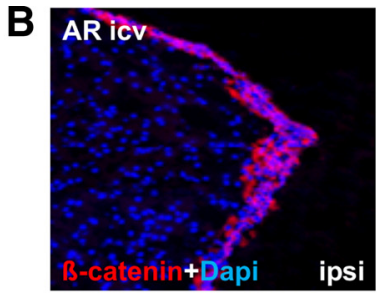
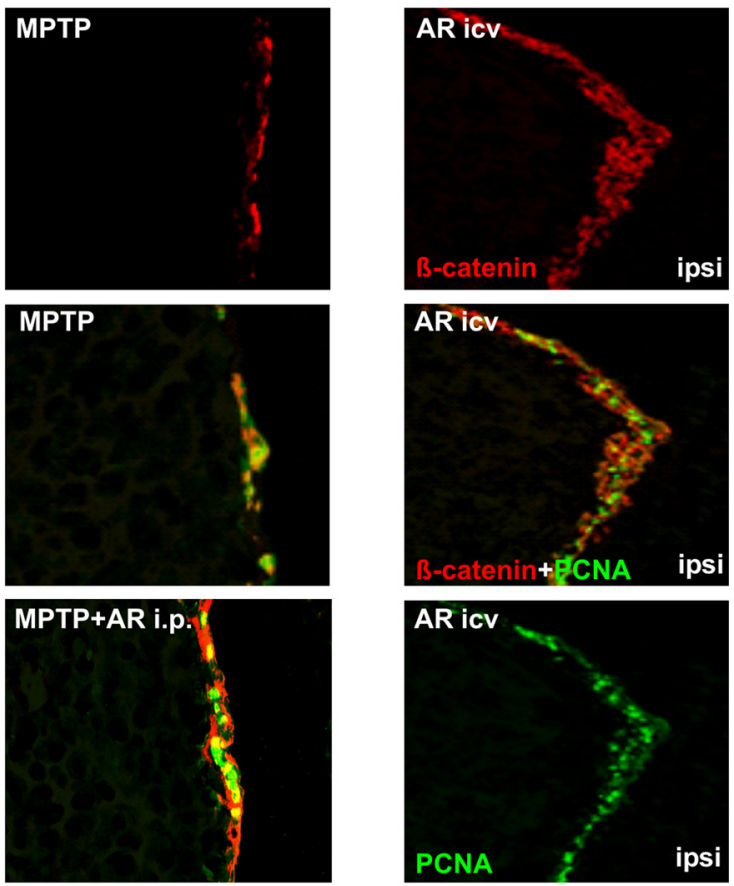

D
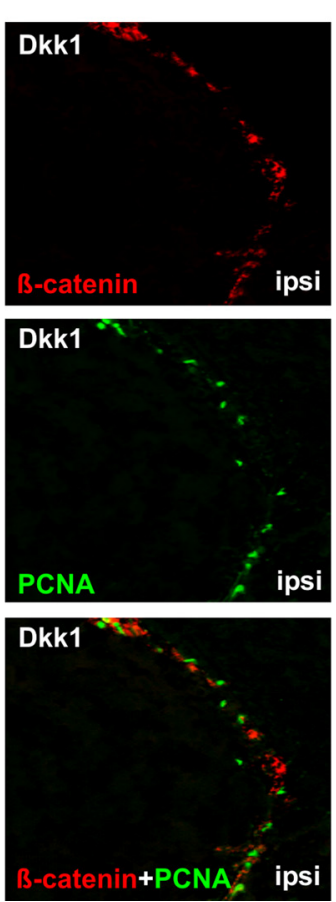
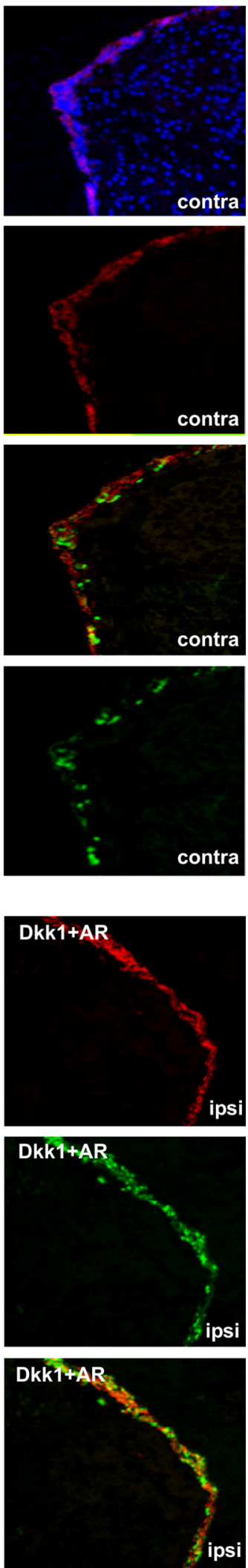

Figure 8. Activation of Wnt/ $\beta$-catenin signaling by GSK-3 $\beta$ antagonism in vivo counteracts MPTP-induced impaired neurogenesis. The effect of pharmacological activation of Wnt/ $\beta$-catenin signaling using the specific GSK-3 $\beta$ inhibitor AR was studied by either systemic or SVZ administration, starting $3 \mathrm{~h}$ after MPTP treatment. The effect of Wnt/ $\beta$-catenin signaling antagonism with Dkk1 intracerebroventricular infusion was studied in the absence or presence of AR systemic administration (for details see text). Mice were killed $3 \mathrm{~d}$ after MPTP, corresponding to maximal neurogenic impairment and exacerbated microglial reaction. $A$, Representative images of coronal sections of striatal SVZ stained with $\beta$-catenin (red) counterstained with the nuclear marker DAPI (blue) showing $\beta$-catenin expression in the SVZ of saline and MPTP mice. Dual localization of $\beta$-catenin and BrdU revealed that a proportion of $\beta$-catenin ${ }^{+}$cells coexpressed BrdU and certain $\beta$-catenin ${ }^{+}$cells exhibited nuclear colocalization. MPTP reduces the $\beta$-catenin-IF signal and $\beta$-catenin ${ }^{+}$cells coexpressing BrdU. B, C, Representative images showing the effect of unilateral infusion of GSK-3 $\beta$ antagonist (AR) in $\beta$-catenin expression ipsilateral (ipsi) compared with the noninfused contralateral (contra) side in saline-injected mice (B). (Figure legend continues.) 
sulted in a sharp increase in $\beta$-catenin expression and cell proliferation in the SVZ ipsilateral to the infusion (Fig. $8 B$ ), compared with contralateral noninfused SVZ (Fig. 8B). Likewise, systemic AR treatment of saline mice resulted in a significant increase in $\beta$-catenin expression and cell proliferation in the SVZ (Fig. $8 A, C)$. When mice exposed to MPTP received, after $3 \mathrm{~h}$, AR by either intracerebroventricular infusion or systemic injection, both treatments resulted in a significant counteraction of the MPTP-induced decreased PCNA ${ }^{+}$cells and $\beta$-catenin expression in the SVZ, $3 \mathrm{~d}$ after MPTP (Fig. $8 A-C$ ), indicating that the acute exogenous activation of $\beta$-catenin signaling during the temporal window of maximal neurogenic impairment and at the peak of microglial exacerbation (Fig. $3 F$ ) may overcome the disrupted neurogenesis observed in the SVZ of MPTP mice in vivo. Conversely, Wnt/ $\beta$-catenin antagonism using the soluble inhibitor $D k k 1$, infused intracerebroventricularly unilaterally (Zhang et al., 2009), mimicked MPTP systemic injection (Fig. $8 D, E$ ), as reflected by a significant decrease in the proportion of $\mathrm{PCNA}^{+}$and $\beta$-catenin ${ }^{+}$cells ipsilateral compared with contralateral noninfused SVZ (Fig. $8 D, E$ ). Importantly, this inhibitory effect was efficiently counteracted by concomitant activation of the downstream transcriptional effector, $\beta$-catenin, with AR systemic injections (Fig. $8 D, E$ ).

Together, the ex vivo, in vitro, and in vivo findings suggested a disruption of Wnt/ $\beta$-catenin signaling in SVZ associated with decreased proliferation of MPTP-injured SVZ. Although further time-dependent in-depth analyses will elucidate the effects Wnt/ $\beta$-catenin manipulation on a longer-term basis, these results showed the ability of pharmacological activation of $\beta$-cateninmediated signaling to counteract the impaired neurogenic potential of MPTP- or Dkk1-infused mice.

\section{Wnt/ק-catenin signaling disruption of MPTP mice is reversed by pharmacological modulation of inflammation: correlation with neuroprotection}

Finally, to support the plasticity of adult NPCs and test the potential to modulate this endogenous system with antiinflammatory drug therapy in vivo, we used the CINOD HCT1026, endowed with a safe profile and previously shown to mitigate microglial activation by reducing PHOX and iNOSderived RNS and to efficiently protect nigrostriatal DAergic neurons in PD rodent models (L'Episcopo et al., 2010a,b, 2011c). In accordance with our in vitro and in vivo findings, using Western blot analysis (Fig. 9A,B) and immunohistochemistry (Fig. 9C), MPTP induced downregulation of $\beta$-catenin protein levels in the SVZ. Specifically, dual labeling with IBA1 and $\beta$-catenin and with GFAP and $\beta$-catenin (Fig. $9 C$ ) supported $\beta$-catenin downregulation during the phase of maximal microglial exacerbation, i.e., at 3 dpt. On the other hand, active GSK-3 $\beta$ (pTyr216 GSK-3 $\beta$ ) was

\section{$\leftarrow$}

(Figure legend continued.) $\quad \beta$-Catenin (red) and cell proliferation measured with PCNA (green) are significantly increased in the ipsilateral AR-infused left SVZ $(\boldsymbol{B}, \boldsymbol{C})$. When mice exposed to MPTP received after $3 \mathrm{~h}$ AR by either intracerebroventricular infusion or systemic injection, both treatments resulted in a significant counteraction of the MPTP-induced decreased PCNA ${ }^{+}$cells and $\beta$-catenin expression in the SVZ, $3 \mathrm{~d}$ after MPTP $(\boldsymbol{A}-\boldsymbol{C})$. Systemic treatment with AR alone also increased proliferation in the SVZ $(\boldsymbol{A}-\boldsymbol{C})$. $\boldsymbol{D}, \boldsymbol{E}$, Dkk1, infused intracerebroventricularly unilaterally, mimicked MPTP systemic injection, resulting in decreased PCNA ${ }^{+}$and $\beta$-catenin ${ }^{+}$cells ipisilateral compared with contralatral noninfused SVZ. The inhibitory effect of Dkk1 was efficiently counteracted by concomitant AR systemic injections. ${ }^{*} p<0.05$ between ipsilateral and contralateral, within the saline and treated groups, respectively; ${ }^{* *} p<0.05$ versus MPTP/-Dkk1 within the different groups. icv, Intracerebroventricular; i.p., intraperitoneal. markedly upregulated (Fig. 9B). In contrast, HCT1026, although inactive in saline-treated mice, efficiently increased $\beta$-catenin protein back to controls after MPTP (Fig. 9A) and sharply decreased active GSK-3 $\beta$ (Fig. 9B) compared with MPTP mice fed with a control diet. Double labeling with $\beta$-catenin and glial markers further revealed normalization $\beta$-catenin-IF staining in SVZ of HCT-MPTP mice and reduced $\mathrm{GFAP}^{+}$and $\mathrm{IBA}^{+}{ }^{+}$cell numbers and reactivity (Fig. 9C).

These effects of HCT1026 were associated with a significant increase in the number of $\mathrm{BrdU}^{+}$- and $\mathrm{DCX}^{+}$-expressing cells in the striatal SVZ (Fig. 9D,E,H). In addition, in dual localization experiments with GFAP and DCX and with GFAP and BrdU (Fig. $9 H), \mathrm{GFAP}^{+}$astrocytes adjacent to the SVZ ensheated the young $\mathrm{DCX}^{+}$neuroblasts and displayed a reduced reactive phenotype after MPTP treatment in HCT1026, compared with mice fed with a control diet, showing disrupted astrocyte-NPC interactions at 3 dpt. Stage 4 microglial cell density was sharply decreased in the Str and SVZ of HCT1026 mice, as opposed to MPTP mice fed with a control diet (Fig. 9F-H). As observed at the ventral midbrain level (L'Episcopo et al., 2010b), these morphological effects were associated with a substantial downregulation of microglial pro-oxidant and inflammatory mediators, such as Mac1, PHOX, and iNOS in HCT1026 as opposed to mice fed with a control diet (data not shown).

As far as striatal DAergic end points are concerned, in agreement with our previous studies (L'Episcopo et al., 2010b), by $14 \mathrm{~d}$ after MPTP, DAT-IF fiber density and DA uptake in striatal synaptosomes were markedly reduced by MPTP in mice fed with a control diet, compared with HCT1026-fed mice, showing a significant degree of DAergic reinnervation (Fig. 9I-K), in line with a significant protection of midbrain cell bodies (data not shown), confirming our previous report (L'Episcopo et al., 2010b).

\section{Discussion}

Impaired neurogenesis in the SVZ of PD patients and PD experimental models has previously been reported. Loss of the neurotransmitter dopamine, from midbrain DAergic cell bodies innervating type C cells in the SVZ, was causally related to decreased neurogenic potential (see Introduction). In addition, certain dopamine agonist therapies can rescue NPC proliferation in PD (van Kampen et al., 2004; Winner et al., 2009). The present work focused on glia and shows that in addition to dopamine, the $\mathrm{PD}$ neurotoxin MPTP/MPP ${ }^{+}$either directly and/or in conjunction with astrocyte- and microglial-derived mediators may contribute to regulate SVZ plasticity in this PD mouse model. Hence, the unfavorable conditions of the SVZ niche during the early degenerative phase, resulting from decreased DAergic innervation and MPTP/MPP ${ }^{+}$-dependent striatal oxidative and nitrosative status, likely inhibit the survival and/or the expansion/ differentiation and/or migration of endogenous NPCs, at least in part via disruption of $\beta$-catenin-mediated $W n t$ signaling in the SVZ. With time, a shift toward a less reactive microglial "harmful" phenotype likely permits the mitigation of the niche microenvironment and the return of astrocyte "beneficial" expression of growth factors and neurogenic signals, including Wnts, together with a progressive striatal reinnervation, likely contributing to NPC recovery (Fig. 10). In keeping with these findings, exogenous activation of $\beta$-catenin signaling or pharmacological mitigation of microglia overactivation upregulated $\beta$-catenin in the SVZ and successfully rescued NPC proliferation and neuroblast formation. Additional studies are clearly required to decipher whether activation of $W n t / \beta$-catenin signaling, either directly or indirectly via inflammation-dependent SVZ modula- 


\section{C}
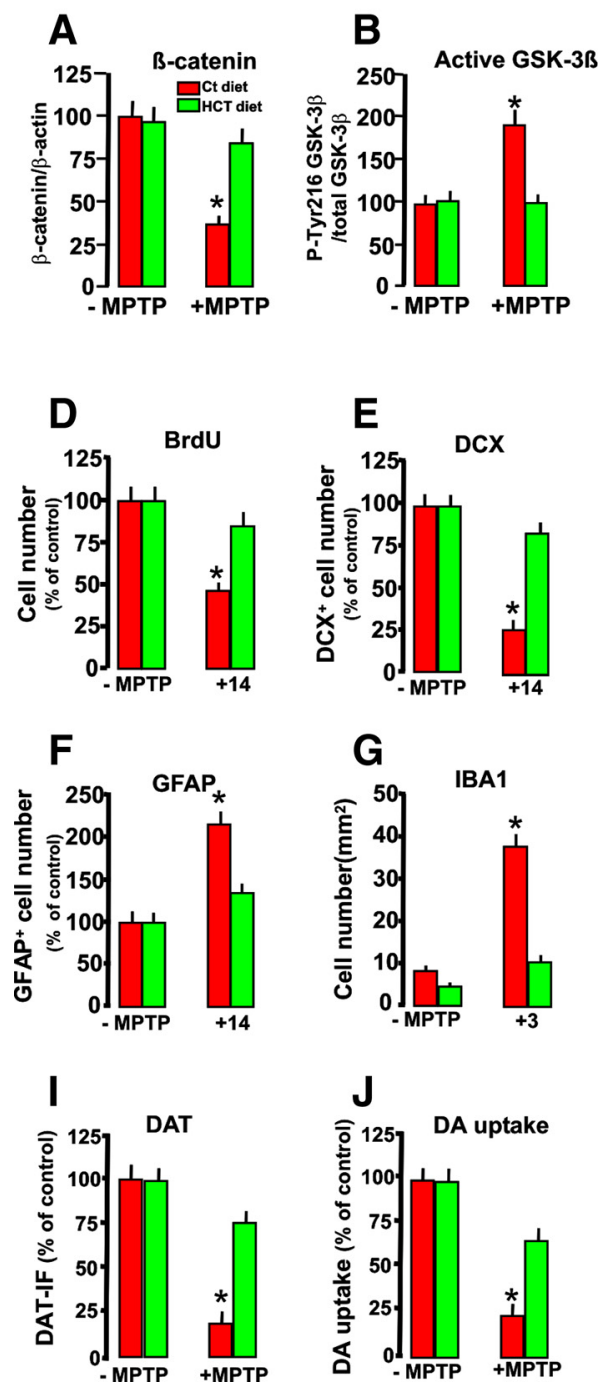

$\mathbf{H}$

K
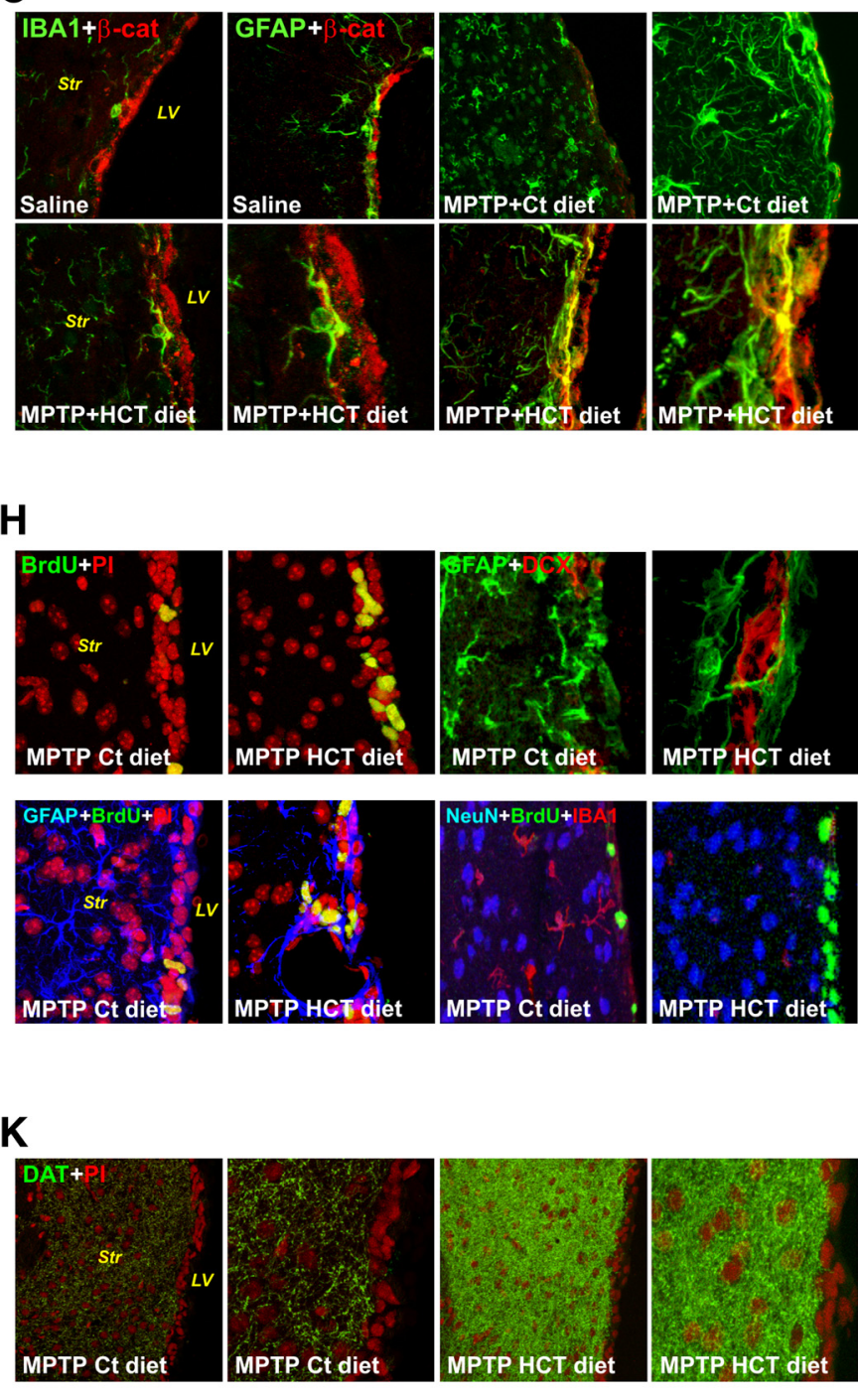

Figure 9. Pharmacological modulation of inflammation in vivo prevents $\beta$-catenin downregulation and reverses MPTP-induced SVZ impairment. Mice were fed with a control (Ct) or HCT1026 (HT) diet, starting $7 \mathrm{~d}$ before saline or MPTP injection and continuing until they were killed. $\boldsymbol{A}, \boldsymbol{B}$, Western blot analysis of $\beta$-catenin $(\boldsymbol{A})$ and active GSK-3 $\beta$ (i.e., phophorylated at tyrosine 216 residue, pTyr216 GSK-3 $\beta$, B) in protein extracts from the SVZ isolated from control and treated mice. ${ }^{*} p<0.05$ versus MPTP, within experimental groups. C, Representative confocal images of dual localization of $\beta$-catenin (red) and $\mathrm{IBA}^{+}{ }^{+}$microglia (green) and of $\beta$-catenin (red) and GFAP (green) in mice fed with a control or HCT1026 diet, with or without MPTP treatment. Note the marked loss of the $\beta$-catenin-IF signal after MPTP in mice fed with a control diet and HCT-1026-induced reversal of the $\beta$-catenin-IF signal loss in SVZ. D, BrdU ${ }^{+}$cell number in the SVZ of mice fed with a control or HCT11026 diet in the absence or presence of MPTP treatment. $\boldsymbol{E}$, Percentage of NPCs expressing DCX in mice fed with a Ct or HCT11026 diet. $F, G, G F A P^{+}(\boldsymbol{F})$ and stage 4 microglial $(\boldsymbol{G})$ cell numbers in the Str of mice fed with a $\mathrm{Ct}$ or HCT1026 diet. Differences were analyzed by ANOVA, followed by the Newman-Keuls test, and were considered significant when $p<0.05$. *Versus saline. $\boldsymbol{H}$, Confocal images of BrdU ${ }^{+}$(green) counterstained with the nuclear marker PI (in red), showing loss of BrdU ${ }^{+}$cells in MPTP mice fed with a Ct diet and the remarkable reversal in HCT1026-fed mice. Note that dual localization of DCX ${ }^{+}$neuroblasts (red) and GFAP ${ }^{+}$astrocytes (green) in SVZ of MPTP mice fed with HCT1026 mice reverses DCX impairment. Dual staining of GFAP ${ }^{+}$astrocytes (blue) and BrdU (green) counterstained with PI (red) in MPTP mice fed with a control diet similarly show the SVZ rescue effect of the HCT1026 diet. Triple staining with the neuronal cell markers NeuN (blue), BrdU (green), and IBA1 (red) in MPTP mice fed with HCT1026 show a significant reversal of MPTP-induced microgliosis and reduced proliferation of mice fed with a ct diet. $I, J$, Striatal DAergic innervation as determined by measurements of Fl of DAT- IR fibers in Str ( () and DA uptake in striatal synaptosomes ( $)$. Data are expressed as percentage values of saline-injected controls. $\boldsymbol{K}$, Representative images showing DAT immunofluorescence (green) in MPTP mice fed with a Ct diet, compared with HCT1026-fed mice, at 14 dpt. Note the remarkable DAergic neuroprotection of MPTP-HCT1026 compared with MPTP mice fed with a ct diet.

tion, has potential implications for DAergic neuroprotection/ self-repair (Wang et al., 2007; Maiese et al., 2008; Toledo et al., 2008; Chong et al., 2010; Inestrosa and Arenas, 2010; Kim et al., 2010; L'Episcopo et al., 2010b, 2011a,b,c; Shruster et al., 2011).

Neuroinflammatory astrocyte- and microglial-derived signals act in concert within the niche microenvironment to shape the SVZ response to MPTP

Previous and more recent studies indicate that within the neurogenic microenvironment, factors arising from glial cells may play important roles, especially after acute or chronic brain damage, where proliferation, and/or fate choice, migration, and maturation, may be differentially affected according to the severity of the lesion, the region affected, and the type of insult (Ekdhal et al., 2003, 2009; Monje et al., 2003; Butowski et al., 2006; Jakubs et al., 2008; Pluchino et al., 2008; Schwartz et al., 2008; Thored et al., 2009). In the MPTP-lesioned mouse model, which recapitulates many of the pathogenetic processes operative in PD (Jackson-Lewis and Przedborski, 2007), glial inflammatory mechanisms are known to contribute to nigrostriatal degenera- 


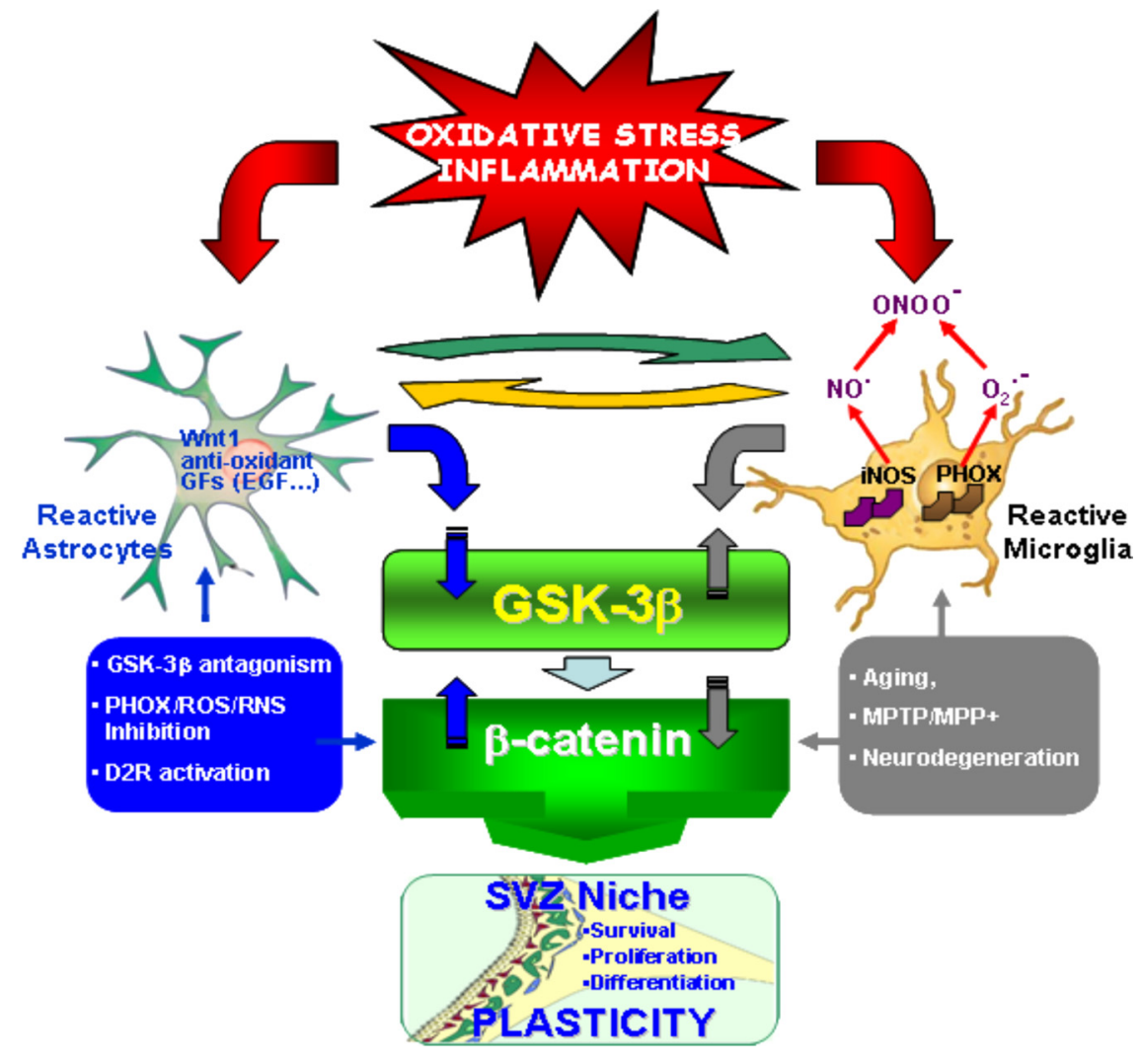

Figure 10. Cross talk between inflammatory and Wnt/ $\beta$-catenin signaling pathways in MPTP-induced SVZ plasticity. A simplified scheme summarizing MPTP-induced neuroinflammation and SVZ plasticity via modulation of $\mathrm{Wnt} / \beta$-catenin signaling is shown. During the early degeneration phase of MPTP toxicity, hyperactivated microglia contributes to the impairment of SVZ neurogenesis at different levels. By increasing oxidative and nitrosative stress and in synergy with MPTP/MPP ${ }^{+}$direct toxicity, microglial-derived mediators (PHOX-derived ROS, iNOS-derived NO, and peroxynitrite) may act as molecular switch for cell signaling pathways critically involved in the physiological control of NPC homeostasis, with harmful consequences for astrocyte and NPC physiology, at least in part through GSK-3 $\beta$ activation, followed by phosphorylation and consequent degradation of $\beta$-catenin. In contrast, pharmacological mitigation of inflammation and oxidative stress with Apo, L-Nil, or HCT1026 upregulates $\beta$-catenin and successfully rescues NPC proliferation and neuroblast formation, a process associated with striatal DAergic neuroprotection, with further positive modulation of SVZ proliferation via $D_{2}$ receptor (D2R) activated mechanisms. The mutual role of astrocytemicroglial interactions in the plasticity of SVZ response to MPTP is exemplified by the astrocyte's ability to overcome microglial inhibitory effects, also via cross talk with Wnt/ $\beta$-catenin signaling.

tion and self-repair (Morale et al. 2004, 2006; Marchetti and Abbracchio, 2005; Marchetti et al., 2005a,b; L'Episcopo et al., 2010a). Here, we linked SVZ impairment with the early and marked upregulation of microglial PHOX and iNOS, generating the highly toxic peroxynitrite fingerprint 3-NT, possibly contributing to NPC mitochondrial dysfunction, increasing NPC vulnerability to cell death, and/or rendering the SVZ microenvironment unfavorable for neuroblast proliferation and/or differentiation. In particular, the studies of Estrada and coworkers (Estrada and Murillo-Carretero, 2005; Torroglosa et al., 2007) have clearly implicated NO as a key factor that regulates stem cell fate in the adult SVZ. The critical role of the microenvironment was also suggested by ex vivo analyses in NPC isolated from MPTP mice, showing a significant early inhibition in their growth rate during the temporal window of SVZ impairment. In analogy with studies performed in a chronic model of brain inflammation (Pluchino et al., 2008), the intrinsic mitogenic properties of NPC from MPTP mice were recovered after $12 \mathrm{~d}$ in vitro in the presence of FGF-II and EGF. In keeping with this concept, the abatement of proinflammatory and oxidative mediators herein observed with time in vivo likely represents a contributing factor in NPC recovery.
Astrocyte-microglia cross talk can switch the balance toward inhibition/ recovery of NPC neurogenesis upon MPTP/MPP ${ }^{+}$injury

Astrocytes are key players in brain homeostasis (Magistretti, 2006; Allaman et al., 2011) and in the context of adult neurogenesis (Alvarez-Buylla et al., 2001; Song et al., 2002; Jiao and Chen, 2008). In addition, microglia, when moderately active, are beneficial and support proliferation, survival, and differentiation of adult NPCs (Ekdahl et al., 2009). Importantly, the chief role of astrocyte-neuron cross talk in neurodegeneration, neuroprotection, and neurorepair is long recognized (Marchetti et al., 2005a,b; Magistretti, 2006; L'Episcopo et al., 2010a; Allaman et al., 2011), but the direct action of MPTP/ $\mathrm{MPP}^{+}$in NPCs, the contributory role of glial cells, and the signaling mechanisms involved, were not yet addressed. Here, by examining in vitro NPC vulnerability to $\mathrm{MPP}^{+}$, we found that doses $\leq 5 \mu \mathrm{M}$ did not affect NPC survival, whereas doses at $\geq 10 \mu \mathrm{M}, \mathrm{MPP}^{+}$induced Caspase- 3 activation in a dose-dependent fashion. In addition, the ability of adult NPCs to proliferate and differentiate into Map $2 \mathrm{a}^{+}$ neurons was dose-dependently reduced by $\mathrm{MPP}^{+}$, indicating the direct ability of the PD neurotoxin to impair SVZ neurogenic potential. The fact that reactive astrocytes but not microglia efficiently reversed NPC impairment is in line with findings indicating that inflammatory factors can be involved in astroglial modulation of adult neurogenesis, whereas microglia activation with LPS or with certain cytokines can impair neurogenesis (Monje et al., 2003; Ekdhal et al., 2003, 2009; Barkho et al., 2006; Butowski et al., 2006; Pluchino et al., 2008). The fact that increasing astrocyte-tomicroglia ratio significantly reversed $\mathrm{MPP}^{+}$-induced NPC impairment also suggests that besides the degree of microglia activation, astrocyte-microglial cross talk may also play a critical role in MPTP modulation of NPC neurogenic potential.

\section{Cross talk between inflammatory and $\mathrm{Wnt} / \boldsymbol{\beta}$-catenin} signaling in MPTP/MPP ${ }^{+}$-induced neurogenic impairment: $\boldsymbol{\beta}$-catenin as a common final pathway

Most of the mechanisms affecting adult neurogenesis in brain diseases are primarily unknown. Oxidative, and especially nitrosative, stress is recognized to influence fundamental cellular processes linked to aging and the development of age-related diseases, especially PD. Wnt/ $\beta$-catenin signaling is a vital pathway regulating self-renewal and differentiation of neural stem cells, and $\beta$-catenin represents a chief transcriptional regulator (Logan and Nusse, 2004). Hence, stabilized $\beta$-catenin can enter the nucleus and associate with T-cell factor/lymphoid enhancer binding factor (TCF/LEF) transcription factors, leading to the transcription of Wnt target genes involved in cell survival, proliferation, and differentiation. Emerging evidence (Lie et al., 2005; Adachi et 
al., 2007; Wexler et al., 2008; Kuwabara et al., 2009; Munji et al., 2011; Zhang et al., 2011) indicates a role for this pathway in adult neurogenesis. Because activation of GSK-3 $\beta$ causes $\beta$-catenin depletion (Aberle et al., 1997), GSK-3 $\beta / \beta$-catenin disruption appeared a potential candidate mediator of MPTP-microgliainduced NPC impairment. The fact that pharmacological inhibition of microglial ROS and RNS resulted in reversal of NPC impairment associated with $\beta$-catenin upregulation coupled to normalization of GSK $3 \beta$ activity also suggested cross talk between inflammatory and $W n t / \beta$-catenin signaling components. The observed upregulation of active $p G S K-3 \beta$ in the face of $\beta$-catenin and Axin 2 downregulation in SVZ of MPTP mice further implicated disruption of $W n t / \beta$-catenin signaling. Because $W n t / \beta$-catenin signaling controls the expression of a variety of target genes, misregulation of this signaling cascade is involved in various diseases, particularly neurodegenerative disorders associated with impaired neurogenesis such as AD and PD (Toledo et al., 2008; He and Shen, 2009; Inestrosa and Arenas, 2010; Kim et al., 2010; L'Episcopo et al., 2011a,b; Shruster et al., 2011). Consistently, the signaling mechanisms involved in $\mathrm{MPTP} / \mathrm{MPP}^{+}$induced neuronal and NPC impairment seem to target the Wnt/ $\beta$-catenin signaling pathway (Duka et al., .2009; Petit-Paitel et al., 2009; L'Episcopo et al., 2011a,b). Accordingly, exogenous activation of $W n t / \beta$-catenin signaling by GSK-3 $\beta$ inhibition/silencing, Wnt1 exposure, or astrocyte coculture overrode MPTP-induced impaired neurogenesis. Likewise, exogenous manipulation of $\mathrm{Wnt} / \beta$-catenin signaling in primary mesencephalic neurons exerts potent neuroprotective effects against oxidative stress, 6-OHDA, and $\mathrm{MPP}^{+}$induced DAergic cell death in vitro and in vivo (L'Episcopo et al., 2011a,b), and additional studies are clearly needed to address the significance and implications of $W n t / \beta$-catenin signaling disruption in conditions associated with exacerbated inflammation, neurodegeneration, and impaired neurogenesis, such as PD. Because $\geq 100$ $\beta$-catenin target genes (http://www.stanford.edu/ rnusse/pathways/targets.html) have been identified, different upstream and downstream signaling cascades may converge in finely tuning $\beta$-catenin transcriptional activity (Jin et al., 2008). For example, NO can inhibit EGF-R and the phosphoinositide 3-kinase (PI3K)/AKT survival pathway (Estrada et al., 2005; Torroglosa et al., 2007), and GSK-3 $\beta$ is a downstream target of Akt (Maiese et al., 2008). In addition, peroxynitrite-induced nitration regulates the p85 subunit of PI3 kinase (Zhang et al., 2005; Trowbridge et al., 2006; Phukan et al., 2010). Moreover, a variety of molecules, including growth factors and dopamine via $\mathrm{D}_{2}$ receptor, can signal through (PI3K)/AKT/ GSK-3 $\beta$ and Wnt signaling activation (Spiegel et al., 2007; Beaulieu et al., 2011; Oieda et al., 2011); thus, "cross talk" among $W n t / \beta$ catenin and prominent intracellular pathways may be envisaged in fine tuning SVZ neurogenic potential/plasticity observed herein (Fig. 10).

In conclusion, within the complex cell-cell interactions and signaling cascades at play in the SVZ, we herein uncovered antagonism of $W n t / \beta$-catenin signaling by MPTP and microglialderived oxidative and nitrosative mediators via upregulation of GSK- $\beta$ and $\beta$-catenin degradation as candidate contributors of neurogenic impairment in PD. Coupled to the critical involvement of astrocyte-derived Wnts and $W n t / \beta$-catenin signaling in rescuing the impaired neurogenic potential observed herein, an in-depth knowledge of the mechanisms involved in the protection, activation, and migration of these endogenous neural progenitors to the site of injury would represent a strategy to promote endogenous restoration of the diseased/injured DAergic neurons in these models (Borta and Hoglinger, 2007; Hermann and Storch, 2008; Ouredinik et al., 2009; Fernando et al., 2010; Deleidi et al., 2011).

\section{References}

Aberle H, Bauer A, Stappert J, Kispert A, Kemler R (1997) Beta-catenin is a target for the ubiquitin-proteasome pathway. EMBO J 16:3797-3804.

Adachi K, Mirzadeh Z, Sakaguchi M, Yamashita T, Nikolcheva T, Gotoh Y, Peltz G, Gong L, Kawase T, Alvarez-Buylla A, Okano H, Sawamoto K (2007) $\beta$-Catenin signaling promotes proliferation of progenitor cells in the adult mouse subventricular zone. Stem Cells 25:2827-2836.

Ahlenius H, Visan V, Kokaia M, Lindvall O, Kokaia Z (2009) Neural stem and progenitor cells retain their potential for proliferation and differentiation into functional neurons despite lower number in aged brain. J Neurosci 29:4408-4419.

Allaman I, Bélanger M, Magistretti PJ (2011) Astrocyte-neuron metabolic relationships: for better and for worse. Trends Neurosci 34:76-87.

Alvarez-Buylla A, Garcia-Verdugo JM, Tramontin AD (2001) A unified hypothesis on the lineage of neural stem cells. Nat Rev Neurosci 2:2287-2293.

Baker SA, Baker KA, Hagg T (2004) Dopaminergic nigrostriatal projections regulate neural precursor cell proliferation in the adult mouse subventricular zone. Eur J Neurosci 20:575-579.

Barkho BZ, Song H, Aimone JB, Smrt RD, Kuwabara T, Nakashima K, Gage $\mathrm{FH}$, Zhao X (2006) Identification of astrocyte-expressed factors that modulate neural stem/progenitor cell differentiation. Stem Cells Dev 15:407-421.

Beaulieu JM, Del'guidice T, Sotnikova TD, Lemasson M, Gainetdinov RR (2011) Beyond cAMP: the regulation of Akt and GSK3 by dopamine receptors. Front Mol Neurosci 4:38.

Bhat RV, Shanley J, Correll MP, Fieles WE, Keith RA, Scott CW, Lee CM (2000) Regulation and localization of tyrosine ${ }^{216}$ phosphorylation of glycogen synthase kinase- $3 \beta$ in cellular and animal models of neuronal degeneration. Proc Natl Acad Sci U S A 97:11074-11079.

Borta A, Hoglinger GU (2007) Dopamine and adult neurogenesis. J Neurochem 100:587-595.

Brazas RM, Hagstrom JE (2005) Delivery of small interfering RNA to mammalian cells in culture by using cationic lipid/polymer-based transfection reagents. Methods Enzymol 392:112-124.

Butovsky O, Ziv Y, Schwartz A, Gennady L, Talpalar AE, Pluchino S, Martino G, Schwartz M (2006) Microglia activated by IL-4 or IFN-gamma differentially induce neurogenesis and oligodendrogenesis from adult stem/ progenitor cells. Mol Cell Neurosci 31:149-160.

Cahoy JD, Emery B, Kaushal A, Foo LC, Zamanian JL, Christopherson KS, Xing Y, Lubischer JL, Krieg PA, Hrupenko SA, Thompson WJ, Barres BA (2008) A transcriptome database for astrocytes, neurons, and oligodendrocytes: a new resource for understanding brain development and function. J Neurosci 28:264-278.

Castelo-Branco G, Rawal N, Arenas E (2004) GSK-3 $\beta$ inhibition/ $\beta$-catenin stabilization in ventral midbrain precursors increases differentiation into dopamine neurons. J Cell Sci 117:5731-5737.

Castelo-Branco G, Sousa KM, Bryja V, Pinto L, Wagner J, Arenas E (2006) Ventral midbrain glia express region-specific transcription factors and regulate dopaminergic neurogenesis through Wnt-5a secretion. Mol Cell Neurosci 31:251-262

Chen G, Bower KA, Ma C, Ma C, Fang S, Thiele CJ, Luo J (2004) Glycogen synthase kinase 3beta (GSK3beta) mediates 6-hydroxy dopamineinduced neuronal death. FASEB J 18:1162-1164.

Chen LW, Wie LC, Qiu Y, Liu HL, Rao ZR, Ju G, Chan YS (2002) Significant up-regulation of nestin protein in the neostriatum of MPTP-treated mice. Are the striatal astrocytes regionally activated after systemic MPTP administration? Brain Res 925:9-17.

Chen LW, Hu JJ, Liu HL, Yung KK, Chan YS (2004) Identification of brainderived neurotrophic factor in nestin-expressing astroglial cells in the neostriatum of 1-methyl-4-phenyl-1,2,3,6-tetrahydropyridine-treated mice. Neuroscience 126:941-956.

Chen PC, Vargas MR, Pani AK, Smeyne RJ, Johnson DA, Kan YW, Johnson JA (2009) Nrf2-mediated neuroprotection in the MPTP mouse model of Parkinson's disease: critical role for the astrocyte. Proc Natl Acad Sci U S A 106:2933-2938.

Chong ZZ, Shang YC, Hou J, Maiese K (2010) Wnt1 neuroprotection translates into improved neurological function during oxidant stress and cere- 
bral ischemia through AKT1 and mitochondrial apoptotic pathways. Oxid Med Cell Longev 3:153-165.

Cooper O, Isacson O (2004) Intrastriatal transforming growth factor $\alpha$ delivery to a model of Parkinson's disease induces proliferation and migration of endogenous adult neural progenitor cells without differentiation into dopaminergic neurons. J Neurosci 24:8924-8931.

Curtis MA, Faull RLM, Eriksson PS (2007) The effect of neurodegenerative diseases on the subventricular zone. Nat Rev Neurosci 8:712-723.

Deleidi M, Hargus G, Hallett P, Osborn T, Isacson O (2011) Development of histocompatible primate induced pluripotent stem cells for neural transplantation. Stem Cells 29:1052-1063.

Doetsch F, García-Verdugo JM, Alvarez-Buylla A (1997) Cellular composition and three-dimensional organization of the subventricular germinal zone in the adult mammalian brain. J Neurosci 17:5046-5061.

Doetsch F, Caillé I, Lim DA, García-Verdugo JM, Alvarez-Buylla A (1999) Subventricular zone astrocytes are neural stem cells in the adult mammalian brain. Cell 97:703-711.

Doetsch F, Petreanu L, Caille I, Garcia-Verdugo JM, Alvarez-Buylla A (2002) EGF converts transit-amplifying neurogenic precursors in the adult brain into multipotent stem cells. Neuron 36:1021-1034.

Duka T, Duka V, Joyce JN, Sidhu A (2009) $\alpha$-Synuclein contributes to GSK$3 \beta$-catalyzed Tau phosphorylation in Parkinson's disease models. FASEB J 23:2820-2830.

Ekdahl CT, Claasen JH, Bonde S, Kokaia Z, Lindvall O (2003) Inflammation is detrimental for neurogenesis in the adult brain. Proc Natl Acad Sci U S A 100:13632-13637.

Ekdahl CT, Kokaia Z, Lindvall O (2009) Brain inflammation and adult neurogenesis: the dual role of microglia. Neuroscience 158:1021-1029.

Estrada C, Murillo-Carretero M (2005) Nitric oxide and adult neurogenesis in health and disease. Neuroscientist 11:294-307.

Fernando CV, Moses D, Parish CL, Tomas D, Drago J, Horne MK (2010) Creating a ventral midbrain stem cell niche in an animal model for Parkinson's disease. Stem Cells Dev 19:1995-2007.

Fiorucci S, Santucci L, Distrutti E (2007) NSAIDs, coxibs, CINOD and $\mathrm{H}_{2} \mathrm{~S}$ releasingNSAIDs: what lies beyond the horizon. Digest Liv Dis 39:1043-1051.

Freundlieb N, François C, Tandé D, Ortel WH, Hirsh EC, Hoglinger GU (2006) Dopaminergic subtantia nigra neurons project topographically organized to the subventricular zone and stimulate precursor cell proliferation in aged primates. J Neurosci 26:2321-2325.

Gallo F, Morale MC, Spina-Purrello V, Tirolo C, Testa N, Farinella Z, Avola R, Beaudet A, Marchetti B (2000a) Basic fibroblast growth factor (bFGF) acts on both neurons and glia to mediate the neurotrophic effects of astrocytes on LHRH neurons in culture. Synapse 36:233-253.

Gallo F, Morale MC, Tirolo C, Testa N, Farinella Z Avola R, Beaudet A Marchetti B (2000b) Basic fibroblast growth factor priming increases the responsiveness of immortalized hypothalamic luteinizing hormone releasing hormone neurones to neutrophic factors. J Neuroendocrinol 12:941-959.

Gao HM, Hong JS (2008) Why neurodegenerative diseases are progressive: uncontrolled inflammation drives disease progression. Trends Immunol 29:357-365.

Gao HM, Liu B, Zhang W, Hong JS (2003) Critical role of microglia NADPH-oxidase-derived free radicals in the in vitro MPTP model of Parkinson's disease. FASEB J 17:1954-1966.

Gao HM, Kotzbauer PT, Kunihiro U, Leight S, Trojanowsski JQ, Lee VMY (2008) Neuroinflammation and oxidation/nitration of $\alpha$-synuclein linked to dopaminergic neurodegeneration. J Neurosci 28:7687-7698.

Gennuso F, Fernetti C, Tirolo C, Testa N, L'Episcopo F, Caniglia S, Morale MC, Ostrow JD, Pascolo L, Tiribelli C, Marchetti B (2004) Bilirubin protects astrocytes from its own toxicity inducing up-regulation and translocation of multidrug resistance-associated protein 1 (Mrp 1). Proc Natl Acad Sci U S A 101:2470-2475.

Gordon MD, Nusse R (2006) Wnt signaling: multiple pathways, multiple receptors and multiple transcription factors. J Biol Chem 281:22429-22433.

Grimes CA, Jope RS (2001) The multifaceted roles of glycogen synthase kinase 3beta in cellular signaling. Prog Neurobiol 65:391-426.

Gritti A, Bonfanti L, Doetsch F, Caille I, Alvarez-Buylla A, Lim DA (2002) Multipotent neural stem cells reside into the rostral extension and olfactory bulb of adult rodents. J Neurosci 22:437-445.
Gundersen HJ, Jensen EB (1987) The efficiency of systematic sampling in stereology and its prediction. J Microsc 147:229-263.

$\mathrm{He}$ P, Shen Y (2009) Interruption of $\beta$-catenin signaling reduces neurogenesis in Alzheimer's disease. J Neurosci 29:6545-6557.

He XJ, Nakayama H, Dong M, Yamauchi H, Ueno M, Uetsuka K, Doi K (2006) Evidence of apoptosis in the subventricular zone and rostral migratory stream in the MPTP mouse model of Parkinson disease. J Neuropathol Exp Neurol 65:873-882.

Hermann A, Storch A (2008) Endogenous regeneration in Parkinson's disease: do we need orthotopic dopaminergic neurogenesis? Stem Cells 26:2749-2752.

Hirsch EC, Hunot S (2009) Neuroinflammation in Parkinson's disease: a target for neuroprotection? Lancet Neurol 8:382-397.

Hoglinger GU, Rizk P, Muriel MP, Duyckaerts C, Oertel WH, Caille I, Hirsch E (2004) Dopamine depletion impairs precursor cell proliferation in Parkinson disease. Nat Neurosci 7:726-735.

Hu X, Zhang D, Pang H, Caudle WM, Li Y, Gao H, Liu Y, Qian L, Wilson B, Di Monte DA, Ali SF, Zhang J, Block ML, Hong JS (2008) Macrophage antigen complex-1 mediates reactive microgliosis and progressive dopaminergic neurodegeneration in the MPTP model of Parkinson's disease. J Immunol 181:7194-7204.

Inestrosa NC, Arenas E (2010) Emerging role of Wnts in the adult nervous system. Nat Rev Neurosci 11:77-86.

Jackson-Lewis V, Przedborski S (2007) Protocol for the MPTP model of Parkinson's disease. Nat Protoc 2:141-151.

Jakubs K, Bonde S, Iosif RE, Ekdahl CT, Kokaia Z, Kopkaia M, Lindvall O (2008) Inflammation regulates functional integration of neurons born in adult brain. J Neurosci 28:12477-12488.

Jho EH, Zhang T, Domon C, Joo CK, Freund JN, Costantini F (2002) Wnt/ beta-catenin/Tcf signaling induces the transcription of Axin2, a negative regulator of the signaling pathway. Mol Cell Biol 22:1172-1183.

Jiao J, Chen DF (2008) Induction of neurogenesis in nonconventional neurogenic regions of the adult central nervous system by niche astrocyteproduced signals. Stem Cells 26:1221-1230.

Jin T, Fantus IG, Sun J (2008) Wnt and beyond Wnt: multiple mechanisms control the transcriptional property of $\beta$-catenin. Cell Signal 20:1697-1704.

Kalani MYS, Cheshir SH, Cord BJ, Bababeygy SR, Vogel H, Weissman IL, Palmer TD, Nusse R (2008) Wnt-mediated self-renewal of neural stem/ progenitor cells. Proc Natl Acad Sci U S A 105:16970-16975.

Kazanis I (2009) The subependymal zone neurogenic niche: a beating heart in the centre of the brain: how plastic is adult neurogenesis? Opportunities for therapy and questions to be addressed. Brain 132:2909-2921.

Keeble JE, Moore PK (2002) Pharmacology and potential therapeutic applications of nitric oxide-releasing non-steroidal anti-inflammatory and related nitric oxide-donating drugs. Br J Pharmacol 137:295-340.

Kim H, Won S, Hwang DY, Lee J, Kim M, Kim R, Kim W, Cha B, Kim T, Kim D, Costantini F, Jho E (2010) Downregulation of Wnt/ $\beta$-catenin signaling causes degeneration of hippocampal neurons in vivo. Neurobiol Aging 32:2316.

King TD, Bijur GN, Jope RS (2001) Caspase-3 activation induced by inhibition of mitochondrial complex I is facilitated by glycogen synthase kinase- $3 \beta$ and attenuated by lithium. Brain Res 919:106-114.

Kreutzberg GW (1996) Microglia: a sensor for pathological events in the CNS. Trends Neurosci 19:312-318.

Kuwabara T, Hsieh J, Muotri A, Yeo G, Warashira M, Lie DC, Moore L, Nakashima K, Asashima M, Gage FH (2009) Wnt-mediated activation of NeuroD1 and retro-elements during adult neurogenesis. Nat Neurosci 12:1097-1105.

Lennington JB, Pope S, Goodheart AE, Drozdowicz L, Daniels SB, Salamone JD, Conover JC (2011) Midbrain dopamine neurons associated with reward processing innervate the neurogenic subventricular zone. J Neurosci 31:13078-13087.

L’Episcopo F, Tirolo C, Testa N, Caniglia S, Morale MC, Marchetti B (2010a) Glia as a turning point in the therapeutic strategy of Parkinson's disease. CNS Neurol Disord 9:349-372.

L'Episcopo F, Tirolo C, Caniglia S, Testa N, Serra PA, Impagnatiello F, Morale MC, Marchetti B (2010b) Combining nitric oxide release with antiinflammatory activity preserves nigrostriatal dopaminergic innervation and prevents motor impairment in a 1-methyl-4-phenyl-1,2,3,6-tetrahydropyridine model of Parkinson's disease. J Neuroinflamm 7:83.

L'Episcopo F, Tirolo C, Testa N, Caniglia S, Morale MC, Cossetti C, D'Adamo 
P, Zardini E, Andreoni L. Ihekwaba AE, Serra PA, Franciotta D, Martino G, Pluchino S, Marchetti B (2011a) Reactive astrocytes and Wnt/betacatenin signaling link nigrostriatal injury to repair in 1-methyl-4-phenyl1,2,3,6-tetrahydropyridine model of Parkinson's disease. Neurobiol Dis 41:508-527.

L'Episcopo F, Serapide MF, Tirolo C, Testa N, Caniglia S, Morale MC, Pluchino S, Marchetti B (2011b) A Wnt1 regulated frizzled-1/ $\beta$-catenin signaling pathway as a candidate regulatory circuit controlling mesencephalic dopaminergic neuron-astrocyte crosstalk: therapeutical relevance for neuron survival and neuroprotection. Mol Neurodegener 6:49.

L'Episcopo F, Tirolo C, Testa N, Caniglia S, Morale MC, Impagniatiello F, Marchetti B (2011c) Switching microglial harmful phenotype promotes life-long restoration of Substantia Nigra dopaminergic neurons from inflammatory neurodegeneration in aged mice. Rejuv Res 14:411-424.

Lie DC, Colamarino SA, Song HG, Désiré L, Mira H, Consiglio A, Lein ES, Jessberger S, Lansford H, Diarie AR, Gage FH (2005) Wnt signaling regulates adult hippocampal neurogenesis. Nature 473:1370-1375.

Lim DA, Alvarez-Buylla A (1999) Interaction between astrocytes and adult subventricular zone precursors stimulates neurogenesis. Proc Natl Acad Sci U S A 96:7526-7531.

Logan CY, Nusse R (2004) The Wnt signaling pathway in development and disease. Annu Rev Cell Dev Biol 20:781-810.

Magistretti PJ (2006) Neuron-glia metabolic coupling and plasticity. J Exp Biol 209:2304-2311.

Maiese K, Faqi L, Chong ZZ, Chen SY (2008) The Wnt signalling pathway: aging gracefully as a protectionist? Pharmacol Ther 118:58-81.

Mander P, Brown G (2005) Activation of microglial NADPH oxidase is synergistic with glial iNOS expression in inducing neuronal death: a dual key mechanism of inflammatory degeneration. J Neuroinflamm 2:20-27.

Mao L, Lau YS, Petroske E, Wan JQ (2001) Profound astrogenesis in the striatum of adult mice following nigrostriatal dopaminergic lesion by repeated MPTP administration. Dev Brain Res 131:57-65.

Marchetti B, Abbracchio MP (2005) To be or not to be (inflamed) is that the question in anti-inflammatory drug therapy of neurodegenerative diseases? Trends Pharmacol Sci 26:517-525.

Marchetti B, Morale MC, Brouwer J, Tirolo C, Testa N, Caniglia S, Barden N, Amor S, Smith PA, Dijkstra CD (2002) Exposure to a dysfunctional glucocorticoid receptor from early embryonic life programs the resistance to experimental autoimmune encephalomyelitis via nitric oxide-induced immunosuppression. J Immunol 168:5848-5859.

Marchetti B, Kettenmann H, Streit WJ (2005a) Glia-neuron crosstalk in neuroinflammation, neurodegeneration and neuroprotection. Brain Res Rev 48:129-132.

Marchetti B, Serra PA, Tirolo C, L'Episcopo F, Caniglia S, Gennuso F, Testa N, Miele E, Desole MS, Barden N, Morale MC (2005b) Glucocorticoid receptor-nitric oxide crosstalk and vulnerability to experimental Parkinsonism: pivotal role for glia-neuron interactions. Brain Res Rev 48:302-321.

Matarredona ER, Murillo-Carretero M, Moreno-Lopez B, Estrada C (2004) Nitric oxide synthesis inhibition increases proliferation of neural precursors isolated from the postnatal mouse subventricular zone. Brain Res 995:274-284.

Matarredona ER, Murillo-Carretero M, Moreno-López B, Estrada C (2005) Role of nitric oxide in subventricular zone neurogenesis. Brain Res Brain Res Rev 2005 49:355-366.

Mohapel P, Frielingsdorf H, Haggblad J, Zachrisson O, Brundin P (2005) Platelet-derived growth factor (PDGF-BB) and brain-derived neurotrophic factor (BDNF) induce striatal neurogenesis in adult rats with 6-hydroxydopamine lesions. Neuroscience 132:767-776.

Moncada S, Bolanos JP (2006) Nitric oxide, cell bioenergetics and neurodegeneration. J Neurochem 97:1676-1689.

Monje ML, Toda H, Palmer TD (2003) Inflammatory blockade restores adult hippocampal neurogenesis. Science 302:1760-1765.

Morale MC, Serra P, Delogu MR, Migheli R, Rocchitta G, Tirolo C, Caniglia S, Testa N, L'Episcopo F, Gennuso F, Scoto GM, Barden N, Miele E, Desole MS, Marchetti B (2004) Glucocorticoid receptor deficiency increases vulnerability of the nigrostriatal dopaminergic system: critical role of glial nitric oxide. FASEB J 18:164-166.

Morale MC, Serra PA, L'Episcopo F, Tirolo C, Caniglia S, Testa N, Gennuso F, Giaquinta G, Rocchitta G, Desole MS, Miele E, Marchetti B (2006) Estrogen, neuroinflammation and neuroprotection in Parkinson's disease: glia dictates resistance versus vulnerability to neurodegeneration. Neuroscience 138:869-878

Moreno-López B, Romero-Grimaldi C, Noval JA, Murillo-Carretero M, Matarredona ER, Estrada C (2004) Nitric oxide is a physiological inhibitor of neurogenesis in the adult mouse subventricular zone and olfactory bulb. J Neurosci 24:85-95.

Morshead CM, van der Kooy D (1992) Postmitotic death is the fate of constitutively proliferating cells in the subependymal layer of the adult mouse brain. J Neurosci 12:249-256.

Morshead CM, Reynolds BA, Craig CG, McBurney MW, Staines WA, Morassutti D (1994) Neural stem cells in the adult mammalian forebrain: a relatively quiescent subpopulation of subependymal cells. Neuron 13:1071-1082.

Munji RN, Choe Y, Li G, Siegenthaler JA, Pleasure SJ (2011) Wnt signaling regulates neuronal differentiation of cortical intermediate progenitors. J Neurosci 31:1676-1687.

Nair VD, Olanow CW (2008) Differential modulation of Akt/glycogen synthase kinase-3beta pathway regulates apoptotic and cytoprotective signalling responses. J Biol Chem 283:15469-15478.

Oieda L, Gao J, Hooten KG, Wang E, Thonhoff JR, Dunn TJ, Gao T Wu P (2011) Critical role of Pl3K/Akt/GSK3 $\beta$ in motoneuron specification from human neural stem cells in response to FGF2 and EGF. PLoS One 6:e23414.

O'Keeffe GO, Barker RA, Caldwell MA (2009a) Dopaminergic modulation of neurogenesis in the subventricular zone of the adult brain. Cell Cycle $8: 18$.

O'Keeffe GO, Tyers P, Aarsland D, Dalley JW, Barker RA, Caldwell MA (2009b) Dopamine-induced proliferation of adult neural precursor cells in the mammalian subventricular zone is mediated through EGF. Proc Natl Acad Sci U S A U S A 106:8754-8759.

Osakada F, Ooto S, Akagi T, Mandai M, Akaike A, Takahashi M (2007) Wnt signalling promotes regeneration in the retina of adult mammals. J Neurosci 27:4210-4219.

Ouredinik VC, Ourednik J, Xu Y, Zhang Y, Lynch WP, Snyder EY, Schachner M (2009) Cross-talk between stem cells and the dysfunctional brain is facilitated by manipulating the niche: evidence from an adhesion molecule. Stem cells 27:2846-2856.

Packer MA, Stasiv Y, Benraiss A, Chmielnicki E, Grinberg A, Westphal H, Goldman SA, Enikolopov G (2003) Nitric oxide negatively regulates mammalian adult neurogenesis. Proc Natl Acad Sci USA 100:9566-9571.

Paxinos G, Watson C (1997) The rat brain in stereotaxic coordinates, Ed 3. San Diego: Academic.

Petit-Paitel A, Brau F, Cazareth J, Chabry J (2009) Involment of cytosolic and mitochondrial GSK-3beta in mitochondrial dysfunction and neuronal cell death of MPTP/MPP +- treated neurons. PLoS One 4:e5491.

Phukan S, Babu VS, Kannoji A, Hariharan R, Balaji VN (2010) GSK3beta: role in therapeutic landscape and development of modulators. Br J Pharmacol 160:1-19.

Pluchino S, Quattrini A, Brambilla E, Gritti A, Salani G, Dina G, Galli R, Del Carro U, Amadio S, Bergami A, Furlan R, Comi G, Vescovi AL, Martino G (2003) Injection of adult neurospheres induces recovery in a chronic model of multiple sclerosis. Nature 422:688-694.

Pluchino S, Zanotti L, Rossi B, Brambilla E, Ottoboni L, Salani G, Martinello M, Cattalini A, Bergami A, Furlan R, Comi G, Costantin G, Martino G (2005) Neurosphere-derived multipotent precursors promote neuroprotection by an immunomodulatory mechanism. Nature 436:266-271.

Pluchino S, Muzio L, Imitola J, Deleidi M, Al faro-Cervello C, Salani G, Porcheri C, Brambilla E, Cavasinni F, Bergamaschi A, Garcia-Verdugo JM, Comi G, Khoury SJ, Martino G (2008) Persistent inflammation alters the function of the endogenous brain stem cell compartment. Brain 131:2564-2578.

Prakash N, Brodski C, Naserke T, Puelles E, Gogoi R, Hall A, Panhuysen M, Echevarria D, Sussel L, Vogt Weisenhorn DM, Martinez S, Arenas E, Simeone A, Wurst W (2006) A Wnt1-regulated genetic network controls the identity and fate of midbrain-dopaminergic progenitors in vivo. Development 133:89-98.

Rietze RL, Reynolds BA (2006) Neural stem cell isolation and characterization. Methods Enzymol 419:3-23.

Sandhu JK, Gardaneh M, Iwasiow R, Lanthier P, Gangaraju S, RibeccoLutkiewicz M, Tremblay R, Kiuchi K, Sikorska M (2009) Astrocytesecreted GDNF and glutathione antioxidant system protect neurons against 6OHDA cytotoxicity. Neurobiol Dis 33:405-414. 
Schwartz M, London A, Shecter R (2009) Boosting T-cell immunity as a therapeutic approach for neurodegenerative conditions: the role of innate immunity. Neuroscience 158:1133-1142.

Semënov MV, Tamai K, Brott BK, Kühl M, Sokol S, He X (2001) Head inducer Dickkopf-1 is a ligand for Wnt coreceptor LRP6. Curr Biol 11:951-961.

Shibui Y, He XJ, Uchida K, Nakayama H (2009) MPTP-induced neuroblast apoptosis in the subventricular zone is not regulated by dopamine or other monoamine transporters. Neurotoxicology 30:1036-1044.

Shimogori T, VanSant J, Paik E, Grove EA (2004) Members of the Wnt, Fz, and Frp gene families expressed in postnatal mouse cerebral cortex. J Comp Neurol 473:496-510.

Shruster A, Eldar-Finkelman H, Melamed E, Offen D (2011) Wnt signaling pathway overcomes the disruption of neuronal differentiation of neural progenitor cells induced by oligomeric amyloid $\beta$-peptide. J Neurochem 116:522-529.

Song H, Stevens CF, Gage FH (2002) Astroglia induce neurogenesis from adult neural stem cells. Nature 417:39-44.

Spiegel A, Shivtiel S, Kalinkovich A, Ludin A, Netzer N, Goichberg P, Azaria Y, Resnick I, Hardan I, Ben-Hur H, Nagler A, Rubinstein m, Lapidot T (2007) Catecholaminergic neurotransmitters regulate migration and repopulation of immature human $\mathrm{CD} 34^{+}$cells through Wnt signaling. Nat Immunol 8:1123-1131.

Tandé D, Hoglinger GU, Debeir T, Freundlieb N, Hirsch EC, Francois C (2006) New striatal dopamine neurons in MPTP-treated macaques result from a phenotypic shift not neurogenesis. Brain 129:1194-1200.

Thored P, Heldmann U, Gomes-Leal W, Gisler R, Darsalia V, Taneera J, Nygren JM, Jacobsen SE, Ekdahl CT, Kokaia Z, Lindvall O (2009) Longterm accumulation of microglia with proneurogenic phenotype concomitant with persistent neurogenesis in adult subventricular zone after stroke. Glia 57:835-849.

Toledo EM, Clombres M, Inestrosa NC (2008) Wnt signaling in neuroprotection and stem cell differentiation. Progr Neurobiol 88:281-296.

Torroglosa A, Murillo-Carretero M, Romero-Grimaldi C, Matarredona ER,
Campos-Caro A, Estrada C (2007) Nitric oxide decreases subventricular zone stem cell proliferation by inhibition of epidermal growth factor receptor and phosphoinositide-3-kinase/Akt pathway. Stem Cells 25:88-97.

Trowbridge JJ, Xenocostas A, Moon RT, Bhatia M (2006) Glycogen synthase kinase- 3 is an in vivo regulator of hematopoietic stem cell repopulation. Nat Med 12:89-98.

van Kampen RM, Hagg T, Robertson HA (2004) Induction of neurogenesis in the adult rat subventricular zone and neostriatum following dopamine D receptor stimulation. Eur J Neurosci 19:2377-2387.

Wang W, Yang Y, Ying C, Li W, Ruan H, Zhu X, You Y, Han Y, Chen R, Wang Y, Li M (2007) Inhibition of glycogen synthase kinase- $3 \beta$ protects dopaminergic neurons from MPTP toxicity. Neuropharmacology 52:16781684.

Wexler EM, Geschwind DH, Palmer TD (2008) Lithium regulates adult hippocampal progenitor development through canonical Wnt pathway activation Mol Psychiatry 13:285-292.

Winner B, Desplats P, Hagl C, Klucken J, Aigner R, Ploetz S, Laemke J, Karl A, Aigner L, Masliah E, Buerger E, Winkler J (2009) Dopamine receptor activation promotes adult neurogenesis in an acute Parkinson model. Exp Neurol 219:543-552.

Wu DC, Jackson-Lewis V, Vila M, Tieu K, Teismann P, Vadseth C, Choi DK, Ischiropoulus H, Przedborski S (2002) Blockade of microglial activation is neuroprotective in the 1-methyl-4-phenyl-1,2,3,6-tetrahydropyridine mouse model of Parkinson disease. J Neurosci 22:1763-1771.

Zhang L, Yang X, Yang S, Zhang J (2011) The Wnt/ $\beta$-catenin signaling pathway in the adult neurogenesis. Eur J Neurosci 33:1-8.

Zhang QG, Wang R, Khan M, Maesh V, Brann DW (2008) Role of Dikkopf-1 (Dkk1), an antagonist of the Wnt- $\beta$-catenin signaling pathway, in estrogen-induced neuroprotection and attenuation of Tau phosphorylation. J Neurosci 28:8430-8441.

Zhang YJ, Xu YF, Liu YH, Yin J, Wang JZ (2005) Nitric oxide induces tau hyperphosphorylation via glycogen synthase kinase-3beta activation. FEBS Lett 579:6230-6236. 